\title{
Patient involvement and medical practice variation
}

\author{
Citation for published version (APA):
}

Brabers, A. E. M. (2018). Patient involvement and medical practice variation: Can patients be ignored in theories about practice variation? [Doctoral Thesis, Maastricht University]. NIVEL. https://doi.org/10.26481/dis.20180322ab

Document status and date:

Published: 01/01/2018

DOI:

10.26481/dis.20180322ab

Document Version:

Publisher's PDF, also known as Version of record

\section{Please check the document version of this publication:}

- A submitted manuscript is the version of the article upon submission and before peer-review. There can be important differences between the submitted version and the official published version of record.

People interested in the research are advised to contact the author for the final version of the publication, or visit the DOI to the publisher's website.

- The final author version and the galley proof are versions of the publication after peer review.

- The final published version features the final layout of the paper including the volume, issue and page numbers.

Link to publication

\footnotetext{
General rights rights.

- You may freely distribute the URL identifying the publication in the public portal. please follow below link for the End User Agreement:

www.umlib.nl/taverne-license

Take down policy

If you believe that this document breaches copyright please contact us at:

repository@maastrichtuniversity.nl

providing details and we will investigate your claim.
}

Copyright and moral rights for the publications made accessible in the public portal are retained by the authors and/or other copyright owners and it is a condition of accessing publications that users recognise and abide by the legal requirements associated with these

- Users may download and print one copy of any publication from the public portal for the purpose of private study or research.

- You may not further distribute the material or use it for any profit-making activity or commercial gain

If the publication is distributed under the terms of Article $25 \mathrm{fa}$ of the Dutch Copyright Act, indicated by the "Taverne" license above, 


\section{Patient involvement and medical practice variation}

Can patients be ignored in theories about practice variation?

Anne Brabers 
Most studies in this thesis are based, or partly based, on information gathered in NIVEL's Dutch Health Care Consumer Panel. This panel is financially supported through the core funding the Dutch Ministry of Health, Welfare and Sport provides to NIVEL. One study was partially supported by The National Health Care Institute of the Netherlands, within the cooperative framework that NIVEL and The National Health Care Institute had together.

The research presented in this thesis was conducted at NIVEL, Netherlands Institute for Health Services Research, Utrecht, The Netherlands. NIVEL participates in the Netherlands School of Primary Care Research (CaRe), which is acknowledged by the Royal Netherlands Academy of Arts and Sciences (KNAW).

ISBN 978-94-6122-480-4

http://www.nivel.nl

nivel@nivel.nl

Telefoon 0302729700

Fax 0302729729

(C)2018 NIVEL, Postbus 1568, 3500 BN UTRECHT

Cover design: $\quad$ Wouter van der Schors en GVO drukkers \& vormgevers B.V. te Ede

Word processing/lay out: Christel van Well

Printing: $\quad$ GVO drukkers \& vormgevers B.V. te Ede

Data from this publication may be reproduced by mentioning NIVEL and the name of the publication. The use of figures and / or text as explanation or support in articles, books and theses is also allowed, provided the source is clearly stated. 


\section{Patient involvement and medical practice variation}

Can patients be ignored in theories about practice variation?

\section{De betrokkenheid van patiënten en variatie in medisch handelen}

Kunnen patiënten worden genegeerd in theorieën over praktijkvariatie?

(met een samenvatting in het Nederlands)

PROEFSCHRIFT

ter verkrijging van de graad van doctor aan de Universiteit Maastricht, op gezag van de Rector Magnificus, Prof. dr. Rianne M. Letschert volgens het besluit van het College van Decanen, in het openbaar te verdedigen op donderdag 22 maart 2018 om 14.00 uur

door

Adriana Elisabeth Maria Brabers

geboren op 6 mei 1987

te Oosterhout (NB) 


\section{Promotoren}

Prof. dr. J.D. de Jong

Prof. dr. P.P. Groenewegen (Universiteit Utrecht)

\section{Beoordelingscommissie}

Prof. dr. G.D.E.M. van der Weijden (voorzitter)

Prof. dr. A.J.H.M. Beurskens

Prof. dr. J.S. Burgers

Prof. dr. G. Elwyn (The Dartmouth Institute; Radboud Universiteit)

Prof. dr. G.P. Westert (Radboud Universiteit) 


\section{Contents}

$1 \quad$ General introduction $\quad 7$

Part A Mechanisms explaining differences in patient involvement in 31 medical decision-making

$2 \quad$ What role does health literacy play in patients' involvement in medical decision-making?

PLOS ONE 2017; 12(3): e0173316

3 Social support plays a role in the attitude that people have towards 55 taking an active role in medical decision-making BMC Health Services Research 2016; 16:502

$4 \quad$ Do social norms play a role in explaining involvement in medical decision-making?

European Journal of Public Health 2016; Dec; 26(6):901-905

\section{Part B Patient involvement and medical practice variation}

5 Does a strategy to promote shared decision-making reduce medical 99 practice variation in the choice of either single or double embryo transfer after in vitro fertilisation?

BMJ Open 2016; 6:e010894

6 Is there a conflict between general practitioners applying guidelines for antibiotic prescribing and including their patients' preferences? Patient Preference and Adherence 2018; 12:9-19

$7 \quad$ General discussion 
Summary

Samenvatting

179

Valorisation

Dankwoord

201

About the author

205

List of publications

207 


\section{General introduction}




\subsection{Introduction}

"Edward (aged 75) had recently been diagnosed as having an enlarged prostate gland causing him bothersome urinary symptoms. He was offered surgery as the most effective treatment and accepted the recommendation. Before surgery he enjoyed an active sex life which was important to him and his wife but this was seriously affected by the surgery. He had been made aware that some men have sexual problems after surgery but he did not feel as if he'd had a chance to consider the extent of this risk or to consider whether this was a concern to him personally. Looking back, he feels that if he had been given more of a chance to discuss his preferences, he may have postponed surgery in favour of "watchful waiting"." (Example taken from Elwyn et al., 2012; p1362 [1])

For diagnoses such as having an enlarged prostate gland, that is benign prostatic hyperplasia (BPH), substantial variation in rates of surgery have been observed [2, 3]. Rates of surgery for BPH may vary by a factor of more than four between hospital referral regions in the United States of America according to the Dartmouth Atlas [3]. Next to surgery, both medication and watchful waiting are considered to be appropriate options for treating BPH [3]. Commonly, as in the case of Edward, the physician is the dominant figure, or "actor" when deciding on which treatment to implement. This paternalistic approach is practised widely, and embedded in the idea that physicians decide on treatment based on both medical science and what is best for an individual patient. In other words, the belief that 'the physician knows best' [4]. Consequently, physicians' judgements rather than patients' preferences often determine which treatment a patient receives $[4 p 9,5]$. Variations in practice are therefore found to be related to physicians rather than to patients $[4,6,7]$. In explaining variation, research thus focuses on the role of physicians and the organisations they work in, while the role of patients receives little attention $[8,9]$. However, this paternalistic approach has gradually come to be questioned during the last decades. At the same time, the position of patients in health care has altered significantly. At an individual level, patients are supposed to adopt an active role in their health [10] and they are expected to be involved in decisions about their health [11]. Furthermore, providing care that is respectful of, and responsive to, an individual patient's preferences, needs and values is regarded as one of the key elements of a good quality of care [12]. Since medical decisionmaking is decisive for medical practice variation, the question is whether patients can be ignored in theories about variation. This question will be the central subject 
of this thesis. In order to achieve some insight into this it has to be examined under which circumstances the physician-patient interaction is not dominated by the physician. This thesis, therefore, explores several mechanisms which may explain the involvement of patients in medical decision-making. In addition, insight is necessary into how patient involvement influences medical decision-making, and thus practice variation. This is a relatively new question in the field. It has been suggested that patient involvement decreases practice variation, however, empirical data confirming this hypothesis is lacking.

\subsection{Variation in medical practice}

Variation in medical treatment means that similar, or apparently similar patients, with a similar health status or medical condition do not receive the same treatment. As early as 1938 Glover had already observed considerable variation in the rate of tonsillectomy procedures between geographic areas in the United Kingdom [13]. Today, variation in medical practice is a well-known phenomenon that has been extensively described in the literature [e.g. 4, 14, 15]. These observed variations are not random. Clear patterns of variation can be found at different levels of aggregation, for example between individual physicians, hospitals, regions, and countries [16].

As mentioned by Andersen and Mooney (1990), "medical practice has the image of being based on solid, scientific grounds" [17 p1]. But, for most patients, medical decision-making is a complete mystery. They leave it to their physician, based on the idea that their physician decides on treatment based on medical science and on the patient's medical condition [4]. If this assumption is true, similar, or apparently similar, patients with similar conditions would receive the same medical treatment, independent of the physician, practice, or hospital they visit. The clear variations observed demonstrate something different; physicians do different things when treating similar, or apparently similar, patients [17]. Medical practice is widely held to be a science, however, many medical decisions do not rely on a strong scientific foundation, simply because of the lack of such a foundation [17]. The patterns of variation observed, which are not random, imply that there are factors other than medical evidence and the patient's clinical condition which influence the physician's decision [e.g. 18]. 


\section{Existing explanations for variation in medical practice}

Understanding that practice variations are related to physicians rather than to patients, research started explaining variation with a focus on the role of physicians and the organisations they work in. Part of these explanations are based on the idea that variations are caused by differences in preferences among physicians with respect to certain treatments. A widely accepted hypothesis, is the 'practice style' hypothesis. It is supposed that physicians apply different treatments because they have somehow learned to value them differently $[7,19,20]$, and, as a consequence, have a different 'practice style'. Furthermore, it has been hypothesised that, locally, physicians tend to apply their practice styles consistently, resulting in the use of a specific treatment at a regional level, the socalled 'surgical signature' $[19,21]$. It has been suggested that differences in practice style emerge due to professional uncertainty $[19,22]$. Variation is the result of applying knowledge to individual patients, and, in applying that knowledge, there might be uncertainty in how to do this. It has been argued that the greatest variation is observed when there is the greatest debate within medical science and vice versa [4]. Next to the practice style hypothesis, Chassin (1993) came up with the 'enthusiasm' hypothesis. He suggested that variations between, for example, geographical areas, are caused by differences in the numbers of physicians who are enthusiastic about certain procedures [23].

An alternative to the explanation of variation based on preferences, is one based on constraints. Westert and Groenewegen (1999) suggest that it is the social context that influences physicians' behaviour in their daily practice [20]. Local circumstances or social conditions influence physicians' behaviour by providing opportunities and constraints. Practice variations are the result of different circumstances $[8,24]$. An implication of this theory is that physicians who share a work environment, and thus constraints and opportunities, show similarities in their behaviour [8, 24]. De Jong (2008) further elaborated upon this by developing a sociological model explaining variations between, and similarities within, a work environment (see upper part of Figure 1.2 for an adapted version of this model, for more detailed information about the model see $[8,24])$. She came up with three mechanisms, at meso level, which are supposed to generate homogeneity: 1) selection, i.e. selection of physicians who work together might be based on similarities in practice style, 2) gradual adaptation towards group norms, i.e. when physicians share a work environment this might cause similarities in medical behaviour, and 3 ) rapid adaption to circumstances, i.e. when there are incentives 
for certain choices this might also cause similarities [8]. The observation of homogeneity within, and variation between, a work environment has been empirically confirmed [24, 25]. According to the model of De Jong (2008), these circumstances are influenced, at macro level, by institutional mechanisms. Based on Scott (2001), she distinguished three mechanisms, the regulative (rules and regulations), the normative (professional norms), and the cultural-cognitive (the framework physicians' use in their decision-making) [24]. De Jong (2008) showed that these mechanisms influence physicians' behaviour, however, no empirical evidence showing that these mechanisms reduce variation was found [24]. For instance, she found that physicians using a Decision Support System (DSS), which is an example of a cultural-cognitive mechanism, conform more to the advice given in the DSS in their prescribing behaviour than physicians not using a DSS. However, variation was the same for physicians using and physicians not using a DSS [24]. De Jong (2008) reasoned that these results suggest that institutional mechanisms can be used as instruments to influence variation, as behaviour can be influenced. Whether these mechanisms will actually reduce variation will probably depend on the room for variation given within the rules and regulations [24].

In conclusion, in explaining variation the focus is on physicians and the organisations they work in. This approach might be adequate in the case where physicians are the dominant actors deciding on the treatment. In the last decades, however, this paternalistic model has come to be questioned. At the same time, there is a growing emphasis on including patients and their preferences in decisionmaking. Moreover, the inclusion of patients and their preferences in providing care is regarded as one aspect of a good quality of care. As such, it is questioned whether patients can be ignored in theories about variation.

\subsection{Patient involvement in medical decision-making}

\section{The interaction between physician and patient: a continuum of treatment decision-making models}

Taking into account patients as co-decision makers, moves the paternalistic approach in which the physician is the dominant actor deciding on the treatment towards a boundary option (see Figure 1.1). The opposite position is the informed decision-making model where the patient is the only decision-maker, for example in cosmetic surgery where patients choose a clinic which is willing to do what they 
want [8]. In between both models is the shared decision-making (SDM) model. SDM is an approach where physician and patient take decisions together using both the best available evidence and the preferences of the patient. Patients are helped to make informed choices by considering the options, and the likely disadvantages and benefits of each option $[1,26]$. SDM has been recognised as a model to promote the involvement of patients and their preferences in medical decision-making [27].

Figure 1.1 The interaction between physician and patient: a continuum of treatment decision-making models (based on De Jong et al., 2015)
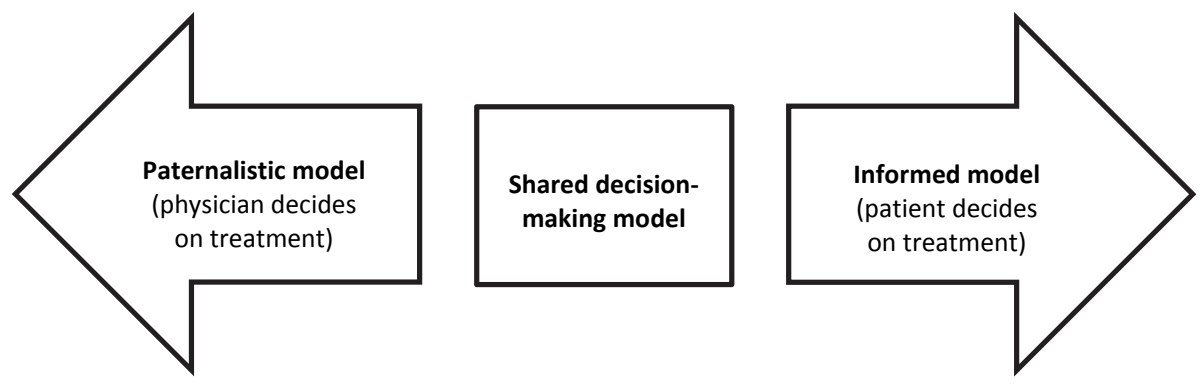

The assumption that the physician is the dominant actor who decides on the treatment is challenged in the case of SDM [8]. Here, the physician and patient take decisions together. This interaction between physician and patient might generate variation in practice, since it is not only the clinical characteristics of the patient which are relevant, but also are the preferences of the patient [8]. Subsequently, patients have to be modelled as actors in the case of SDM. Yet, this physicianpatient interaction is not included in current theories about variation [8].

\section{Variation in patient involvement in medical decision-making}

Patients only have to be modelled as actors if they share medical decision-making with their physician. A systematic review of Chewning et al. (2012), shows that most patients want to participate in medical decision-making [28]. On the other hand, it is known that some groups of patients prefer to delegate decision-making to their physician [29]. If this is the case, current theories to explain variation fit. Patients' preferences for sharing decisions are related to many factors. These include: their relationship with health professionals, the type of decision, the experience of illness and medical care, the diagnosis and health status, and demographic characteristics, such as gender, age and level of education [29]. 
In general, women, younger people, and higher educated people more often prefer to share decisions than men, older people, and lower educated people [29]. This indicates that there is variation in patients' preferences towards SDM. However, the observation of differences in whether categories of patients prefer to share decisions does not in itself provide an explanation for the variation observed. Therefore, insight into mechanisms explaining patient involvement is necessary. As such, we achieve insight into the circumstances under which patients take an active role in medical decision-making, and thus have to be included in theories about variation.

In conclusion, due to the growing emphasis on including patients in medical decision-making, explaining practice variation with a focus on physicians and the organisations they work in might no longer be adequate [8]. In this thesis, we will consider under which circumstances the physician does not dominate the physician-patient interaction. We will do this by examining mechanisms which might explain the involvement of patients in medical decision-making. Also, we will consider how patient involvement influences the decision taken, and thus practice variation. De Jong et al. (2015) provide a theoretical framework explaining variation in medical practice and including the interaction between the patient and physician [8]. This model, in an adapted form, will be used in this thesis as a theoretical framework. Figure 1.2 depicts the theoretical model of this thesis. It will be explained further in section 1.5 .

\section{The preconditions required for our theoretical model}

It is not possible for physicians and patients to take decisions together in every situation. A precondition is that there is room for different decisions. There has to be several treatment options with the clinical evidence not supporting any one option clearly and where the choice of treatment should depend upon patient preferences (preference sensitive care) [4]. By contrast, in a situation where patients are incapacitated or in the case of an emergency, delegating decisionmaking to the physician is widely accepted, and maybe the only feasible decisionmaking model $[27,30]$. Such situations are not part of this thesis. 
Figure 1.2 Theoretical model of this thesis (based on De Jong et al., 2015) (the grey parts of the model are not examined within this thesis)

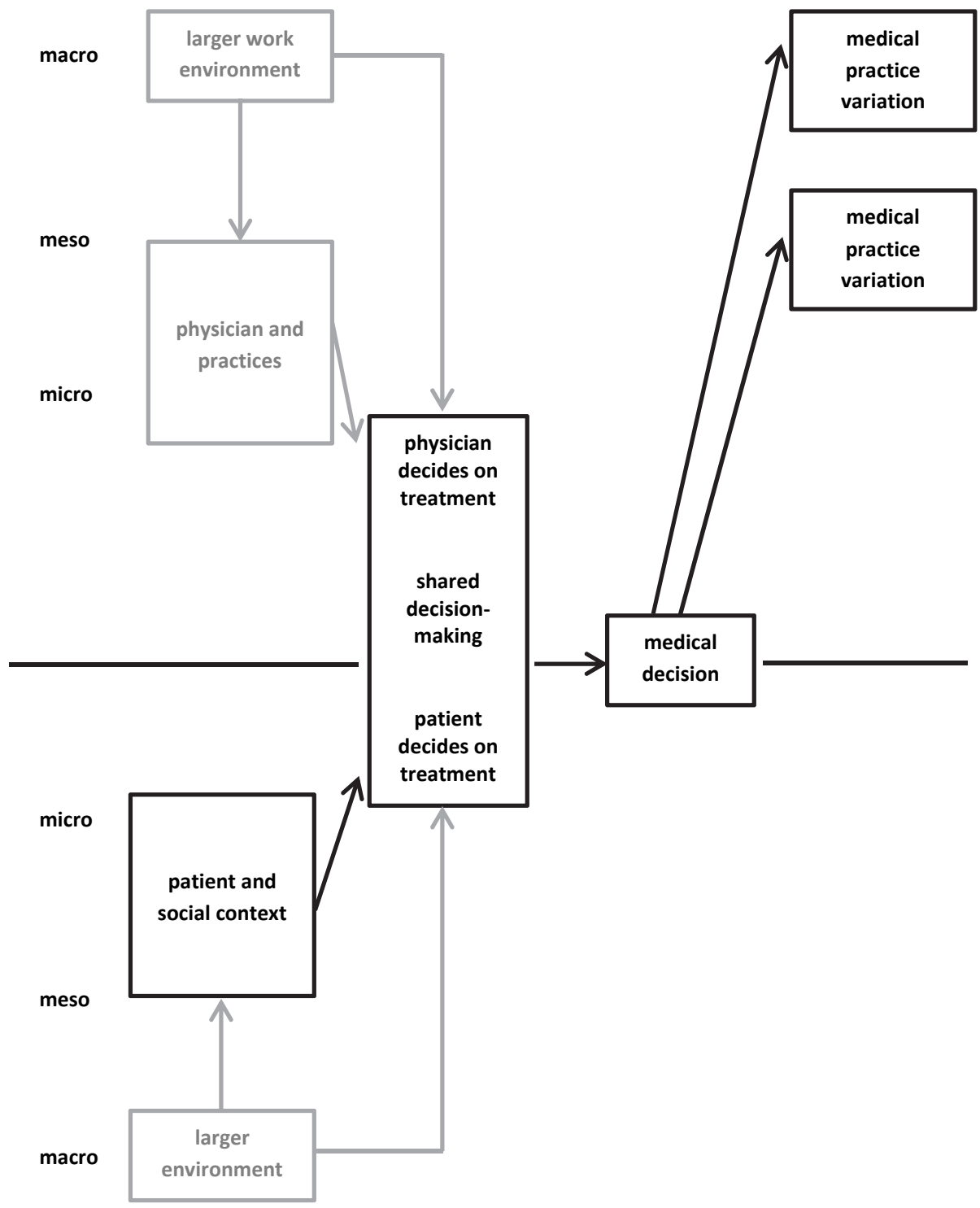




\subsection{Research questions of this thesis}

In this thesis, two research questions are addressed. Before achieving insight into how patient involvement influences variation in medical practice, it is important to explore under which circumstances the physician does not dominate the interaction with the patient. If this is the case, the patient has to be modelled as an actor. Therefore, in this thesis, we address mechanisms which explain the involvement of patients in medical decision-making. The first question asked in this thesis is:

1. Which mechanisms explain differences in patient involvement in medical decision-making?

Although there is an increased emphasis on including patients in medical decisionmaking, the question of how this influences variation in medical practice is a new one in the field. There are no clear theoretically derived hypotheses. It has been suggested, however, that the involvement of the patient, and more specifically SDM, decreases practice variation. Empirical data confirming such a decrease in variation is lacking. Therefore, the second question addressed in this thesis is:

2. How does patient involvement, and more specifically shared decision-making, influence medical practice variation?

\subsection{Theoretical considerations and general hypotheses}

Several mechanisms underlying physician decision-making have been studied (see section 1.2 and light grey parts in the upper part of Figure 1.2) [8, 24]. De Jong et al. (2015) propose that the mechanisms influencing patients in how they make decisions are not very different from the ones which influence physicians [8]. Just as physicians, patients are expected to strive to achieve certain goals. In general, they strive for physical well-being and social approval, whereby health is part of physical well-being. The extent to which patients are able to achieve these goals is determined by their resources and constraints [31]. It can, for instance, be argued that just as with physicians, patients have to explain when they deviate from certain norms. For patients, norms in their social contexts, such as with family and friends, are expected to be important. In addition, patients can differ in their 
resources, such as knowledge and health literacy [8]. We focus here on three mechanisms, both at the micro (patient) and the meso (social context) level, which may explain patient involvement in medical decision-making. These are: 1 ) health literacy, 2) social support, and 3) social norms. And, just as with physicians, patients can also be influenced by the structure and institutions of the health care system (the macro level) [8]. This level, however, is not part of this thesis as all patients in the Netherlands are subject to the same health care system based on managed competition.

\section{Health literacy}

People can differ in their ability to become an active participant with regard to their health, and the competencies they have acquired to make informed decisions about their health. An important theoretical concept in this context is health literacy. This has been considered as an important determinant of health [32 33]. We define health literacy in this thesis as "personal characteristics and social resources needed for people to access, understand and use information to make decisions about health" [34 p2, 35 p1]. Health literacy refers to a resource that is integrated into the daily lives of people and includes information and decisionmaking skills that are necessary in a range of different contexts [36]. By using this definition of health literacy, the concept operates on both the micro (personal resources) and the meso (social resources) level of our model. People with higher health literacy are presumable better able to obtain, understand, appraise and apply information required for medical decision-making. As such, we hypothesise that a high level of health literacy enables people to be more involved in decisionmaking.

H1: People with higher health literacy are more involved in medical decisionmaking.

\section{Social support and social norms}

It are not only characteristics of the patient which have to be taken into account in explaining whether patients are involved in medical decision-making. Someone's social context has to be considered too. The reason for this is that a patient's preferences cannot be interpreted as merely individual. In an individual's social context, such as work, family, or neighbourhood, individuals meet members of their social network. A social network refers to the web of social relationships surrounding an individual [37]. These relationships influence health, and health 
behaviour, through different mechanisms [37-39]. They can provide social resources, as well as create social norms that affect behaviour [37, 38, 40].

An individual's social capital, or social resources, is formed by the pool of resources residing in the members of an individual's social network [41,42]. Social resources can be provided to people in the form of social support [43]. We consider two types of social support in this thesis: informational support (the provision of information by others), and emotional support (providing empathy, listening and giving advice) [44, 45]. The information asymmetry between physician and patient is one of the reasons for patients to leave medical decision-making to their physician [46]. Patients believe that medical decision-making requires knowledge that they do not have [47]. We expect that getting informational support from others may compensate for this lack of knowledge. Another reason to leave decision-making to the physician is that ill people feel vulnerable and thus do not want to, or even cannot, take a decision [48, 49]. We expect that emotional support can compensate for this. Emotional support can, for instance, be provided in the form of being accompanied during the consultation. We expect that patients feel less vulnerable when receiving emotional support as it has been suggested that patients feel more confident when a companion is present [50]. In short, we hypothesise that both the availability of informational and emotional support positively influence patient involvement in medical decision-making.

H2: The more informational and emotional support people have available in their social network, the more they are involved in medical decision-making.

Social norms specify what actions are regarded as normal by a group of people, and what actions are regarded as deviant [40]. As mentioned, people strive for social approval and, as such, will have to explain themselves when deviating from certain norms [8]. We thus reason that if it is common in someone's social context to leave decision-making to physicians, because there is great respect for them, then patients are expected to be less likely to be involved in medical decision-making, as this is the norm.

H3: The more common it is in someone's social context to leave the decision to a physician, the less someone is involved in medical decision-making. 


\section{Influence of patient involvement, and more specifically of shared decision- making, on medical practice variation}

Through patient involvement in medical decision-making treatment decisions may differ from those in which a physician does not take the patient into account. The reason for this is that patients' preferences for treatment may deviate from physicians' judgements [51]. As a result patterns of variation may change through patient involvement as medical decision-making is a decisive factor for variation. SDM is one specific approach to enable the preferences of patients to be included in decision-making [27, 52]. It has been hypothesised that through patient involvement, and more specifically through SDM, practice variation decreases [21, 52-55]. This hypothesis is based on research showing that patients, through a combination of education and participation, are less ready to accept certain procedures [53]. Several studies demonstrated that, in general, informed patients prefer less invasive treatment options [e.g. 4, 56-59]. A Cochrane review concluded that seven out of 11 trials, involving major elective surgery, and applying a decision aid, demonstrated rates of reductions of between $21 \%-74 \%$ in the use of the more invasive surgical option. Instead patients preferred more conservative options such as medication [57, 60]. According to Stacey and Légaré (2015), "the underlying mechanism of this effect is likely in moderating expectations and communicating values" of patients [60, p466]. The authors hypothesise that when patients have a major health problem, their first reaction is to 'cut it out', or 'get rid of' the organ [60]. This is in line with the view that physicians may decide to choose more invasive treatment options in some situations, for instance in too long treatment in end-of-life care [61]. When patients learn more about the possible alternatives, and know that there is more potential harm associated with the more aggressive procedures, some decide to choose more conservative procedures [60].

The hypothesis that patient involvement reduces practice variation assumes that patients are less diverse in their preferences than physicians, despite the fact that physicians have a shared training and socialisation that has no parallel among patients [53]. It also assumes that patients do not select a physician based on their preferences for a particular treatment. In the situation where patients would select a physician based on their treatment preferences, a number of the patients are expected to select a physician who prefers a conservative option, and a number of others a physician who prefers an invasive option. In this situation in which patients select a physician based upon their preferences, variation between physicians is not expected to decrease as little will change in the decision-making of both 
physicians preferring the conservative option, and those preferring the invasive option. Research showed, however, that the majority of patients do not actively choose a physician [62].

Therefore, we expect that due to SDM a more conservative treatment option will be chosen in units, such as a hospital, where physicians already prefer the more conservative option, as well as in units where physicians prefer the invasive option. This is because informed patients prefer the more conservative option. As such, we hypothesise that SDM is associated with less variation between units. We focus on variation between units instead of between individual physicians, as previous research showed that this is the level at which variation has to be examined [24].

H4: SDM reduces variation in medical treatment between units (e.g. hospitals)

\section{Two mechanisms aimed at reducing variation in medical practice: do they conflict with each other?}

Patient involvement, and more specifically SDM, is one mechanism which is expected to reduce variation in medical practice. On the physician's side of the model (see Figure 1.2), the existence of guidelines is an institutional mechanism, at macro level, which has the potential to decrease variation in medical practice. Guidelines give recommendations about appropriate health care, and are expected to decrease variation since physicians are expected to operate increasingly in a predictable manner $[63,64]$. Adherence to guidelines varies widely between physicians and practices, as well as between guidelines [e.g. 65-67]. One perceived barrier to adhering to guidelines, stated by physicians, is the existence of patient preferences [68]. In theory, physicians bring the guidelines and clinically relevant characteristics of patients into the decision-making process, whereas patients bring in their preferences. A question that arises is whether a conflict will emerge as the two mechanisms - guidelines and patient involvement - which have the potential to reduce variation, come together. In other words, in making decisions, is there a conflict between applying guidelines, on the one hand, and including patient preferences on the other $[53,69]$ ? We aim to gain insight into this potential conflict. We hypothesise that patient preferences have a larger role in medical decision-making if the guideline provides room to take patient preferences into account. In other words, if the guideline provides an option for treatment which can be considered rather than a clear recommendation for a specific treatment or not. 
H5: Patient preferences have a larger role in medical decision-making if the guideline provides room to take patient preferences into account.

\subsection{General methodology}

To be able to answer the research questions in this thesis, the aforementioned hypotheses were tested in five different studies. Here, we describe the data sources and methods used in this thesis. Table 1.1 provides, for each chapter of this thesis, an overview of the hypotheses tested and the data sources used.

\section{Dutch Health Care Consumer Panel (Chapters 2, 3 and 4)}

For most studies conducted in this thesis, data have been collected within NIVEL's Dutch Health Care Consumer Panel. Three studies are based on data from the Consumer Panel only (Chapters 2, 3 and 4), while one study (Chapter 6) consists of data from the Consumer Panel combined with additional data.

The Dutch Health Care Consumer Panel aims to measure opinions on, and knowledge of, health care as well as the expectations of, and experiences with, health care among a cross-section of the Dutch population (see [70] for more detailed information). The Consumer Panel is a so-called access panel. An access panel consists of a large number of people who have agreed to answer questions on a regular basis. Many background characteristics of the panel members are known, such as their age, gender and highest level of education completed. At the time in which the studies referred to in this thesis were conducted, the Consumer Panel consisted of approximately 8,500 people aged 18 years and older in June 2013, rising to approximately 12,000 in May 2015 and March 2016. In general, each individual panel member receives a questionnaire approximately three times a year and could resign from the panel at any time. At the start of their membership, panel members can choose whether they want to receive questionnaires by post or through the internet. There is no possibility of people signing up for the panel on their own initiative. The Consumer Panel is renewed on a regular basis. Renewal is necessary in order to make sure that members do not develop specific knowledge of, and attention for, health care issues, and that no 'questionnaire fatigue' occurs. Moreover, a system of renewal compensates for panel members who, for example, have died or moved without providing a forwarding address. Data are processed anonymously and the protection of the data collected is registered with the Dutch 
Data Protection Authority (nr. 1262949). A privacy regulation is available for the Consumer Panel. According to Dutch legislation, neither obtaining informed consent nor approval by a medical ethics committee is obligatory for conducting research through the panel [71].

All three studies based solely on Consumer Panel data have a cross-sectional design. In these studies, we use the attitude towards taking an active role in medical decision-making, or self-reported involvement, as outcome measures. The measurements included cover the whole decision-making continuum of Figure 1.1 and are based on two propositions developed by Flynn et al. (2006) [72]. We perform regression analyses in all three studies to test the relationships between the mechanisms (health literacy, social support, and social norms) on the one hand, and involvement, on the other.

\section{NIVEL Primary Care Database combined with the Consumer Panel (Chapter 6)}

We use a combined set of data from the Consumer Panel and the NIVEL Primary Care Database (NIVEL-PCD) in order to study the possible conflict between applying guidelines and including patient preferences in medical decision-making in the prescription of antibiotics in general practice. The NIVEL-PCD collects data from the routine electronic health records of a large and dynamic pool of general practices across the Netherlands over time [73]. The data comprise information on consultations, morbidity and prescriptions. Data from NIVEL-PCD are used to assess indications and prescriptions for antibiotics. We combine these data with a questionnaire among members of the Consumer Panel to examine patient preferences. We then perform a logistic multilevel regression analysis in order to test our hypothesis about the role of patient preferences in the prescription of antibiotics.

\section{A randomised controlled trial investigating the choice of a single or double embryo transfer after in vitro fertilisation (Chapter 5)}

We also use data from a randomised controlled trial (RCT) investigating the choice of a single or double embryo transfer after in vitro fertilisation (IVF) [58]. In this trial, a multifaceted empowerment strategy, including among others a decision aid, was used to promote SDM. The control group received standard IVF care, whereas the intervention group received, next to the standard care, the multifaceted empowerment strategy [58]. We will perform a secondary analysis on the trial data to test, empirically, the hypothesis that SDM reduces variation in medical practice. 


\subsection{Outline of this thesis}

The results of this thesis are presented in Chapters 2 to 6 . The hypotheses outlined in this chapter are elaborated upon in these five chapters. The five chapters in this thesis are each written to be read as stand-alone article. Some degree of overlap across the chapters is therefore inevitable. In line with the two research questions, the chapters can be divided into two parts. Part A comprises Chapters 2 to 4 , whereas part B comprises Chapters 5 and 6 . The hypotheses tested in the chapters as well as the data sources used in each chapter are presented in Table 1.1.

Table 1.1 Summary of hypotheses, chapters in which they are tested and data sources used

\begin{tabular}{|c|c|c|}
\hline General hypothesis in the introduction & Chapter & Data source \\
\hline $\begin{array}{l}\mathrm{H} 1 \text { : } \\
\text { People with higher health literacy are more involved in } \\
\text { medical decision-making. }\end{array}$ & Chapter 2 & $\begin{array}{l}\text { Dutch Health Care Consumer } \\
\text { Panel of NIVEL }\end{array}$ \\
\hline $\begin{array}{l}\mathrm{H} 2 \text { : } \\
\text { The more informational and emotional support people } \\
\text { have available in their social network, the more they are } \\
\text { involved in medical decision-making. }\end{array}$ & Chapter 3 & $\begin{array}{l}\text { Dutch Health Care Consumer } \\
\text { Panel of NIVEL }\end{array}$ \\
\hline $\begin{array}{l}\text { H3: } \\
\text { The more common it is in someone's social context to } \\
\text { leave the decision to a physician, the less someone is } \\
\text { involved in medical decision-making. }\end{array}$ & Chapter 4 & $\begin{array}{l}\text { Dutch Health Care Consumer } \\
\text { Panel of NIVEL }\end{array}$ \\
\hline $\begin{array}{l}\mathrm{H} 4 \text { : } \\
\text { SDM reduces variation in medical treatment between } \\
\text { units (e.g. hospitals). }\end{array}$ & Chapter 5 & $\begin{array}{l}\text { RCT Van Peperstraten et al. } \\
(2010)\end{array}$ \\
\hline H5: & Chapter 6 & Combined set of data from the \\
\hline $\begin{array}{l}\text { Patient preferences have a larger role in medical decision- } \\
\text { making if the guideline provides room to take patient } \\
\text { preferences into account. }\end{array}$ & & $\begin{array}{l}\text { NIVEL Primary Care Database } \\
\text { and data from the Dutch Health } \\
\text { Care Consumer Panel of NIVEL }\end{array}$ \\
\hline
\end{tabular}

The aim of part $A$ is to achieve insight into three possible mechanisms which may explain patient involvement in medical decision-making. Chapter 2 focuses on the relationship between health literacy and self-reported involvement in decisionmaking. Chapter 3 studies the role of social support on the attitude towards taking an active role in medical decision-making. Chapter 4 provides insight into how social norms are an influence upon self-reported involvement in decision-making. 
The aim of part $B$ is to achieve insight into the question of how patient involvement, and more specifically SDM, influences variation in medical practice. In Chapter 5, we test, empirically, the hypothesis that SDM reduces medical practice variation. Chapter 6 provides insight into the possible conflict between applying guidelines on the one hand, and including patient preferences in medical decisionmaking on the other.

Lastly, Chapter 7 provides a summary of the conclusions from all five studies and an overall discussion. 


\section{References}

1. Elwyn G, Frosch D, Thomson R, Joseph-Williams N, Lloyd A, Kinnersley P, et al. Shared decision making: a model for clinical practice. Journal of General Intern Medicine 2012; 27(10):1361-7

2. Sung JC, Curtis LH, Schulman KA, Albala DM. Geographic variations in the use of medical and surgical therapies for benign prostatic hyperplasia. The Journal of Urology 2006; 175(3 Pt 1):1023-7

3. Wennberg JE. The Dartmouth Atlas of Health Care in the United States American Hospital Association, 1996

4. Wennberg JE. Tracking medicine: a researcher's quest to understand health care. New York: Oxford University Press, 2010

5. Wennberg JE. Unwarranted variations in healthcare delivery: implications for academic medical centres. The BMJ 2002; 325(7370):961

6. McPherson K. Why do variations occur? In: Andersen TF, Mooney G, eds. The challenges of medical practice variations. London: The Macmillan Press, 1990; 16-35

7. Wennberg JE, Gittelsohn A. Health care delivery in Maine I: patterns of use of common surgical procedures. The Journal of the Maine Medical Association 1975; 66(5):123-30, 49

8. De Jong JD, Groenewegen PP, Westert GP. Sociological Model for Understanding Medical Practice Variations. In: Sobolev B (Series ed), Johnson A, Stukel T (eds). Health Services Research Series. Medical Practice Variations. New York: Springer, 2015; 25-39

9. Mercuri M, Gafni A. Medical practice variations: what the literature tells us (or does not) about what are warranted and unwarranted variations. Journal of Evaluation in Clinical Practice 2011; 17(4):671-7

10. Van de Bovenkamp HM, Trappenburg MJ, Grit KJ. Patient participation in collective healthcare decision making: the Dutch model. Health Expectations 2010; 13(1):73-85

11. Guadagnoli E, Ward P. Patient participation in decision-making. Social Science \& Medicine 1998; 47(3):329-39 
12. Institute of Medicine. Crossing the quality chasm: A new health system for the 21st century: National Academies Press, 2001

13. Glover JA. The Incidence of Tonsillectomy in School Children: (Section of Epidemiology and State Medicine). Proceedings of the Royal Society of Medicine 1938; 31(10):121936

14. Corallo AN, Croxford R, Goodman DC, Bryan EL, Srivastava D, Stukel TA. A systematic review of medical practice variation in OECD countries. Health Policy 2014; 114(1):5-14

15. Paul-Shaheen P, Clark JD, Williams D. Small area analysis: a review and analysis of the North American literature. Journal of health politics, policy and law 1987; 12(4):741809

16. Ham C. Health care variations: assessing the evidence: King's Fund Institute, 1988

17. Andersen TF, Mooney G. Medical Practice Variations: Where are we? In: Andersen TF, Mooney G, eds. The challenges of medical practice variations. London: The Macmillan Press, 1990; 1-15

18. McKinlay JB, Potter DA, Feldman HA. Non-medical influences on medical decisionmaking. Social Science \& Medicine 1996; 42(5):769-76

19. Wennberg J, Gittelsohn A. Variations in medical care among small areas. Scientific American 1982;246(4):120-34

20. Westert GP, Groenewegen PP. Medical practice variations: changing the theoretical approach. Scandinavian journal of public health 1999; 27(3):173-80

21. Weinstein JN, Bronner KK, Morgan TS, Wennberg JE. Trends and geographic variations in major surgery for degenerative diseases of the hip, knee, and spine. Health Affairs 2004; Suppl Variation:Var81-9

22. Wennberg JE, Bunker JP, Barnes B. The need for assessing the outcome of common medical practices. Annual review of public health 1980; 1(1):277-95

23. Chassin MR. Explaining geographic variations. The enthusiasm hypothesis. Medical Care 1993; 31(5 Suppl):Ys37-44 
24. De Jong JD. Explaining medical practice variation. Social organization and institutional mechanisms. NIVEL, 2008

25. Westert GP. Variation in use of hospital care (dissertation). Assen: Van Gorcum, 1992

26. Elwyn G, Laitner S, Coulter A, Walker E, Watson P, Thomson R. Implementing shared decision making in the NHS. The BMJ 2010; 341:c5146

27. Charles C, Gafni A, Whelan T. Shared decision-making in the medical encounter: what does it mean? (or it takes at least two to tango). Social Science \& Medicine 1997; 44(5):681-92

28. Chewning B, Bylund CL, Shah B, Arora NK, Gueguen JA, Makoul G. Patient preferences for shared decisions: a systematic review. Patient Education \& Counseling 2012; $86(1): 9-18$

29. Say R, Murtagh M, Thomson R. Patients' preference for involvement in medical decision making: a narrative review. Patient Education \& Counseling 2006;60(2):102-14

30. Frosch DL, Kaplan RM. Shared decision making in clinical medicine: past research and future directions. American Journal of Preventive Medicine 1999; 17(4):285-94

31. Groenewegen P. Dealing with micro-macro relations: a heuristic approach with examples from health services research. 1997

32. WHO Commission on Social Determinants of Health. Achieving health equity: From root causes to fair outcomes. Geneva: WHO, 2007

33. Ad Hoc Committee on Health Literacy for the Council on Scientific Affairs AMA. Health literacy: report of the Council on Scientific Affairs. JAMA 1999; 281(6):552-7

34. Beauchamp A, Buchbinder R, Dodson S, Batterham RW, Elsworth GR, McPhee C, et al. Distribution of health literacy strengths and weaknesses across socio-demographic groups: a cross-sectional survey using the Health Literacy Questionnaire (HLQ). BMC Public Health 2015; 15:678

35. Dodson S, Beauchamp A, Batterham RW, Osborne RH. Information sheet 1: What is health literacy? In Ophelia Toolkit: A step-by-step guide for identifying and responding to health literacy needs within local communities. www.ophelia.net.au 
36. Peerson A, Saunders M. Health literacy revisited: what do we mean and why does it matter? Health Promotion International 2009; 24(3):285-96

37. Umberson D, Montez JK. Social relationships and health: a flashpoint for health policy. Journal of Health and Social Behavior 2010; 51 Suppl:S54-66

38. Berkman LF, Glass T, Brissette I, Seeman TE. From social integration to health: Durkheim in the new millennium. Social Science \& Medicine 2000; 51(6):843-57

39. Umberson D, Crosnoe R, Reczek C. Social Relationships and Health Behavior Across Life Course. Annual Review of Sociology 2010; 36:139-57

40. Coleman J. Foundations of social theory. Cambridge, MA: Belknap 1990

41. Van der Gaag M. Measurement of individual social capital. Rijksuniversiteit Groningen, 2005

42. Lin N. Building a network theory of social capital. Connections 1999; 22(1):28-51

43. Cohen S. Social relationships and health. American psychologist 2004; 59(8):676

44. Cooke BD, Rossmann MM, McCubbin HI, Patterson JM. Examining the definition and assessment of social support: A resource for individuals and families. Family Relations 1988: $211-16$

45. House JS. Work stress and social support. Reading, MA: Addison-Wesley, 1981

46. Arrow KJ. Uncertainty and the welfare economics of medical care. The American economic review 1963: 941-73

47. Charles C, Whelan T, Gafni A, Reyno L, Redko C. Doing Nothing is No Choice: Lay Constructions of Treatment Decision-making Among Women with Early-stage Breast Cancer. Sociology of Health \& Illness 1998; 20(1):71-95

48. Marzuk PM. The right kind of paternalism. New England Journal of Medicine 1985; 313(23):1474-6

49. Pellegrino ED. Patient and physician autonomy: conflicting rights and obligations in the physician-patient relationship. The Journal of Contemporary Health Law and Policy 1994; 10:47 
50. Wolff JL, Roter DL. Family presence in routine medical visits: a meta-analytical review. Social Science \& Medicine 2011; 72(6):823-31

51. Wennberg JE. Variation in Use of Medicare Services among Regions and Selected Academic Medical Centers: Is More Better? Commonwealth Fund, 2005

52. O'Connor AM, Llewellyn-Thomas HA, Flood AB. Modifying unwarranted variations in health care: shared decision making using patient decision aids. Health Affairs 2004; Var63-72

53. Greer AL, Goodwin JS, Freeman JL, Wu ZH. Bringing the patient back in. Guidelines, practice variations, and the social context of medical practice. International Journal of Technology Assessment in Health Care 2002; 18(4):747-61

54. O'Connor AM, Wennberg JE, Legare F, Llewellyn-Thomas HA, Moulton BW, Sepucha $K R$, et al. Toward the 'tipping point': decision aids and informed patient choice. Health Affairs 2007; 26(3):716-25

55. Stiggelbout AM, Van der Weijden T, De Wit MP, Frosch D, Legare F, Montori VM, et al. Shared decision making: really putting patients at the centre of healthcare. The BMJ 2012; 344:e256

56. Deyo RA, Cherkin DC, Weinstein J, Howe J, Ciol M, Mulley AG, Jr. Involving patients in clinical decisions: impact of an interactive video program on use of back surgery. Medical Care 2000; 38(9):959-69

57. Stacey D, Bennett CL, Barry MJ, Col NF, Eden KB, Holmes-Rovner M, et al. Decision aids for people facing health treatment or screening decisions. The Cochrane Database of Systematic Reviews 2011; (10):Cd001431

58. Van Peperstraten A, Nelen W, Grol R, Zielhuis G, Adang E, Stalmeier P, et al. The effect of a multifaceted empowerment strategy on decision making about the number of embryos transferred in in vitro fertilisation: randomised controlled trial. The BMJ 2010; 341:c2501

59. Coxeter P, Del Mar CB, McGregor L, Beller EM, Hoffmann TC. Interventions to facilitate shared decision making to address antibiotic use for acute respiratory infections in primary care. The Cochrane Database of Systematic Reviews 2015; (11):Cd010907 
60. Stacey D, Légaré F. Shared Decision-Making for Medical Practice Variations in Elective Surgeries and Tests. In: Sobolev B (Series ed), Johnson A, Stukel T (eds). Health Services Research Series. Medical Practice Variations. New York: Springer, 2015; 459-73

61. Visser J. De arts staat in de behandelmodus. Medisch Contact 2012; 67(22):1326-29

62. Victoor A. (How) do patients choose a healthcare provider? Tilburg: Tilburg Universiteit, 2015

63. De Jong JD, Groenewegen PP, Spreeuwenberg P, Schellevis F, Westert GP. Do guidelines create uniformity in medical practice? Social Science \& Medicine 2010; 70(2):209-16

64. Graham R, Mancher M, Wolman DM, Greenfield S, Steinberg E. Clinical practice guidelines we can trust: National Academies Press, 2011

65. Van Dijk L, De Jong JD, Westert GP, De Bakker DH. Variation in formulary adherence in general practice over time (2003-2007). Family Practice 2011; 28(6):624-31

66. Ivanovska V, Hek K, Mantel Teeuwisse AK, Leufkens HG, Nielen MM, Van Dijk L. Antibiotic prescribing for children in primary care and adherence to treatment guidelines. Journal of Antimicrobial Chemotherapy 2016; 71(6):1707-14

67. Van den Berg MJ, De Bakker DH, Spreeuwenberg P, Westert GP, Braspenning JC, Van der Zee J, et al. Labour intensity of guidelines may have a greater effect on adherence than GPs' workload. BMC Family Practice 2009; 10(1):74

68. Lugtenberg M, Burgers JS, Besters CF, Han D, Westert GP. Perceived barriers to guideline adherence: a survey among general practitioners. BMC Family Practice 2011; $12: 98$

69. Krahn M, Naglie G. The next step in guideline development: incorporating patient preferences. JAMA 2008; 300(4):436-8

70. Brabers A, Reitsma-Van Rooijen M, De Jong J. Consumentenpanel Gezondheidszorg: Basisrapport met informatie over het panel (2015). Utrecht: NIVEL, 2015

71. CCMO. Your research: does it fall under the WMO? The Hague. Available at: http://www.ccmo.nl/en/your-research-does-it-fall-under-the-wmo (26 August, 2015, date last accessed) 
72. Flynn KE, Smith MA, Vanness D. A typology of preferences for participation in healthcare decision making. Social Science \& Medicine 2006; 63(5):1158-69

73. NIVEL. NIVEL Primary Care Database. Utrecht. Available at: http://www.nivel.nl/ en/nivel-primary-care-database (3 February, 2017, date last accessed) 


\section{Part A}

Mechanisms explaining differences in patient involvement in medical decision-making 


\section{2}

\section{What role does health literacy play in patients' involvement in medical decision-making?}

This article is published as:

Brabers AEM, Rademakers JJDJM, Groenewegen PP, Van Dijk L, De Jong JD. What role does health literacy play in patients' involvement in medical decision-making? PloS ONE 2017; 12(3): e0173316 doi/10.1371/journal.pone.0173316 


\begin{abstract}
Patients vary in their preferences towards involvement in medical decision-making. Previous research, however, gives no clear explanation for this observed variation in their involvement. One possible explanation might be health literacy. Health literacy refers to personal characteristics and social resources needed for people to access, understand and use information to make decisions about their health. This study aimed to examine the relationship between health literacy and self-reported patient involvement. With respect to health literacy, we focused on those competences relevant for medical decision-making. We hypothesised that people with higher health literacy report that they are more involved in medical decisionmaking.
\end{abstract}

A structured questionnaire was sent to members of the Dutch Health Care Consumer Panel in May 2015 (response 46\%, N=974). Health literacy was measured using five scales of the Health Literacy Questionnaire. A regression model was used to estimate the relationship between health literacy and self-reported involvement.

In general, our results did not show a relationship between health literacy and selfreported involvement. We did find a positive significant association between the health literacy scale appraisal of health information and self-reported involvement. Our hypothesis was partly confirmed.

The results from this study suggest that higher order competences, that is to say critical health literacy, in particular, are important in reporting involvement in medical decision-making. Future research is recommended to unravel further the relationship between health literacy and patient involvement in order to gain insight into whether health literacy might be an asset to enhance patient participation in medical decision-making. 


\subsection{Introduction}

Patients are increasingly expected to be in charge of their health and to be involved in decisions about their health [1-3]. This is partly because of the recognition of the ethical imperative to involve patients properly in decision-making about their health, and also due to the growing evidence that patient participation has several benefits [2, 4-6]. Examples of these benefits are increased patient knowledge, increased patient satisfaction with treatment decisions, reduced patient anxiety and better treatment adherence [5-8]. Furthermore, providing care that is respectful of, and responsive to, an individual patient's preferences, needs and values is regarded as one of the key elements of good quality of care [9].

Several studies examined patients' preferences towards involvement in medical decision-making. These studies observed that although some patient groups prefer to leave the decision to their physician, most patients want to share decisions with their physician [10-13]. Whether patients want to participate in medical decisionmaking is associated with a variety of factors. These include, among others: their relationship with health professionals; the type of decision they need to make; their experience of illness and medical care; their diagnosis and health status; and demographic characteristics, such as gender, age and level of education [13]. In general, women, younger people, and higher educated people prefer a more active role in decision-making $[10,12,13]$. Several studies also observed that patients largely experience their preferred style of decision-making [14-17].

The above-mentioned studies indicate that there is a variation in patients' preferences towards an active role in medical decision-making. However, research so far is primarily descriptive and does not give a clear explanation for the variation observed in involvement in medical decision-making. A possible explanation is that the variation observed in involvement reflects differences in the ability of people to become an active participant with regard to their health, and the competencies they have acquired to make informed decisions about their health. An important theoretical concept in this context is "health literacy". Health literacy has been considered as important determinant of health $[18,19]$. It is defined as "personal characteristics and social resources needed for people to access, understand and use information to make decisions about health" [20,21]. It refers to a resource that is integrated into people's daily lives and includes information and decisionmaking skills that are necessary in a range of different contexts [22]. The focus has 
shifted, over time, from functional literacy, for example, reading health information, to a broader focus on higher order competences [23]. In this respect, Nutbeam's definition of health literacy became influential. Nutbeam $(2000 ; 2008)$ discerned three different sequential types of health literacy. These include functional literacy, that is a basic knowledge of reading and writing. Communicative or interactive literacy, involving more advanced cognitive and literacy skills which can be used in everyday activities and to apply new information to changing circumstances. And critical literacy, the most advanced cognitive skills which can be applied to critically analyse information and to use it to exert greater control over life events and situations [24, 25]. Higher levels of health literacy enable people to engage in a range of actions aimed at enhancing health [25].

With regard to patient involvement in medical decision-making, it can be hypothesised that a high level of health literacy enables people to play a more active role. They are presumably able to obtain, understand, appraise and apply information required for medical decision-making better. The following phases can be discerned within medical decision-making: information exchange; deliberation; and deciding on which treatment to implement [26-29]. If both physician and patient are involved, they collect and share information with each other in the first phase, for example about possible treatment options. The second phase refers to the process of expressing and discussing treatment preferences. In the last phase, they decide together on the treatment [27]. Health competences such as finding and having enough information, understanding and appraising this information, and being able to engage with physicians are thus especially relevant in order for people to play an active role.

Several studies have already examined the relationship between health literacy and medical decision-making. In general, these studies observed that people with low health literacy desire less participation [30-36]. Most of the studies conducted, however, are based on specific patient groups, and only included functional health literacy such as reading instead of a broader concept of health literacy.

We aimed in this study to examine the relationship between health literacy and patient involvement in medical decision-making. We performed our study among a sample of health care users in the Netherlands, and focused on their self-reported involvement in medical decision-making. With respect to health literacy, we focused on those competences necessary for medical decision-making. These are: 
finding and having enough information; understanding and appraising the information; and the ability to engage with health care providers. As explained above, we hypothesised that people with higher health literacy report that they are more involved in medical decision-making.

\subsection{Materials and methods}

\section{Setting}

Data were collected from the Dutch Health Care Consumer Panel, which aims to measure opinions on, and knowledge of, health care as well as the expectations of, and experiences with, health care among a cross-section of the Dutch population (see for more detailed information [37]). The Dutch Health Care Consumer Panel is a so-called access panel. An access panel consists of a large number of people who have agreed to answer questions on a regular basis. Many background characteristics of the panel members are known such as their age, gender and highest level of education completed. At the time of this study (May 2015), the Consumer Panel consisted of about 12,000 people aged 18 years and older. Each individual panel member receives a questionnaire about three times a year and can resign from the panel at any time. At the start of their membership, panel members can choose whether they want to receive a postal or web-based questionnaire. There is no possibility of people signing up for the panel on their own initiative. The Dutch Health Care Consumer Panel is renewed on a regular basis. We recruit possible new members by means of two ways. First, we buy an address file from an address supplier. As such, possible new members for the panel are sampled at random from the general population in the Netherlands. Second, we recruit possible new members via general practices participating in the NIVEL Primary Care Database [38]. Data are processed anonymously and the protection of the data collected is registered with the Dutch Data Protection Authority (nr. 1262949). A privacy regulation is available for the Consumer Panel. There is no legal requirement to obtain informed consent nor approval by a medical ethics committee when conducting research through the panel [39]. For this study, a questionnaire was sent to a sample of 2,116 panel members in late May 2015. The sample consisted of all migrants (both western and non-western) included in the panel $(N=1,058)$ and the same number of non-migrants $(N=1,058)$. The group of non-migrants was matched to the group of migrants based on gender, age and educational level. Migrants were overrepresented in the study sample because the 
questionnaire was also used for other studies, which specifically focused on migrant groups. One postal reminder (after two weeks), and two electronic reminders (after one and after two weeks) were sent to panel members who did not respond. Panel members were free to answer the questions or not. The questionnaire was returned by 974 panel members (response rate $46 \%$ ).

\section{Measurements}

\section{Involvement in medical decision-making}

We used two items to measure involvement in medical decision-making. 1) How often do you think that your doctor takes the decisions about what's best for your health? And, 2) how often do you think that the important medical decisions will be taken by your doctor and not by yourself? The options for answering were: 1 ) never; 2) sometimes; 3) often, and; 4) always. Both items were based on items developed by Flynn et al. (2006) [40]. An earlier study, using the same two items as dependent variable, showed that both measured a single concept (Cronbach's alpha 0.78) [41]. We recoded both items $(1=4,2=3$ etc.), and only included respondents that filled out both (included: $\mathrm{N}=956$, excluded: $\mathrm{N}=18$ ). A mean score was calculated ranging from 1 to 4 , in which higher scores indicated that respondents report being more involved in medical decision-making. This mean score was, to a fair degree, normally distributed.

\section{Health literacy}

We used five scales of the Health Literacy Questionnaire (HLQ) developed by Osborne et al. (2013) [42] in order to measure the concept of health literacy. The complete HLQ includes nine different scales of health literacy skills based on 44 different items. As argued, competences such as finding and having enough information, understanding and appraising this information, and being able to engage with physicians are particularly relevant in the context of medical decisionmaking. We, therefore, included the following five scales of the HLQ: 1) having sufficient information to manage my health (four items); 2) appraisal of health information (five items); 3) ability to actively engage with health care providers (five items); 4) ability to find good health information (five items), and; 5) understanding health information well enough to know what to do (five items). In line with Nutbeam's definition of health literacy, the scales one, four and five can be considered as functional literacy, scale three as communicative or interactive literacy, and scale two as critical literacy. For the items of the scales one and two, respondents were asked to what extent they agree with a statement, for example, 
'I have enough information to help me deal with my health problems' and 'I always compare health information from different sources and decide what is best for me'. The items could be answered using the following options: 1) strongly disagree; 2) disagree; 3) agree, and; 4) strongly agree. For the items of the scales three, four and five, respondents were asked how difficult or easy a number of tasks are for them. For example, tasks included: 'Have good discussions about your health with doctors', and; 'Read and understand written health information'. These items could be answered using the following options: 1) cannot do; 2) very difficult; 3) quite difficult; 4) quite easy, and; 5) very easy. We used the Dutch version of the HLQ for our study. This has been translated and validated. We constructed a scale score for each of the five scales included instead of one total health literacy score. This is because we expected that the different health competences might have a different impact upon self-reported involvement. To construct these scale scores, mean scores were calculated for the five scales included for each respondent. If responses to one or two items were missing, the mean of the available items was used. If more than two items in a scale were missing, the scale score was regarded as missing. The number of respondents excluded per scale ranged from $\mathrm{N}=48$ to $\mathrm{N}=96$. The internal consistency given by Cronbach's alpha varied, depending on the scale, between 0.73 and 0.89 . The mean scores for the scales having sufficient information to manage my health and appraisal of health information ranged from 1 to 4 , whereas the mean scores for the scales ability to actively engage with health care providers, ability to find good health information, and understanding health information well enough to know what to do ranged from 1 to 5 . For all scales, higher scores indicated higher health literacy.

\section{Socio-demographics}

The following socio-demographics were included: age (continuous); gender ( $0=$ man, $1=$ woman); highest level of education completed (1=low, $2=$ middle, and $3=$ high); ethnicity (1=non-migrant, $2=$ western migrant, and $3=$ non-western migrant), and; self-reported general health (1=excellent/very good, $2=$ good, and $3=$ fair/bad).

\section{Statistical analyses}

We performed descriptive statistics first in order to describe the characteristics of the respondents. Secondly, we constructed a multiple linear regression model (model-I) including self-reported involvement as the dependent variable, and the socio-demographics as the independent variables, in order to test whether our 
data are consistent with earlier studies. Thirdly, we tested the association between health literacy and involvement in medical decision-making. We ran five different multiple linear regression analyses. In each analysis, we included self-reported involvement as a dependent variable, and one of the five health literacy scales and the socio-demographics as independent variables (model-II to model-VI). We did not include all five scales in one model because of the correlations between the scales $(0.21$ to 0.84$)$. We controlled all models for whether a respondent filled out the questionnaire through the internet (1), or by post (0). In the regression analyses, categorical variables (educational level, ethnicity and self-reported general health) were recoded into dummy variables. The level of statistical significance was fixed at 0.05 . All statistical analyses were carried out using STATA, version 13.1.

\subsection{Results}

Approximately half (53\%) of the respondents were women and the mean age of the respondents was 63 years (range 19 to 90 years; Table 2.1). About half (51\%) had a middle level of education. Table 2.1 shows that $55 \%$ of the respondents were nonmigrant, 36\% western migrant and $9 \%$ non-western migrant. General health was self-reported as excellent/very good by $28 \%$ of the respondents. Compared to the general Dutch population aged 18 years and older, there was some overrepresentation in the group of respondents, mainly in elderly (65 years and older) and western migrants [37]. The reason for this is that these groups were also overrepresented in the study sample due to the fact that the questionnaire was also used for other studies focusing on migrant groups.

The mean score for self-reported involvement in medical decision-making was 2.40 (SD 0.78) on a scale from 1 (no involvement) to 4 (most involvement) (Table 2.1). Approximately half (49\%) of the respondents had a score of 2 or lower. This means that, on average, respondents were slightly more inclined to leave medical decision-making to the physician. Table 2.1 also presents the mean scores per health literacy scale. 
Table 2.1 Descriptive statistics of the respondents

\begin{tabular}{|c|c|c|}
\hline & $\mathbf{N}$ & $\begin{array}{l}\text { \% ormean } \\
\text { (SD) }\end{array}$ \\
\hline Gender & 974 & \\
\hline male & 461 & 47.3 \\
\hline female & 513 & 52.7 \\
\hline Age & 974 & $63(15.7)$ \\
\hline Level of education & 955 & \\
\hline low (none, primary school or pre-vocational education) & 154 & 16.1 \\
\hline middle (secondary or vocational education) & 485 & 50.8 \\
\hline high (professional higher education or university) & 316 & 33.1 \\
\hline Ethnicity & 974 & \\
\hline non-migrant & 532 & 54.6 \\
\hline western migrant & 353 & 36.2 \\
\hline non-western migrant & 89 & 9.1 \\
\hline Self-reported general health & 925 & \\
\hline excellent/verygood & 257 & 27.8 \\
\hline good & 454 & 49.1 \\
\hline fair/bad & 214 & 23.1 \\
\hline Questionnaire & 974 & \\
\hline post & 499 & 51.2 \\
\hline internet & 475 & 48.8 \\
\hline $\begin{array}{l}\text { Involvement in medical decision-making (range } 1-4, \text { higher scores indicate } \\
\text { more involvement) }\end{array}$ & 956 & $2.40(0.78)$ \\
\hline \multicolumn{3}{|l|}{ HLQ (higher scores indicate higher levels of health literacy) } \\
\hline having sufficient information to manage my health (range $1-4$ ) & 926 & $2.85(0.39)$ \\
\hline appraisal of health information (range $1-4$ ) & 919 & $2.62(0.45)$ \\
\hline ability to actively engage with health care providers (range $1-5$ ) & 892 & $3.82(0.62)$ \\
\hline ability to find good health information (range $1-5$ ) & 891 & $3.80(0.61)$ \\
\hline $\begin{array}{l}\text { understanding health information well enough to know what to do (range } \\
1-5)\end{array}$ & 878 & $3.89(0.57)$ \\
\hline
\end{tabular}

Younger people $(\beta=-0.102, p=0.004)$ and women $(\beta=0.121, p=0.000)$ report being more involved in medical decision-making than older people and men (Table 2.2, model-I). Also, people with a high level of education $(\beta=0.240, p=0.000)$ report being more involved in medical decision-making compared with people with a low level of education. No significant association was observed for ethnicity and selfreported general health. The explained variance of the model was $7 \%$. 


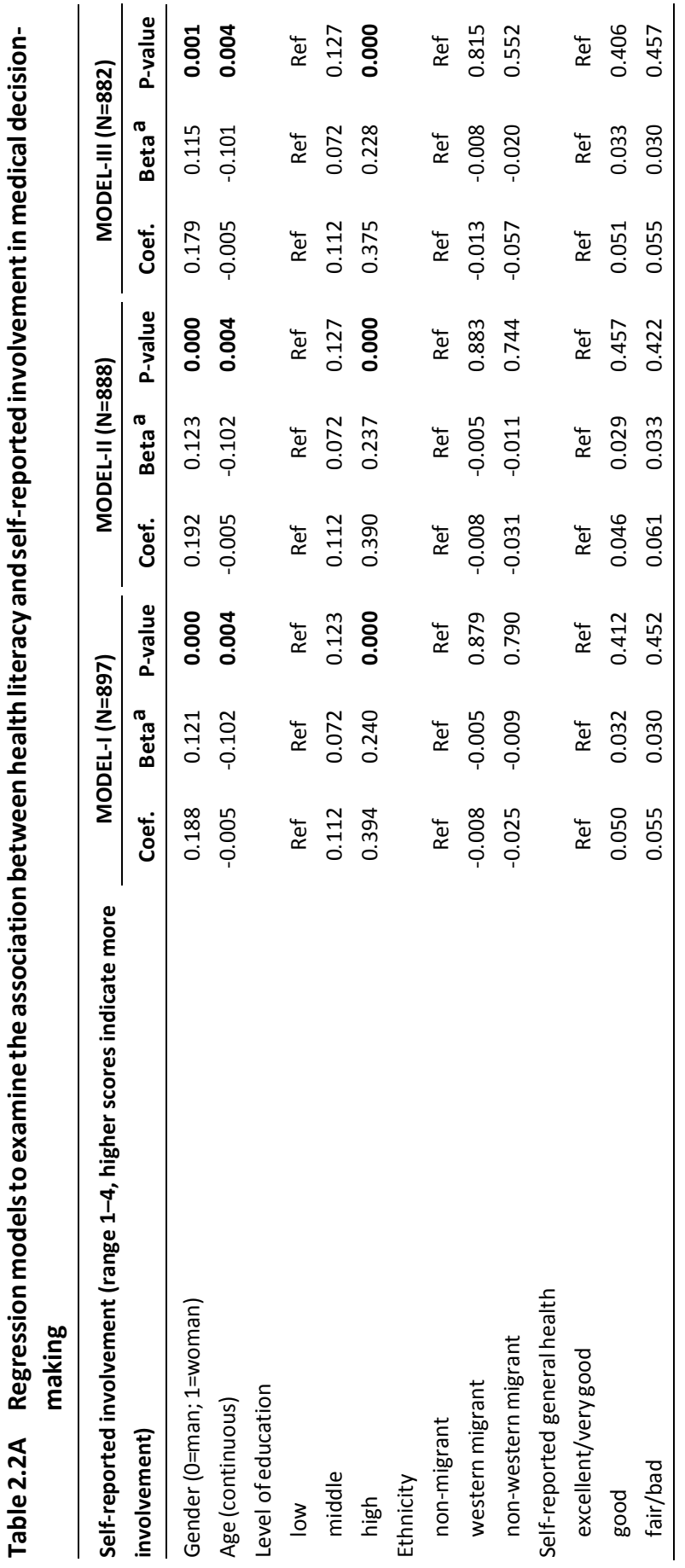




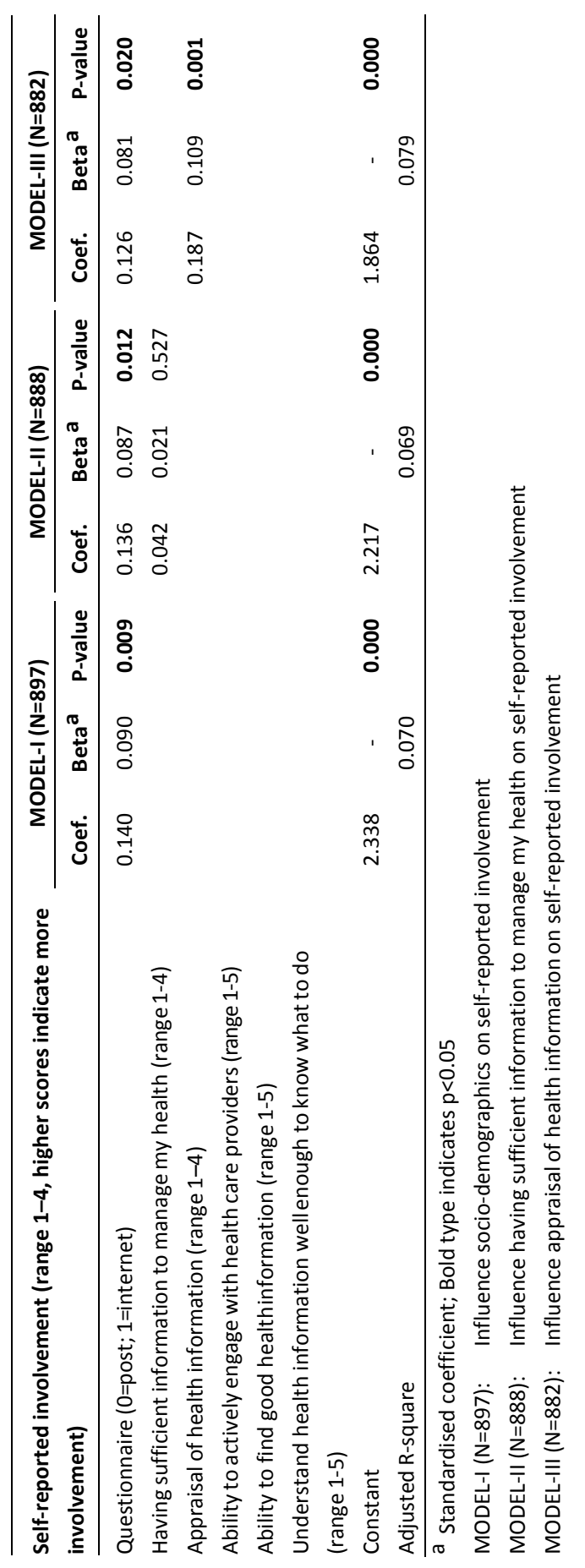




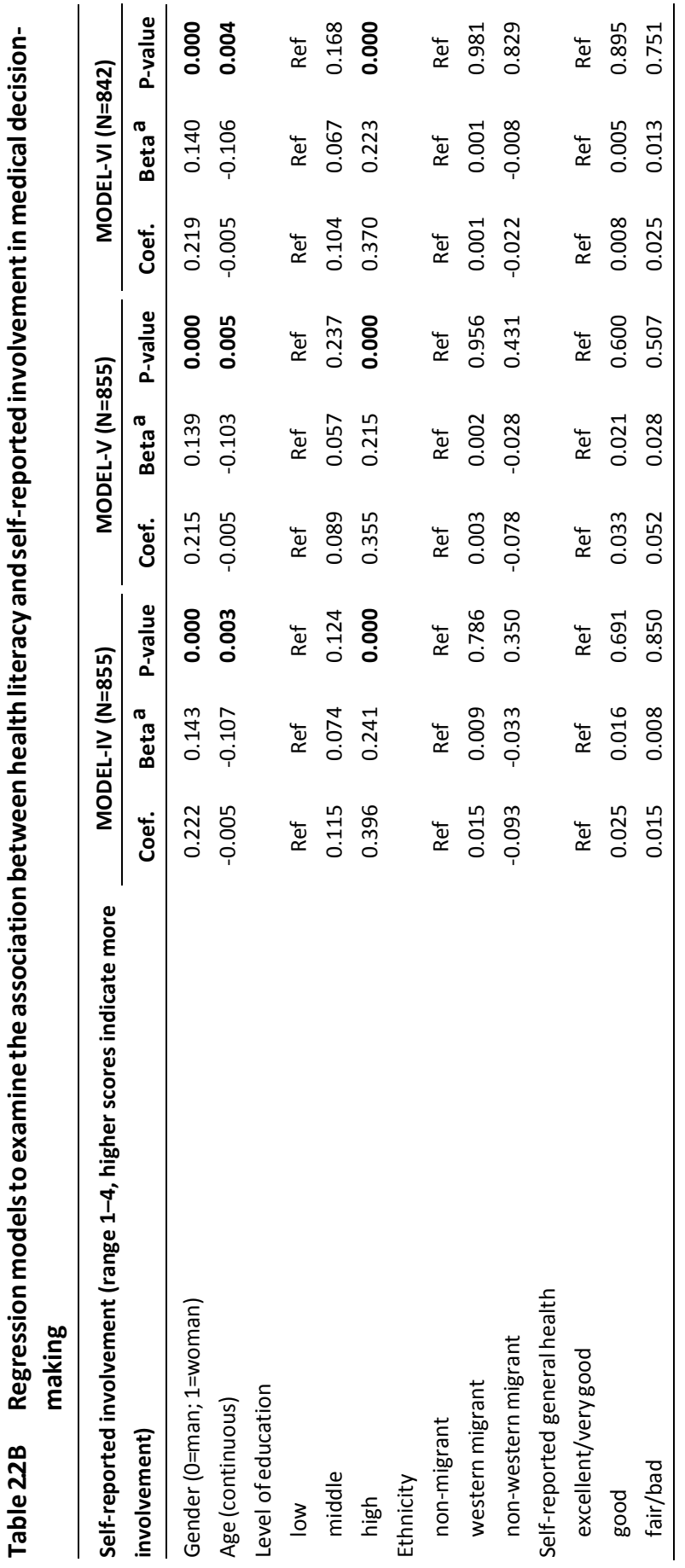




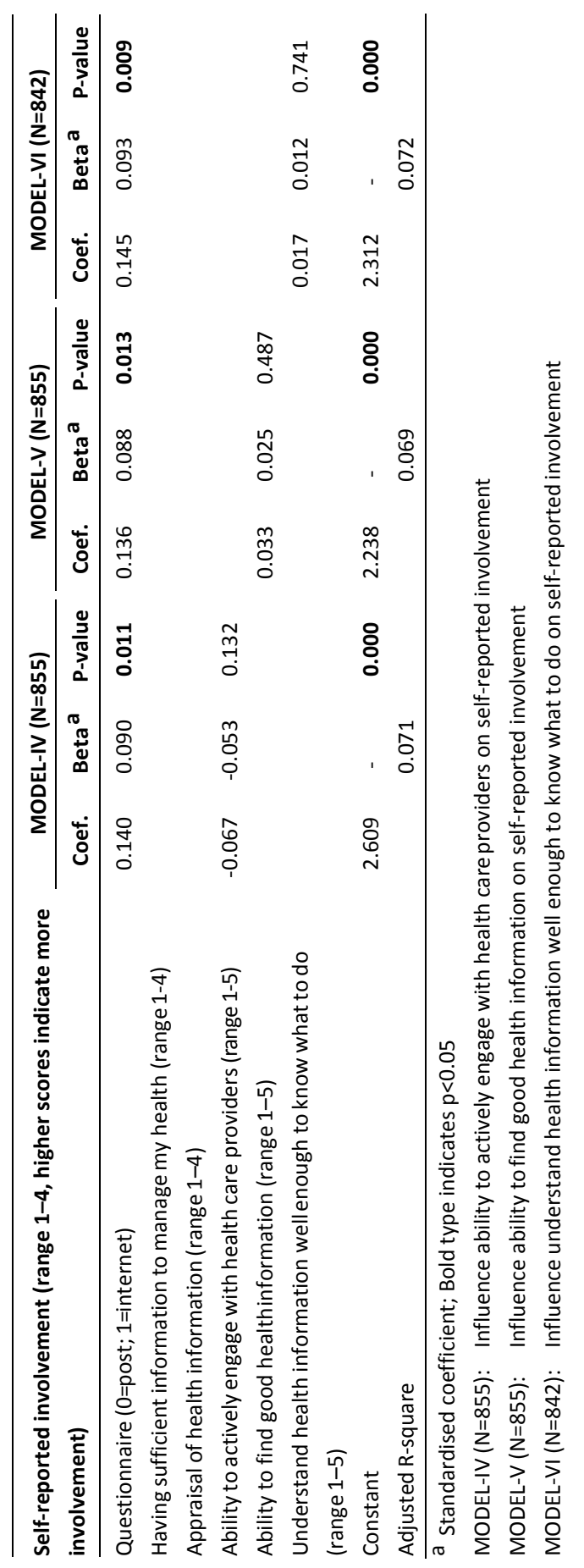


We added the health literacy scales as independent variables in the models-II to $\mathrm{VI}$ in order to examine whether health literacy might be an explanation for the variation observed in the involvement in medical decision-making. Table 2.2 showed that it is only the health literacy scale appraisal of health information (model-III) which is associated significantly with self-reported involvement in medical decision-making $(\beta=0.109, p=0.001)$. The higher respondents scored on the scale the appraisal of health information, the more they reported being involved in medical decision-making. Just as in model-I, women $(\beta=0.115, p=0.001)$, younger people $(\beta=-0.101, p=0.004)$ and high educated people $(\beta=0.228, p=0.000)$, report being more involved in medical decision-making. The explained variance of modelIII was $8 \%$. No significant association with self-reported involvement was observed for the other four health literacy scales. We did find significant associations in all these four models between the socio-demographics gender, age and educational level and self-reported involvement in medical decision-making (Table 2.2).

\subsection{Discussion}

This study sought to gain insight into the relationship between health literacy and self-reported involvement in medical decision-making. We focused on a broad concept of health literacy instead of only on functional health literacy. In general, our results did not show a positive association between health literacy and selfreported involvement. We found that the higher respondents score on the health literacy scale appraisal of health information, the more they report being involved. Our hypothesis is, therefore, only partly confirmed.

We did not find a relationship between most aspects of health literacy and involvement in medical decision-making. Previous research generally found a positive relationship between health literacy and involvement [30-36]. It is difficult to compare our results with these previous studies as these predominantly focused on the relationship between functional health literacy, for example simply reading health information, and peoples' preferences towards participation. Our study focused on a broader concept of health literacy and on self-reported involvement in medical decision-making. As such, we included a range of various resources and skills covering all domains of health literacy instead of only including reading skills. Furthermore, these studies were mainly performed among specific patient groups. 
We performed our study among a general sample of health care users in the Netherlands.

We observed a positive significant relationship between the health literacy scale appraisal of health information and self-reported involvement in medical decisionmaking. This suggests that higher order competences, that is critical health literacy, are more important when it comes to reporting involvement in medical decisionmaking as opposed to functional and communicative or interactive competences. Chinn (2011) noticed that "information appraisal" is one component of critical health literacy. Critical appraisal of information is about cognitive skills in managing and interpreting information, as well as about assessing the personal relevance of information [43]. In the context of our study, it appears that in order to take an active role in the decision-making process people have to be able to interpret information and weigh this information against their own preferences.

It has been argued that both functional and communicative or interactive health literacy need to be in place in order for critical health literacy to emerge [44]. Our results do not support this, as we only observed a relationship between critical health literacy and involvement, and not between functional and communicative or interactive health literacy and involvement. One possible explanation for this might be that our respondents in general scored quite high on these lower order competences. It has also been suggested that the functional, communicative or interactive and critical components of health literacy can be seen as complementary [45]. Research showed that it depends upon the type of behaviour which health literacy skills are required. Different types of health literacy, be they functional, communicative or interactive, or critical, have a different impact upon different outcome measures $[45,46]$. Our results are in line with this. This means that it is possible that when other outcome measures such as preferences, or wishes, for involvement are used, a relationship might be found between other types of health literacy and these outcomes. Future research is recommended to unravel further the relationship between health literacy and involvement. This may enable researchers to gain more insight into whether health literacy might be an asset to enhance patient participation in medical decision-making.

Besides the influence of the health literacy scale appraisal of health information, we also found that younger people, women, and highly educated people report being more involved in the decision-making process. These results are consistent 
with previous empirical research showing that involvement in medical decisionmaking is associated with socio-demographics $[10,12,13]$.

Our model-III does not explain much of the variance in self-reported involvement in medical decision-making. This implies that factors other than health literacy and socio-demographics explain such involvement. One of these mechanisms is someone's social context, as this influences individual behaviour [47]. Someone's social network affects individual behaviour through different mechanisms, such as social support and social norms [48-50]. Another factor that might play a role is the trust that patients have in physicians.

A first strength of this study is the use of the health literacy questionnaire (HLQ). This HLQ is a comprehensive measurement of health literacy encompassing both a broad range of resources and various skills [42]. Previous studies investigating the relationship between health literacy and involvement in medical decision-making included only functional health literacy by using, for instance, the Test of Functional Health Literacy in Adults (TOFHLA). Although focusing on a narrow conception of health literacy, instruments like the TOFHLA have the virtue of directly assessing peoples capabilities. A limitation of the HLQ is that it is a subjective measurement; it provides an indication of the perceived resources and skills of people. However, currently, no universally agreed measurement which captures all aspects of the concept of health literacy is available [51]. Another strength is the large sample size, even though the response rate was less than $50 \%$. However, a limitation is that there are several challenges to how far our results can be applied generally. Our respondents were not representative of the general Dutch population aged 18 years and older. By comparison with this population, mainly elderly (65 years and older) and western migrants were overrepresented in this study's group of respondents [37]. The reason for this is that these groups were also overrepresented in the study sample due to the fact that the questionnaire was also used for other studies focusing on migrant groups. We expect, however, that this does not affect our regression results, since all subgroups are of sufficient size for association analyses. It can also be argued that members of a health care panel are more interested in health care and therefore might take a more active role in medical decision-making. Furthermore, it is possible that we overestimate the level of health literacy in our sample due to the nature of the data collection - as people with very low levels of health literacy may not participate in a written questionnaire. Our results show that, except for the appraisal of health 
information, respondents score quite high on the scales included. Another limitation might be that we examined self-reported involvement in medical decision-making, instead of actual observed behaviour. In the questionnaire, we did not refer to a specific treatment decision, but asked about involvement in general. It remains unclear from this study whether people do indeed take an active role in a situation where a specific, concrete decision is made. From the literature it is known that the type of care people have to decide upon has an impact upon the importance they attach to shared decision-making, as well as upon their actual involvement in decision-making [52]. Using self-reported involvement as an outcome might also be a strength, as this gives insight into how people themselves experience their involvement. We also examined self-reported levels of health literacy. In a real life situation, people might have more difficulty with health literacy than they reported. For example due to emotions such as stress. In addition, it is possible that respondents with lower capabilities overestimate their abilities, whereas respondents with higher capabilities tend to underestimate their abilities [53]. A final limitation is that our data were obtained using a cross-sectional study design, and as such cannot provide any information about causal relationships.

\subsection{Conclusion}

This study suggests that higher order competences - that is critical health literacy in particular are important for the reporting of involvement in medical decisionmaking. Future research is recommended to unravel further the relationship between health literacy and patient involvement in order to gain insight into whether health literacy might be an asset to enhance patient participation in medical decision-making. 


\section{References}

1. RVZ. De participerende patiënt. Den Haag, 2013.

2. Guadagnoli E, Ward P. Patient participation in decision-making. Social Science \& Medicine 1998; 47(3):329-39

3. Van de Bovenkamp HM, Trappenburg MJ, Grit KJ. Patient participation in collective healthcare decision making: the Dutch model. Health Expectations 2010; 13(1):73-85

4. Elwyn G, Laitner S, Coulter A, Walker E, Watson P, Thomson R. Implementing shared decision making in the NHS. The BMJ 2010; 341:c5146

5. Vahdat S, Hamzehgardeshi L, Hessam S, Hamzehgardeshi Z. Patient involvement in health care decision making: a review. Iranian Red Crescent Medical Journal 2014; 16(1):e12454

6. Coulter A, Ellins J. Effectiveness of strategies for informing, educating, and involving patients. The BMJ 2007; 335(7609):24-7

7. Coulter A. Patient engagement-what works? The Journal of Ambulatory Care Management 2012; 35(2):80-9

8. Stacey D, Bennett CL, Barry MJ, Col NF, Eden KB, Holmes-Rovner M, et al. Decision aids for people facing health treatment or screening decisions. The Cochrane Database of Systematic Reviews 2011(10):Cd001431

9. Institute of Medicine. Crossing the quality chasm: A new health system for the 21st century: National Academies Press, 2001

10. Arora NK, McHorney CA. Patient preferences for medical decision making: who really wants to participate? Medical Care 2000; 38(3):335-41.

11. Chewning B, Bylund CL, Shah B, Arora NK, Gueguen JA, Makoul G. Patient preferences for shared decisions: a systematic review. Patient Education \& Counseling 2012; 86(1):9-18

12. Degner LF, Sloan JA. Decision making during serious illness: what role do patients really want to play? Journal of Clinical Epidemiology 1992; 45(9):941-50 
13. Say R, Murtagh $M$, Thomson R. Patients' preference for involvement in medical decision making: a narrative review. Patient Education \& Counseling 2006; 60(2):10214

14. Ambigapathy $\mathrm{R}$, Chia $\mathrm{YC}, \mathrm{Ng}$ CJ. Patient involvement in decision-making: a crosssectional study in a Malaysian primary care clinic. BMJ Open 2016; 6(1):e010063

15. Brom L, Hopmans W, Pasman HR, Timmermans DR, Widdershoven GA, OnwuteakaPhilipsen BD. Congruence between patients' preferred and perceived participation in medical decision-making: a review of the literature. BMC Medical Informatics and Decision Making 2014; 14:25

16. Murray E, Pollack L, White M, Lo B. Clinical decision-making: Patients' preferences and experiences. Patient Education \& Counseling 2007; 65(2):189-96

17. Rademakers J, Delnoij D, Nijman J, De Boer D. Educational inequalities in patientcentred care: patients' preferences and experiences. BMC Health Services Research 2012; $12: 261$

18. WHO Commission on Social Determinants of Health. Achieving health equity: From root causes to fair outcomes. Geneva: WHO, 2007

19. Ad Hoc Committee on Health Literacy for the Council on Scientific Affairs AMA. Health literacy: report of the Council on Scientific Affairs. JAMA 1999; 281(6):552-7

20. Beauchamp A, Buchbinder R, Dodson S, Batterham RW, Elsworth GR, McPhee C, et al. Distribution of health literacy strengths and weaknesses across socio-demographic groups: a cross-sectional survey using the Health Literacy Questionnaire (HLQ). BMC Public Health 2015; 15:678.

21. Dodson S, Beauchamp A, Batterham RW, Osborne RH. Information sheet 1: What is health literacy? In Ophelia Toolkit: A step-by-step guide for identifying and responding to health literacy needs within local communities. www.ophelia.net.au

22. Peerson A, Saunders M. Health literacy revisited: what do we mean and why does it matter? Health Promotion International 2009; 24(3):285-96.

23. Sorensen K, Van den Broucke S, Fullam J, Doyle G, Pelikan J, Slonska Z, et al. Health literacy and public health: a systematic review and integration of definitions and models. BMC Public Health 2012; 12:80. 
24. Nutbeam D. Health literacy as a public health goal: a challenge for contemporary health education and communication strategies into the 21st century. Health promotion international 2000; 15(3):259-67

25. Nutbeam D. The evolving concept of health literacy. Social Science \& Medicine 2008; 67(12):2072-8

26. Charles C, Gafni A, Whelan T. Shared decision-making in the medical encounter: what does it mean? (or it takes at least two to tango). Social Science \& Medicine 1997; 44(5):681-92

27. Charles C, Gafni A, Whelan T. Decision-making in the physician-patient encounter: revisiting the shared treatment decision-making model. Social Science \& Medicine 1999; 49(5):651-61

28. Makoul G, Clayman ML. An integrative model of shared decision making in medical encounters. Patient Education \& Counseling 2006; 60(3):301-12.

29. Lin GA, Fagerlin A. Shared decision making: state of the science. Circulation: Cardiovascular Quality and Outcomes 2014; 7(2):328-34.

30. Barton JL, Trupin L, Tonner C, Imboden J, Katz P, Schillinger D, et al. English language proficiency, health literacy, and trust in physician are associated with shared decision making in rheumatoid arthritis. The Journal of Rheumatology 2014; 41(7):1290-7

31. Goggins KM, Wallston KA, Nwosu S, Schildcrout JS, Castel L, Kripalani S. Health literacy, numeracy, and other characteristics associated with hospitalized patients' preferences for involvement in decision making. Journal of Health Communication 2014; 19 Suppl 2:29-43

32. McCaffery KJ, Holmes-Rovner M, Smith SK, Rovner D, Nutbeam D, Clayman ML, et al. Addressing health literacy in patient decision aids. BMC Medical Informatics and Decision Making 2013; 13 Suppl 2:S10

33. Naik AD, Street RL Jr., Castillo D, Abraham NS. Health literacy and decision making styles for complex antithrombotic therapy among older multimorbid adults. Patient Education \& Counseling 2011; 85(3):499-504. 
34. Yin HS, Dreyer BP, Vivar KL, MacFarland S, van Schaick L, Mendelsohn AL. Perceived barriers to care and attitudes towards shared decision-making among low socioeconomic status parents: role of health literacy. Academic Pediatrics 2012; 12(2):117-24.

35. Seo J, Goodman MS, Politi M, Blanchard M, Kaphingst KA. Effect of Health Literacy on Decision-Making Preferences among Medically Underserved Patients. Medical Decision Making 2016; 36(4):550-6

36. Smith SK, Simpson JM, Trevena LJ, McCaffery KJ. Factors Associated with Informed Decisions and Participation in Bowel Cancer Screening among Adults with Lower Education and Literacy. Medical Decision Making 2014; 34(6):756-72

37. Brabers A, Reitsma-Van Rooijen M, De Jong J. Consumentenpanel Gezondheidszorg: Basisrapport met informatie over het panel (2015). Utrecht: NIVEL, 2015

38. NIVEL. NIVEL Primary Care Database. Utrecht. Available at: http://www.nivel.nl/ en/nivel-primary-care-database (3 February, 2017, date last accessed)

39. CCMO. Your research: does it fall under the WMO? The Hague. Available at: http://www.ccmo.nl/en/your-research-does-it-fall-under-the-wmo (26 August, 2015, date last accessed)

40. Flynn KE, Smith MA, Vanness D. A typology of preferences for participation in healthcare decision making. Social Science \& Medicine 2006; 63(5):1158-69

41. Brabers AEM, Van Dijk L, Groenewegen PP, De Jong JD. Do social norms play a role in explaining involvement in medical decision-making? European Journal of Public Health 2016; 26(6):901-05

42. Osborne RH, Batterham RW, Elsworth GR, Hawkins M, Buchbinder R. The grounded psychometric development and initial validation of the Health Literacy Questionnaire (HLQ). BMC Public Health 2013; 13:658

43. Chinn D. Critical health literacy: a review and critical analysis. Social Science \& Medicine 2011; 73(1):60-7.

44. Sykes S, Wills J, Rowlands G, Popple K. Understanding critical health literacy: a concept analysis. BMC Public Health 2013; 13:150. 
45. Van der Heide I, Heijmans M, Schuit AJ, Uiters E, Rademakers J. Functional, interactive and critical health literacy: Varying relationships with control over care and number of GP visits. Patient Education \& Counseling 2015; 98(8):998-1004

46. Heijmans M, Waverijn G, Rademakers J, Van der Vaart R, Rijken M. Functional, communicative and critical health literacy of chronic disease patients and their importance for self-management. Patient Education \& Counseling 2015; 98(1):41-8

47. Burke NJ, Joseph G, Pasick RJ, Barker JC. Theorizing social context: rethinking behavioral theory. Health Education \& Behavior 2009; 36(5 Suppl):55s-70s

48. Coleman J. Foundations of social theory. Cambridge MA: The Belknap Press of Harvard University Press, 1990

49. Berkman LF, Glass T, Brissette I, Seeman TE. From social integration to health: Durkheim in the new millennium. Social Science \& Medicine 2000; 51(6):843-57

50. Umberson D, Montez JK. Social relationships and health: a flashpoint for health policy. Journal of Health and Social Behavior 2010; 51 Suppl:S54-66

51. Duell $P$, Wright $D$, Renzaho AM, Bhattacharya $D$. Optimal health literacy measurement for the clinical setting: A systematic review. Patient Education \& Counseling 2015; 98(11):1295-307

52. Van den Brink-Muinen A, Spreeuwenberg P, Rijken M. Preferences and experiences of chronically ill and disabled patients regarding shared decision-making: does the type of care to be decided upon matter? Patient Education \& Counseling 2011; 84(1):111-7

53. Kruger J, Dunning D. Unskilled and unaware of it: how difficulties in recognizing one's own incompetence lead to inflated self-assessments. Journal of Personality and Social Psychology 1999; 77(6):1121-34 
3

Social support plays a role in the attitude that people have towards taking an active role in medical decision-making

This article is published as:

Brabers AEM, De Jong JD, Groenewegen PP, Van Dijk L. Social support plays a role in the attitude that people have towards taking an active role in medical decisionmaking. BMC Health Services Research 2016; 16:502 doi/10.1186/s12913-0161767-x 


\begin{abstract}

\section{Background}

There is a growing emphasis towards including patients in medical decision-making. However, not all patients are actively involved in such decisions. Research has so far focused mainly on the influence of patient characteristics on preferences for active involvement. However, it can be argued that a patient's social context has to be taken into account as well, because social norms and resources affect behaviour. This study aims to examine the role of social resources, in the form of the availability of informational and emotional support, on the attitude towards taking an active role in medical decision-making.
\end{abstract}

\title{
Methods
}

A questionnaire was sent to members of the Dutch Health Care Consumer Panel (response $70 \% ; n=1300$ ) in June 2013. A regression model was then used to estimate the relation between medical and lay informational support and emotional support and the attitude towards taking an active role in medical decision-making.

\section{Results}

Availability of emotional support is positively related to the attitude towards taking an active role in medical decision-making only in people with a low level of education, not in persons with a middle and high level of education. The latter have a more positive attitude towards taking an active role in medical decision-making, irrespective of the level of emotional support available. People with better access to medical informational support have a more positive attitude towards taking an active role in medical decision-making; but no significant association was found for lay informational support.

\section{Conclusions}

This study shows that social resources are associated with the attitude towards taking an active role in medical decision-making. Strategies aimed at increasing patient involvement have to address this. 


\subsection{Background}

Patients traditionally delegate decision-making to physicians because they trust that physicians take decisions based both on scientific evidence and on what is best for an individual patient [1 p7-8]. As physicians control most of the medical decisions, professional judgements rather than collaborative decisions including patients' own preferences often determine which treatment a patient receives [1 p9]. However, this paternalistic model, has come to be questioned in the past decades. At the same time, the position of patients in health care has altered significantly, at least in theory. Patients are supposed to take an active role in their health [2], and they are expected to be involved in decisions about their health [3]. The right of patients to engage in these decisions has been enshrined in the laws of several countries [4]. In the Netherlands, the setting for this study, the approach of patient participation in decision-making is formally defined in the Medical Treatment Agreement Act (WGBO) [5]. There is, thus, a growing emphasis on involving patients in medical decision-making. Providing care that is respectful of, and responsive to, an individual patient's preferences, is regarded as one of the aspects of good quality of care [6].

Most patients prefer to be involved in medical decision-making [7]. Moreover, it has been found that preferences for involvement, as well as actual involvement in decision-making, have increased over time $[7,8]$. On the other hand, it has been recognised that categories of patients prefer to leave the decision to their physician [9]. Among others, diagnosis, health status and characteristics of the patient affect whether patients prefer to be involved in decision-making [10]. For example, in a situation where patients are acutely ill or incapacitated, they generally have to delegate the decision-making process to their physician [11, 12]. Patient characteristics are associated with preferences regarding decision-making. Several studies consistently found that younger people, higher educated people, and women want, more often, an active role in decision-making $[9,10,13]$.

However it is not only patient characteristics which have to be taken into account in explaining whether patients want to participate in medical decision-making, but also has a patient's social context. The reason for this is that patients' preferences cannot be interpreted as merely individual. Social resources, as well as social norms affect individual behaviour [14-16]. Therefore, in this study, we aim to examine the role of social resources in relation to whether patients want to have an active role 
in medical decision-making. To our knowledge, this has not yet been studied. By investigating patients in the Netherlands, we aim to answer the following research question in this study: How are a patient's social resources associated with taking an active role in medical decision-making? We focus on the attitude towards taking such an active role role in medical decision-making.

\subsection{Theory and hypotheses}

Within an individual's social contexts, such as their work, family, or neighbourhood, individuals meet members of their social network. Someone's social network refers to the web of social relationships surrounding this person [14]. Social relationships influence health - and health behaviour - by different mechanisms [15, 17]. They can create social norms, as well as provide resources that affect behaviour [14-16]. In this study, we focus specifically on how resources provided by someone's social network affect the attitude towards taking an active role in medical decisionmaking.

The pool of resources residing in members of an individual's social network form an individual's social capital, or social resources $[18,19]$. Social resources can be provided in the form of social support [20]. The literature provides multiple interpretations of the concept of social support [21]. We will use the framework of Tardy [21], who argues that social support consists of five aspects:

1. Network - as mentioned before, the social network of a patient serves as a source of support.

2. Direction - social support can be both given and received. We opt to examine social support from the direction of the recipient.

3. Disposition - social support can be both available and received. We focus here on an attitude towards behaviour, and therefore on the availability of support. "Support availability refers to the quality or quantity of support to which people have access" [21, p188].

4. Description or evaluation - since we focus on the availability of support, we examined the description of social support, that is the degree to which social support is available.

5. Content - Often distinguished types of social support are: emotional, instrumental, and informational support. Emotional support includes providing empathy, listening, and giving advice. Instrumental support refers to the 
tangible help that others may provide, for example, offering money, transport and time. Informational support is the help others may give through the provision of information $[20,22,23]$. We think that for participation in medical decision-making, the availability of both informational and emotional support are important. Informational support can be related to the provision of advice about different treatments. With respect to emotional support, we expect that support, especially in the form of being accompanied during the medical consultation, is relevant. People who accompany others to such consultations called companions - play an important role in providing emotional support [24]. We argue that instrumental support is less relevant in our context. One reason for this is that in the Netherlands the costs for most medical care, medicines and medical devices are covered by the basic health insurance package [25], and also because there is a low level of out-of-pocket payments [26]. Furthermore, the aspects of time and transport, for example having someone who brings you to the consultation, is already included, since we focus on emotional support in the form of being accompanied during the consultation.

To summarise, we focus on how the availability of emotional and informational support is associated with the attitude towards taking an active role in medical decision-making.

\section{Hypotheses}

Traditionally patients have left the decision-making process to their physician. One reason for this might be that patients who are seriously ill feel vulnerable, and therefore cannot, or do not want to, take the responsibility of being involved in medical decision-making [27, 28]. Another reason might be the information asymmetry between physicians and patients: physicians have information that patients do not [29]. It has been acknowledged that patients believe that medical decision-making requires specific knowledge that they do not have [30] and therefore they leave the decision to their physician. We expect that this lack of knowledge can be compensated by getting advice from others - that is informational support - and by receiving emotional support. By receiving informational support patients acquire specific knowledge required for participating in medical decision-making. Patients can receive this information from health care professionals in their social network - that is medical informational support - as well as from lay people in their network - that is lay informational support. Consequently, we expect that the more medical and lay informational support 
people have available, the more positive their attitude will be towards taking an active role in medical decision-making.

In the context of our study, emotional support can be provided by accompanying the patient during the consultation. We expect that patients will feel less vulnerable due to receiving emotional support. The reason for this is that it has been suggested that patients feel more confident when a companion is present [31]. Furthermore, comparable to informational support, emotional support also has a role in acquiring information necessary for medical decision-making. It has been suggested that having a companion present during the consultation can support the interaction between the patient and the physician by supporting the patient's communication. For example by asking the patient questions, prompting the patient to talk, and asking for the patient's opinion. In addition physicians are more informative when a companion is present [31-33]. Furthermore, companions remember information, which is likely to benefit the patient [34]. As a result, we expect that patients who have more emotional support available take a more positive attitude towards taking an active role in medical decision-making.

H1: The more medical informational support people have available in their social network, the more positive their attitude is towards taking an active role in medical decision-making.

$\mathrm{H} 2$ : The more lay informational support people have available in their social network, the more positive their attitude is towards taking an active role in medical decision-making.

H3: The more emotional support people have available in their social network, the more positive their attitude is towards taking an active role in medical decision-making.

People also possess personal resources, such as knowledge and skills in, for example, communication and numeracy. We expect that the relationship between social support and the attitude towards taking an active role in medical decisionmaking will differ between people possessing more or less of this knowledge and skills. More specifically, we hypothesise that informational support is of less value for people with more knowledge and skills, as there is less information asymmetry between them and the physician compared to people with less knowledge and skills. For example, higher educated people receive more information from physicians than lower educated people [35]. We also expect that for people with 
more knowledge and skills, the role of a companion, especially in the function of acquiring more information, is of less value. The reason for this is that higher educated people are not only more assertive and expressive, but also ask more questions themselves [35]. This allows them to acquire more knowledge necessary for medical decision-making. We thus hypothesise that the role of emotional support in taking an active role in medical decision-making is less important for people with more knowledge and skills.

$\mathrm{H} 4$ : The role of medical informational support on the attitude towards taking an active role in medical decision-making is more important for people with less knowledge and skills compared to people with more knowledge and skills.

H5: The role of lay informational support on the attitude towards taking an active role in medical decision-making is more important for people with less knowledge and skills compared to people with more knowledge and skills.

H6: The role of emotional support on the attitude towards taking an active role in medical decision-making is more important for people with less knowledge and skills compared to people with more knowledge and skills.

Based on the theory and hypotheses proposed, Figure 3.1 presents the model tested in this study.

Figure 3.1 Theoretical model tested within this study

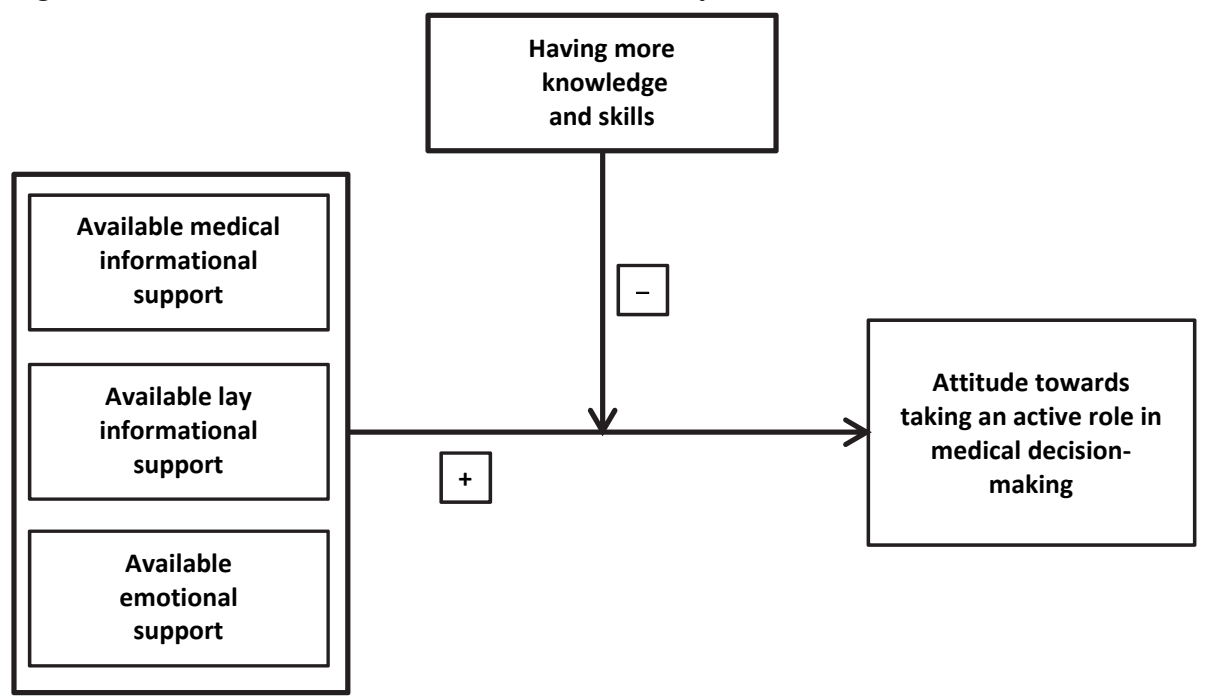




\subsection{Methods}

\section{Setting}

Data were collected through the Dutch Health Care Consumer Panel [36]. This panel aims to measure the attitude towards, and knowledge of, health care, as well as the expectations and experiences of health care among a cross-section of the Dutch population. The Consumer Panel is a so-called access panel. An access panel consists of a large number of people who have agreed to answer questions on a regular basis. In addition, many background characteristics, for example age, gender, and the level of education of these people are known. At the time of the study (June 2013), the access panel consisted of approximately 8,500 people aged 18 years and older. Each individual panel member receives a questionnaire approximately three times a year and can quit the panel at any time. There is no possibility for people to sign up for the panel on their own initiative. The Consumer Panel is renewed on a regular basis. Renewal is necessary to make sure that members do not develop specific knowledge of, and attention for, health care issues, and that no 'questionnaire fatigue' occurs. Moreover, a system of renewal compensates for panel members who, for example, have died or moved without providing a forwarding address. All panel members included in this study were recruited in the spring of 2013 via seven general practices (GPs) participating in the NIVEL Primary Care Database (see this website http://www.nivel.nl/nl/NZR/ zorgregistraties-eerstelijn for more information). Data are processed anonymously, and the data collection is registered with the Dutch Data Protection Authority (nr. 1262949). In addition, a privacy regulation is available for the Consumer Panel. According to the Dutch legislation, neither obtaining informed consent nor approval by a medical ethics committee, is obligatory for carrying out research in the panel (see this website http://www.ccmo.nl/en/yourresearch-does-it-fallunder-the-wmo).

\section{Questionnaire}

We sent the self-administered questionnaire to a sample of 1,854 panel members, recruited from these seven practices, early in June 2013. According to their preference, stated previously, 765 members received a questionnaire by post and 1,089 through the internet. Panel members were free to answer the questions or not. 
Two electronic reminders (after 1 and after 2 weeks), and one postal reminder (after 2 weeks) were sent to panel members who had not yet responded. The closing date for the questionnaire was 4 weeks after the initial sending. The questionnaire was returned by 1,300 panel members (response rate $70 \%$ ).

\section{Measures}

\section{Dependent variable}

We used two propositions of Flynn et al. [37] to measure the attitude towards taking an active role in medical decision-making. They argue that preferences towards medical decision-making may be different depending on the nature of a particular decision [37]. The authors performed their study among a populationbased sample of older adults, and therefore included four broad-spectrum propositions rather than specific propositions [37]. These four propositions were based on the three phases of the framework of Charles et al. [11, 38]: information exchange, deliberation and deciding on which treatment to implement, as well as on the Autonomy Preference Index [39]. Because we also performed our study among a population-based sample, we decided to use the propositions of Flynn et al. [37]. Since our study focuses on decision-making around treatment, we only included the two propositions that concern this subject. These two propositions were: 1) 'I would rather have my doctor make the decisions about what's best for my health than to be given a whole lot of choices'; 2) 'The important medical decisions should be made by my doctor, not by me'. The propositions were translated from English to Dutch. The propositions were scored on a 5-point Likert scale, ranging from strongly disagree (score 1) to strongly agree (score 5). We evaluated whether the two propositions measured a single concept by calculating the internal consistency given by Cronbach's alpha. We recoded both propositions (i.e. 5=1, 4=2 etc). Moreover, we only included the respondents who filled out both propositions (included $\mathrm{N}=1285$; excluded $\mathrm{N}=15$ ). The internal consistency was good (alpha 0.84). Subsequently, a mean score was calculated ranging from 1 to 5 , in which higher scores indicated a more positive attitude towards taking an active role in medical decision-making.

\section{Independent variables}

Several instruments exist to measure social support, however, these instruments did not fit within the context of our study, namely the availability of support relevant for medical decision-making. Therefore, we decided to develop our own propositions. 


\section{The availability of medical informational support}

To assess whether people have medical informational support available in their social network, we asked them if they know people who practice one of the following medical professions: general practitioner (GP), medical specialist, and nurse. We asked respondents to indicate, for all three medical professions, whether they know someone, with the following options: 'yes, my partner is', 'yes, my child is', 'yes, someone else is', 'I don't know a'. We clarified that it was not about the respondent's own GP, medical specialist, or nurse. For each proposition, multiple answers were possible, however, the option, 'I don't know a...' could not be filled out with the other three answers. We scored, for each of the three medical professions, whether a respondent knows at least someone practicing that profession (1), or not (0). We evaluated whether these three propositions measured a single concept by calculating the internal consistency given by Cronbach's alpha ( $\alpha$ 0.65). Factor analysis of the data identified one factor. Thereafter, we summed up the scores of the three propositions to construct a scale for the availability of medical informational support ranging from 0 to 3 , in which a higher score indicates more access to medical informational support. We only included respondents who filled out all three propositions (included $\mathrm{N}=1146$; excluded $\mathrm{N}=154$ ).

\section{The availability of lay informational support}

We presented six propositions to assess the availability of lay informational support which respondents may enjoy in their social network. The propositions were: Who would you 1) 'involve in seeking information regarding your medical condition and/or what test results mean for you?'; 2) 'involve in understanding the information gathered about your condition and/or test results?'; 3) 'involve in seeking information about different treatment options?'; 4) 'involve in understanding the information gathered about the different treatment options?'; 5) 'involve in making a choice for one of the treatment options?'; 6) 'ask if he or she agrees with your choice of treatment?'. We asked respondents to indicate, for each proposition, who they would involve in that step, with the following options: 'partner', 'child', 'someone else', and 'nobody'. We instructed the respondents that it was not about common complaints, but about more severe ones. For each proposition, multiple answers were possible, however, the option 'nobody' could not be filled out with the other three options. For each proposition, we scored whether a respondent would involve at least someone (1), or nobody (0). We evaluated whether these six propositions measured a single concept by calculating 
the internal consistency given by Cronbach's alpha. Factor analysis of the data identified one factor and the internal consistency was good (Cronbach's $\alpha$ 0.88). Thereafter, we summed up the scores of the six propositions in order to construct a scale for the availability of lay informational support ranging from 0 to 6 , in which a higher score indicates more access to lay informational support. We only included respondents who filled out all six propositions (included $\mathrm{N}=1269$; excluded $\mathrm{N}=31$ ).

\section{The availability of emotional support}

We presented four propositions in order to assess the emotional support respondents have available in their social network. The propositions were: Who would you 1) 'take with you to a medical consultation where you explained your symptoms?'; 2) 'take with you to a medical consultation where you heard the results of medical tests?'; 3) 'take with you to a medical consultation where you were told about the different options for treatment?'; 4) 'take with you to a medical consultation where you discussed with your physician your different options for treatment?'. We asked respondents to indicate for each proposition who they would involve in that step, with the following options: 'partner', 'child', 'someone else', and 'nobody'. We instructed the respondents that it was not about common complaints, but about more severe complaints. For each proposition, multiple answers were possible, however, the option 'nobody' could not be filled out with the other three options. For each proposition, we scored whether a respondent would involve at least someone (1), or nobody (0). We evaluated whether these four propositions measured a single concept by calculating the internal consistency given by Cronbach's alpha. Factor analysis of the data identified one factor and the internal consistency was good (Cronbach's $\alpha$ 0.81). Thereafter, we summed up the scores of the four propositions in order to construct a scale for the availability of emotional support ranging from 0 to 4 , in which a higher score indicates more access to emotional support. We only included respondents who filled out all four propositions (included $\mathrm{N}=1276$; excluded $\mathrm{N}=24$ ).

\section{Interaction variable}

Knowledge and skills was operationalised by the highest level of education completed. The level of education was classified as low (none, primary school or pre-vocational education) (0), middle (secondary or vocational education) (1), and high (2) (professional higher education or university). 


\section{Control variables}

We included age (continuous), gender ( $0=$ men, $1=$ women), and whether the respondent filled out the questionnaire through the internet (1), or by post (0) as control variables.

\section{Statistical analyses}

Firstly, we performed descriptive analyses. By one-way analyses of variance, we tested whether the attitude towards taking an active role in medical decisionmaking differed between the seven GPs from which the respondents included in this study were recruited. If there were differences between the seven GPs then we had to take these into account throughout the rest of our analyses. Secondly, in order to test the hypotheses, a regression model was constructed. We constructed a lineair regression model including all the main and the interaction variables.

The interaction effects were examined to test the hypotheses that the relationship between medical decision-making and the three aspects: the emotional support available; lay informational support and medical informational support available, is modified by another mechanism ( $\mathrm{H} 4, \mathrm{H} 5$ and $\mathrm{H} 6$ ). We subsequently removed stepwise the interaction effects that were not significant, starting with the one that was least significant, from the regression model in order to facilitate the interpretation of the other effects. In the regression analyses, categorical variables, for example, the level of education, were recoded into dummy variables. The continuous variable, age, was centred on the mean age. This ensures that 0 has a meaningful value, and that the interpretation of effects will occur at a meaningful value. The level of statistical significance was fixed at 0.05 . All statistical analyses were carried out using STATA, version 13.1.

\subsection{Results}

The mean age of the respondents was 56 years, ranging from 18 to 84 years, and more than half (55\%) of the respondents were women (Table 3.1). Almost half (47\%) had a middle level of education. Compared to the Dutch population aged 18 years and older, older people ( $\geq 65$ years) were overrepresented in the group of respondents [36]. 
The mean score for attitude towards taking an active role in medical decisionmaking was 3.22 (SD 1.03) on a scale from 1 to 5, where a higher score indicates that respondents are more positive towards taking an active role in such decisions (Table 3.1). One-way analyses of variance showed that the attitude towards taking an active role in medical decision-making did not differ between the seven GPs (range mean score: 3.11-3.39, $\mathrm{p}=0.329$ ). Consequently, we did not have to take into account from which GP the respondents were recruited.

\section{Table 3.1 Descriptive statistics of the respondents}

\begin{tabular}{|c|c|c|}
\hline & $\mathbf{N}$ & $\%$ or mean (SD) \\
\hline Gender & 1,300 & \\
\hline male & 583 & 44.9 \\
\hline female & 717 & 55.2 \\
\hline Age (SD) & 1,300 & $56(15.8)$ \\
\hline Education & 1,270 & \\
\hline low (none, primary school or pre-vocational education) & 273 & 21.5 \\
\hline middle (secondary or vocational education) & 596 & 46.9 \\
\hline high (professional higher education or university) & 401 & 31.6 \\
\hline Questionnaire & 1,300 & \\
\hline post & 571 & 43.9 \\
\hline internet & 729 & 56.1 \\
\hline $\begin{array}{l}\text { Attitude towards taking an active role in medical decision-making (SD) } \\
\text { (range } 1-5, \text { higher scores indicates a more positive attitude) }\end{array}$ & 1,285 & $3.22(1.03)$ \\
\hline Available medical informational support (SD) (range 0-3) & 1,146 & $1.01(1.03)$ \\
\hline having no medical informational support available & & $39 \%$ \\
\hline Available lay informational support (SD) (range 0-6) & 1,269 & $5.40(1.43)$ \\
\hline having no lay informational support available & & $4 \%$ \\
\hline Available emotional support (SD) (range 0-4) & 1,276 & $3.20(1.23)$ \\
\hline having no emotional support available & & $8 \%$ \\
\hline
\end{tabular}

The mean score for the availability of medical informational support was 1.0 on a scale from 0 to 3 , where 3 is the highest level of medical informational support available (Table 3.1). Thirty-nine per cent of the respondents indicated that they do not know anyone from a medical profession. Table 3.1 shows that the mean score for the availability of lay informational support was 5.4 on a scale from 0 to 6 , where 6 is the highest level of lay informational support available. Four per cent $(\mathrm{N}=49)$ of the respondents indicated that they had no lay informational support available at all. The mean score for the availability of emotional support was 3.2 on a scale from 0 to 4 , where 4 is the highest level of emotional support available. 
Eight per cent $(\mathrm{N}=101)$ of the respondents indicated that they had no emotional support, in the form of someone to accompany them to the consultation, available at all.

\section{Test of the hypotheses}

Table 3.2 shows the results of the regression analysis to test the hypotheses about the role of the availability of informational and emotional support on the attitude towards taking an active role in medical decision-making. The interaction effect between knowledge and skills - measured as the highest level of education completed - and emotional support was significant and therefore kept in the model. The other two hypothesised interaction effects ( $\mathrm{H} 4$ and $\mathrm{H} 5$ ) were not significant and thus removed from the model in order to facilitate the interpretation of the other effects. The explained variance of the model was $18 \%$ (adjusted R-square 0.175).

Table 3.2 Regression model to examine the association between the availability of informational and emotional support and attitude towards taking an active role in medical decision-making $(\mathrm{N}=1,089)$

\begin{tabular}{|c|c|c|c|}
\hline $\begin{array}{l}\text { Attitude towards taking an active role in medical decision-making } \\
\text { (range 1-5, higher scores indicates a more positive attitude) }\end{array}$ & Coef. & Beta $^{a}$ & P-value \\
\hline Available medical informational support $(0=$ no; $3=$ most $)$ & 0.106 & 0.106 & 0.000 \\
\hline Available lay informational support $(0=$ no; $6=$ most $)$ & -0.023 & -0.032 & 0.352 \\
\hline Available emotional support $(0=$ no; $4=$ most $)$ & 0.167 & 0.202 & 0.002 \\
\hline \multicolumn{4}{|l|}{ Available emotional support * level of education } \\
\hline low (none, primary school or prevocational education) & Ref & Ref & Ref \\
\hline middle (secondary or vocational education) & -0.184 & -0.323 & 0.002 \\
\hline high (professional higher education or university) & -0.159 & -0.251 & 0.016 \\
\hline \multicolumn{4}{|l|}{ Level of education } \\
\hline low (none, primary school or prevocational education) & Ref & Ref & Ref \\
\hline middle (secondary or vocational education) & 1.100 & 0.534 & 0.000 \\
\hline high (professional higher education or university) & 1.381 & 0.632 & 0.000 \\
\hline Gender ( 0 = man; 1 = woman $)$ & 0.111 & 0.054 & 0.057 \\
\hline Age (centred around mean age) & -0.008 & -0.117 & 0.000 \\
\hline Questionnaire ( 1 = internet; 0 = post) & 0.167 & 0.081 & 0.005 \\
\hline Constant & 2.019 & - & 0.000 \\
\hline
\end{tabular}

Adjusted R-square: 0.175

${ }^{a}$ Standardised coefficients; Bold type indicates $p<0.05$ 
The association between the availability of medical and lay informational support and the attitude towards taking an active role in medical decision-making (H1, H2, H4 \& H5)

In line with $\mathrm{H} 1$, Table 3.2 demonstrates that the availability of medical informational support is significantly associated with the attitude towards taking an active role in medical decision-making. This implies that people with more medical informational support available have a more positive attitude towards taking an active role in medical decision-making. No significant effect was observed for the availability of lay informational support, rejecting $\mathrm{H} 2$. Contrary to our hypotheses ( $\mathrm{H} 4$ and $\mathrm{H} 5$ ), we did not find an interaction effect between both the availability of medical and lay informational support and educational level, as an indication for one's own knowledge and skills.

\section{The association between the availability of emotional support and the attitude towards taking an active role in medical decision-making (H3 \& H6)}

We found an interaction effect between educational level and available emotional support. This interaction effect means that the relationship between the availability of emotional support and the attitude towards taking an active role in medical decision-making varies by educational level, confirming H6. Further examination of this interaction effect shows that it depends on the level of education whether there is a positive relationship between the available emotional support and the attitude towards taking an active role in medical decision-making (Figure 3.2). Only in cases of people with a low level of education is the available emotional support positively associated with the attitude towards taking an active role in medical decision-making. There is no significant relation between the available emotional support and the attitude towards taking an active role in medical decision-making for people with a middle and high level of education. H3 is only confirmed for people with a low educational level. The interaction effect of the available emotional support and the level of education also indicates that the effect of educational level on the attitude towards taking an active role in medical decisionmaking varies with the level of the availability of emotional support. Further examination of this effect demonstrates that whether educational level influences the attitude towards taking an active role in medical decision-making does not depend on the level of the availability of emotional support. No matter what the level of the availability of emotional support, people with a middle and high educational level have a more positive attitude towards taking an active role in medical decision-making than people with a low educational level. 
Figure 3.2 Relation between the availability of emotional support and attitude towards taking an active role in medical decision-making for people with a low, middle and high level of education

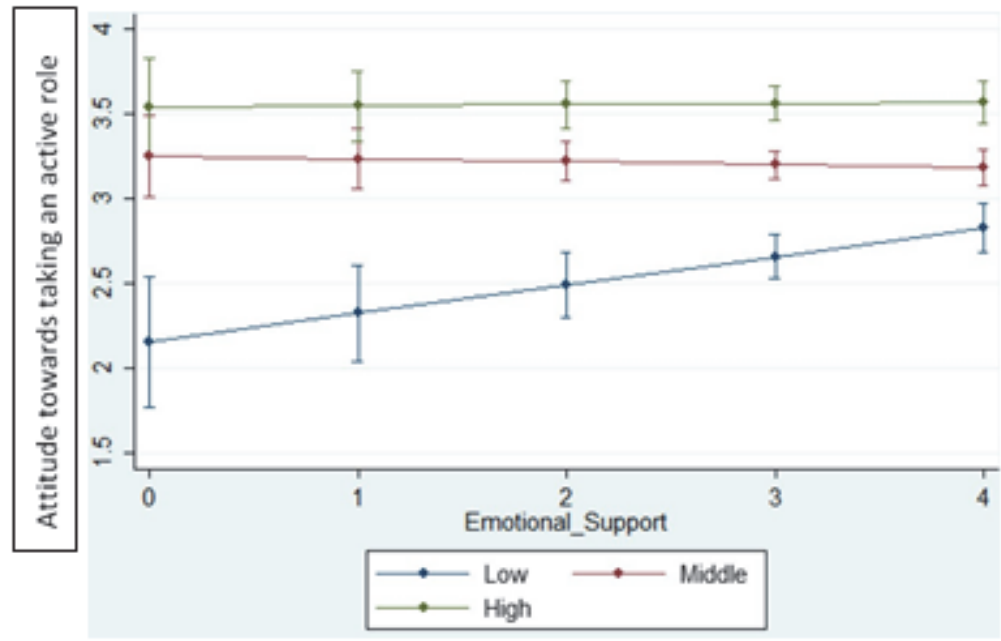

\section{Control variables}

Age is significantly associated with the attitude towards taking an active role in medical decision-making, while no significant effect is observed for gender. Respondents that filled out the questionnaire through the internet have a more positive attitude than respondents that filled out the questionnaire by post (see Table 3.2).

\subsection{Discussion}

This study examined the association between the availability of informational (both medical and lay) and emotional support and people's attitude towards taking an active role in medical decision-making. In line with our hypothesis, we found that people who enjoyed more available medical informational support are more positive towards taking an active role in medical decision-making. This study also showed that only for people with a low level of education the availability of emotional support was positively related to the attitude towards taking an active role in medical decision-making, partially confirming our hypothesis. We also found that no matter what level of emotional support was available, people with a middle and high level of education have a more positive attitude towards taking an active 
role in medical decision-making. Contrary to our hypothesis, no effect was observed for the availability of lay informational support. In line with earlier research, we found that older people have a less positive attitude towards taking an active role in medical decision-making. Finally, we found that people who filled out the questionnaire through the internet have a more positive attitude towards taking an active role in medical decision-making.

We showed that social resources play a role in the attitude towards taking an active role in medical decision-making. People with more health care professionals in their network have a more positive attitude towards taking an active role. The reason for this might be that these people are more easily able to contact a health care professional within their network that they trust in order to seek information about their medical problems and related treatment options. These professionals in their network can, for instance, inform patients about different treatment options, but also advise them on which treatment option to choose. As a result, people are better equipped with information necessary for medical decisionmaking. We noticed that for people with a low educational level, the availability of emotional support contributes positively to their attitude towards taking an active role in medical decision-making. This is in line with what we expected. The reason for this might be that a companion compensates for less knowledge and skills by, for example, prompting questions, as well as that people feel more confident when someone is present during the consultation.

Besides the influence of social resources, we also found a significant association between educational level and the attitude towards taking an active role in medical decision-making. Compared to people with a low level of education, middle and high educated people have a more positive attitude towards taking an active role in medical decision-making. These results confirm empirical research $[9,10,13]$. Finally, in line with earlier research $[9,10,13]$, we found that older people have a less positive attitude towards taking an active role in medical decision-making.

This study gives a first insight into the role of social resources on the attitude towards taking an active role in medical decision-making. Our study confirms that someone's social resources are related to their attitude towards taking an active role in medical decision-making. However, our model does not explain most of the variance in the attitude towards taking an active role in such decisions. This implies that other factors besides the availability of support and patient characteristics 
influence the attitude towards taking an active role. Social relationships influence individual behaviour through different mechanisms, of which providing resources is only one. Someone's social network also influences individual behaviour through the creation and sharing of norms [16]. Social norms specify what actions are regarded by a group of people as normal, and what actions are regarded as deviant [16 p242]. If it is common in a social environment to leave the decision to physicians, because there is great respect towards physicians, then individuals are expected to be less likely to take an active role in the process, since this is the norm. For further research, we recommend examining the relationship between social norms and taking an active role in these medical decisions.

The highest level of education completed can be used as operationalisation for knowledge and skills. However, educational level might not completely cover this concept [40]. Another operationalisation might be someone's health literacy skills. Health literacy is defined by the Institute of Medicine as "the degree to which individuals have the capacity to obtain, process, and understand basic health information and services needed to make appropriate health decisions" [41]. Yet, several studies have examined the relation between health literacy and involvement in medical decision-making [42-48]. Future research is recommended to further examine the relation between health literacy and involvement in medical decision-making.

Currently, decision aids (DAs) are increasingly being used to enhance patient participation in the decision-making process. A DA aims to provide patients with information about options in sufficient detail for patients to arrive at informed judgements about the personal value of those options [49 p717]. As such, patients are expected to be better equipped with the medical information required for taking a decision. A literature review shows that DAs increase patient involvement [50]. Using a DA as a source of information might differ from using social relationships for one. For future research, it is recommended examining whether a DA and informational support are complementary to each other, or substitute each other, in regard to the attitude towards taking an active role in medical decisionmaking.

The strengths of the study are the large sample size, the response rate of $70 \%$ and the fact that the questionnaire was both sent through the internet and by post. However, the respondents were not fully representative of the Dutch population 
aged 18 years and older. Compared to this population, older people ( $\geq 65$ years) are overrepresented. We expect that this does not affect our regression results, since all subgroups are of sufficient size to perform association analyses. Nevertheless, it can be argued that members of a health care panel are more interested in health care and therefore might have a more positive attitude towards taking an active role in medical decision-making. In the questionnaire, we provided a hypothetical situation to the respondents. We only informed them that it was not about common complaints, but about more severe ones. This could limit the degree to which our findings are generally applicable. The reason for this is that participation preferences are expected to be different depending on the nature of a particular decision [37]. For example, the type of care on which to decide upon, for example medical care and home care, has an impact upon the importance people attach to shared decision-making, as well as their actual involvement in decision-making [51]. Research also shows that diagnosis may affect patients' preferences [10]. Some studies show that patients with a severe illness are less likely to prefer involvement than patients who are less ill, while others show the opposite [10]. Furthermore, we examined an attitude towards behaviour, instead of actual behaviour. Also the physicians' role in the decision-making process was not included in this study. It remains unsure from this study what decisions people would make in real life, and whether they actually use their available support.

A limitation might also be that we excluded respondents who did not fill out all propositions concerning the emotional support available $(\mathrm{N}=24 ; 1.8 \%)$, the lay informational support available $(\mathrm{N}=31 ; 2.4 \%)$, or the medical informational support available ( $\mathrm{N}=154 ; 11.8 \%)$. We performed sensitivity analyses in which we interpreted missing as the answer option 'nobody'. The sensitivity analyses showed the same results. As mentioned, the available measurements of social support did not fit within the context of our study. We therefore believe that our measurement provides a starting point for the further development of measurements of social support in the context of medical decision-making. With regards to the availability of lay informational support, a limitation is that we had no insight into the person meant by the 'someone else' response. We did not include the concept of instrumental support as in the Netherlands costs for most medical care, medicines and medical devices are covered by the basic health insurance package [25], and also because there is a low level of out-of-pocket payments [26]. Nevertheless, lack of instrumental support (e.g. money or transportation) might be a barrier for people to take an active role in medical decision-making, particularly in other 
countries. We therefore recommend further research to also include the concept of instrumental support. A final limitation is that our data were obtained using a cross-sectional study design, and as such cannot provide any information about causal relationships.

\subsection{Conclusions}

This study provides further insight into circumstances under which patients have a positive attitude towards taking an active role in medical decision-making. We found that people who have more medical informational support available have a more positive attitude towards taking an active role in medical decision-making. The availability of emotional support is only positively associated with the attitude towards taking an active role in medical decision-making among people who have a low level of education. This study shows that social resources are related to the attitude towards taking an active role in medical decision-making. Strategies aimed at increasing patient involvement have to address this. 


\section{References}

1. Wennberg JE. Tracking medicine: a researcher's quest to understand health care. New York: Oxford University Press, 2010

2. Van de Bovenkamp HM, Trappenburg MJ, Grit KJ. Patient participation in collective healthcare decision making: the Dutch model. Health Expectations 2010;13(1):73-85

3. Guadagnoli E, Ward P. Patient participation in decision-making. Social Science \& Medicine 1998; 47(3):329-39

4. Coulter A, Parsons S, Askham J, et al. Where are the patients in decision-making about their own care? Copenhagen, Denmark: World Health Organization Regional Office for Europe, 2008

5. Van der Weijden T, Van Veenendaal H, Timmermans D. Shared decision-making in the Netherlands-current state and future perspectives. Zeitschrift für Evidenz, Fortbildung und Qualität im Gesundheitswesen 2007; 101(4):241-6

6. Institute of Medicine. Crossing the quality chasm: A new health system for the 21st century. Washington DC: National Academies Press, 2001

7. Chewning B, Bylund $\mathrm{CL}$, Shah B, et al. Patient preferences for shared decisions: a systematic review. Patient Education \& Counseling 2012; 86(1):9-18

8. Van den Brink-Muinen A, Van Dulmen SM, De Haes HC, et al. Has patients' involvement in the decision-making process changed over time? Health Expectations 2006; 9(4):333-42

9. Arora NK, McHorney CA. Patient preferences for medical decision making: who really wants to participate? Medical Care 2000; 38(3):335-41

10. Say R, Murtagh $M$, Thomson R. Patients' preference for involvement in medical decision making: a narrative review. Patient Education \& Counseling 2006; 60(2):10214

11. Charles C, Gafni A, Whelan T. Shared decision-making in the medical encounter: what does it mean? (or it takes at least two to tango). Social Science \& Medicine 1997; 44(5):681-92 
12. Frosch DL, Kaplan RM. Shared decision making in clinical medicine: past research and future directions. American Journal of Preventive Medicine 1999; 17(4):285-94

13. Brom L, Hopmans W, Pasman HR, et al. Congruence between patients' preferred and perceived participation in medical decision-making: a review of the literature. BMC BMC Medical Informatics and Decision Making 2014; 14:25

14. Umberson D, Montez JK. Social relationships and health: a flashpoint for health policy. Journal of Health and Social Behavior 2010; 51(Suppl):S54-66

15. Berkman LF, Glass T, Brissette I, et al. From social integration to health: Durkheim in the new millennium. Social Science \& Medicine 2000; 51(6):843-57

16. Coleman J. Foundations of social theory. Cambridge: The Belknap Press of Harvard University Press; 1990

17. Umberson $D$, Crosnoe $R$, Reczek $C$. Social relationships and health behavior across life course. Annual Review of Sociology. 2010;36:139-57

18. Van der Gaag M. Measurement of individual social capital. Groningen, The Netherlands: Rijksuniversiteit Groningen. 2005

19. Lin N. Building a network theory of social capital. Connections. 1999; 22(1):28-51

20. Cohen S. Social relationships and health. American Psychologist 2004; 59(8):676

21. Tardy CH. Social support measurement. American Journal of Community Psychology 1985; 13(2):187-202

22. Cooke BD, Rossmann MM, McCubbin $\mathrm{HI}$, et al. Examining the definition and assessment of social support: A resource for individuals and families. Family Relations 1988; 37(2):211-16

23. House JS. Work stress and social support. Reading: Addison-Wesley; 1981

24. Ellingson LL. The roles of companions in geriatric patient-interdisciplinary oncology team interactions. Journal of Aging Studies 2002; 16(4):361-82 
25. VWS. Wat zit er in het basispakket van de zorgverzekering? http://www. rijksoverheid.nl/onderwerpen/zorgverzekering/vraag-en-antwoord/wat-zit-erin-hetbasispakket-van-de-zorgverzekering.html (19 September, 2016, date last accessed)

26. OECD. Healthcare at a glance 2013: OECD Indicators. OECD Publishing. 2013. http://dx.doi.org/10.1787/health_glance-2013-en

27. Marzuk PM. The right kind of paternalism. New England Journal of Medicine 1985; 313(23):1474-6

28. Pellegrino ED. Patient and physician autonomy: conflicting rights and obligations in the physician-patient relationship. The Journal of Contemporary Health Law and Policy 1994; 10:47

29. Arrow KJ. Uncertainty and the welfare economics of medical care. American Economic Review 1963; 53:941-73

30. Charles C, Whelan T, Gafni A, et al. Doing nothing is No choice: lay constructions of treatment decision-making among women with early-stage breast cancer. Sociology of Health \& Illness 1998; 20(1):71-95

31. Wolff JL, Roter DL. Family presence in routine medical visits: a meta-analytical review. Social Science \& Medicine 2011; 72(6):823-31

32. Ishikawa H, Roter DL, Yamazaki $\mathrm{Y}$, et al. Physician-elderly patient-companion communication and roles of companions in Japanese geriatric encounters. Social Science \& Medicine 2005; 60(10):2307-20

33. Clayman ML, Roter D, Wissow LS, et al. Autonomy-related behaviors of patient companions and their effect on decision-making activity in geriatric primary care visits. Social Science \& Medicine 2005; 60(7):1583-91

34. Jansen J, Van Weert JC, Wijngaards-de Meij L, et al. The role of companions in aiding older cancer patients to recall medical information. Psychooncology 2010; 19(2):170-9

35. Verlinde E, De Laender N, De Maesschalck S, et al. The social gradient in doctor-patient communication. International Journal for Equity in Health 2012; 11(1):12

36. Brabers A, Reitsma-Van Rooijen M, De Jong J. Consumentenpanel Gezondheidszorg: Basisrapport met informatie over het panel (2015). Utrecht: NIVEL; 2015 
37. Flynn KE, Smith MA, Vanness D. A typology of preferences for participation in healthcare decision making. Social Science \& Medicine 2006; 63(5):1158-69

38. Charles C, Gafni A, Whelan T. Decision-making in the physician-patient encounter: revisiting the shared treatment decision-making model. Social Science \& Medicine 1999; 49(5): 651-61

39. Ende J, Kazis L, Ash A, et al. Measuring patients' desire for autonomy: decision making and information-seeking preferences among medical patients. Journal of General Internal Medicine 1989; 4(1):23-30

40. OECD. Human Capital Investment: An International Comparison. Paris. 1998

41. Institute of Medicine. Health literacy: a prescription to end confusion. Washington: The National Academies Press; 2004

42. Barton JL, Trupin L, Tonner C, et al. English language proficiency, health literacy, and trust in physician are associated with shared decision making in rheumatoid arthritis. The Journal of Rheumatology 2014; 41(7):1290-7

43. Goggins KM, Wallston KA, Nwosu S, et al. Health literacy, numeracy, and other characteristics associated with hospitalized patients' preferences for involvement in decision making. Journal of Health Communication 2014; 19 Suppl 2:29-43

44. McCaffery KJ, Holmes-Rovner M, Smith SK, et al. Addressing health literacy in patient decision aids. BMC Medical Informatics and Decision Making 2013; 13 Suppl 2:S10

45. Naik AD, Street Jr RL, Castillo D, et al. Health literacy and decision making styles for complex antithrombotic therapy among older multimorbid adults. Patient Education \& Counseling 2011; 85(3):499-504

46. Smith SK, Simpson JM, Trevena L, et al. Factors associated with informed decisions and participation in bowel cancer screening among adults with lower education and literacy. Medical Decision Making 2014; 34(6):756-72

47. Yin HS, Dreyer BP, Vivar KL, et al. Perceived barriers to care and attitudes towards shared decision-making among low socioeconomic status parents: role of health literacy. Academic Pediatrics 2012; 12(2):117-24 
48. Seo J, Goodman MS, Politi M, et al. Effect of health literacy on decision-making preferences among medically underserved patients. Medical Decision Making 2016; 36: 550-6

49. O'Connor AM, Wennberg JE, Legare F, et al. Toward the 'tipping point': decision aids and informed patient choice. Health Affairs 2007; 26(3): 716-25

50. Stacey D, Bennett CL, Barry MJ, et al. Decision aids for people facing health treatment or screening decisions. The Cochrane Database of Systematic Reviews 2011; 10: Cd001431

51. Van den Brink-Muinen A, Spreeuwenberg P, Rijken M. Preferences and experiences of chronically ill and disabled patients regarding shared decision-making: does the type of care to be decided upon matter? Patient Education \& Counseling 2011; 84(1):111-7 


\section{4 \\ Do social norms play a role in explaining involvement in medical decision-making?}

This article is published as:

Brabers AEM, Van Dijk L, Groenewegen PP, De Jong JD. Do social norms play a role in explaining involvement in medical decision-making? European Journal of Public Health 2016; Dec; 26(6):901-905 doi: 10.1093/eurpub/ckw069

This is a pre-copyedited, author-produced PDF of an article accepted for publication in the European Journal of Public Health following peer review. The version of record Brabers AEM, Van Dijk L, Groenewegen PP, De Jong JD. Do social norms play a role in explaining involvement in medical decisionmaking? European Journal of Public Health 2016; Dec; 26(6):901-905 doi: 10.1093/eurpub/ckw069 is available online at: https://academic.oup.com/eurpub/article/26/6/901/2616240 


\begin{abstract}
Background

Patients' involvement in medical decision-making is crucial to provide good quality of care that is respectful of, and responsive to, patients' preferences, needs and values. Whether people want to be involved in medical decision-making is associated with individual patient characteristics, and health status. However, the observation of differences in whether people want to be involved does not in itself provide an explanation. Insight is necessary into mechanisms that explain people's involvement. This study aims to examine one mechanism, namely social norms. We make a distinction between subjective norms, that is doing what others think one ought to do, and descriptive norms, doing what others do. We focus on selfreported involvement in medical decision-making.
\end{abstract}

\title{
Methods
}

A questionnaire was sent to members of the Dutch Health Care Consumer Panel in May 2015 (response 46\%; N=974). A regression model was used to estimate the relationship between socio-demographics, social norms and involvement in medical decision-making.

\section{Results}

In line with our hypotheses, we observed that the more conservative social norms are, the less people are involved in medical decision-making. The effects for both types of norms were comparable.

\section{Conclusion}

This study indicates that social norms play a role as a mechanism to explain involvement in medical decision-making. Our study offers a first insight into the possibility that the decision to be involved in medical decision-making is not as individual as it at first seems; someone's social context also plays a role. Strategies aimed at emphasizing patient involvement have to address this social context. 


\subsection{Introduction}

One aspect of good quality of care is regarded as providing care that is respectful of, and responsive to, an individual patient's preferences, needs and values [1]. This implicitly requires that patients are involved in decisions about their health [2]. In the past decades, a shift has been observed from a paternalistic, or conservative, decision-making approach, adhering to the status quo where physicians play a dominant role, towards new approaches to decision-making incorporating a larger role for patients $[3,4]$. One approach that promotes patient involvement, and respects patient autonomy, is shared decision-making [5]. As Elwyn et al. [5 p971] say 'shared decision-making is an approach where clinicians and patients make decisions together using the best available evidence'.

A systematic review by Chewning et al. (2012) [6] shows that most patients want to participate in medical decision-making. The number of patients that want to be involved in such decision-making, as well as those actually involved, has increased over time $[6,7]$. On the other hand, it is known that some categories of patients want to leave the decision to their physician $[8,9]$. Whether patients want to be involved in medical decision-making is associated with individual patient characteristics, e.g. socio-demographics, and health status [6, 10-12]. Women, younger people and higher educated people want to be involved more often in the decision-making process $[10,12]$. Conflicting results, however, are observed about whether patients with severe illness want to be involved in taking such decisions [12]. However, the observation of differences in whether categories of patients want to be involved in medical decision-making does not in itself provide an explanation. Insight is necessary into the mechanisms that explain why patients are actively involved in medical decision-making.

One of the possible mechanisms that might explain why people are actively involved in such decision-making is someone's social context, as this influences individual behaviour [13]. Someone's social context influences behaviour through the existence of norms [14 p241]. Social norms specify what actions are regarded by a group of people as normal, and what actions are regarded as deviant [14 p242]. Two types of social norms that are recognised in the literature are: (i) subjective norms, and (ii) descriptive norms [15]. 'Subjective' norms refer to the perception of what most people approve or disapprove of, that is doing what others think one ought to do [15]. It is concerned with perceived social pressure, 
the person's potential to gain approval or not from others for engaging in a behaviour [16]. 'Descriptive' norms refer to how others act in similar situations that is doing what others do [15]. The actions of others provide information that people may use in deciding what to do themselves [16].

We ask in this study: 'How are social norms related to patient involvement in medical decision-making?' The focus of this study is on self-reported involvement in such decision-making. We hypothesise that the more a person thinks that, according to significant others, he or she should leave the decision to the physician, the less a person is involved in medical decision-making ('subjective' norm hypothesis). We also hypothesise that the more a person thinks that significant others leave the decision to the physician, the less a person is involved in medical decision-making ('descriptive' norm hypothesis).

\subsection{Methods}

\section{Setting}

Data were collected from the Dutch Health Care Consumer Panel, which aims to measure opinions on, and knowledge of, health care as well as the expectations of, and experiences with, health care among a cross-section of the Dutch population (see for more detailed information [17]). The Consumer Panel is a so-called access panel. An access panel consists of a large number of people who have agreed to answer questions on a regular basis. Many of the background characteristics of the panel members are known such as their age, gender and level of education. At the time of this study (May 2015), the Consumer Panel consisted of about 12,000 people aged 18 years and older. Each individual panel member receives a questionnaire about three times a year and can quit the panel at any time. At the start of their membership, panel members can choose whether they want to receive questionnaires by post or through the internet. There is no possibility of people signing up for the panel on their own initiative. The Consumer Panel is renewed on a regular basis. Data are processed anonymously and the protection of the data collected is registered with the Dutch Data Protection Authority (nr. 1262949). A privacy regulation is available for the Consumer Panel. According to Dutch legislation, neither obtaining informed consent nor approval by a medical ethics committee is obligatory for conducting research through the panel [18]. 


\section{Questionnaire}

A questionnaire was sent to a sample of 2,116 panel members in late May 2015. We sampled all migrants (both western and non-western) included in our panel $(\mathrm{N}=1,058)$ and sampled the same number of non-migrants $(\mathrm{N}=1,058)$. The group of non-migrants was matched to the group of migrants based on gender, age and educational level. According to their previously stated preference, 967 members received a questionnaire by post and 1,149 through the internet. One postal reminder (after 2 weeks), and two electronic reminders (after 1 and after 2 weeks) were sent to panel members who had not yet responded. The closing date was 4 weeks after the initial sending. The questionnaire was returned by 974 (46\%) panel members.

\section{Measurements}

\section{Involvement in medical decision-making}

We used two questions to measure involvement in medical decision-making (Table 4.1). These questions were based on two propositions developed by Flynn et al. (2006) [19]. We evaluated whether the two questions measured a single concept by calculating the internal consistency given by Cronbach's alpha. Only respondents who filled out both questions were included (included: $N=956$, excluded: $N=18$ ). The internal consistency was reasonable (alpha $0.78,95 \% \mathrm{Cl}: 0.75-0.81$ ). A mean score over the two questions was calculated ranging from 1 to 4 , in which higher scores indicated that respondents reported being less involved in medical decisionmaking.

\section{Subjective and descriptive norms}

The subjective and descriptive norms were both measured by two sets of three questions (Table 4.1). The questions were developed by the research team and based on research about social norms [20,21]. We recoded the answer option 'not applicable, I don't have....' to 'missing' for all questions, since it provided no information about social norms. Factor analysis showed two factors: one consisting of the six questions on subjective norms (Cronbach's alpha 0.95, 95\% Cl: 0.940.95), and a second consisting of the six questions on descriptive norms (Cronbach's alpha 0.91, 95\% Cl: 0.90-0.92). A mean score was calculated for the subjective norm (range 1 (completely disagree) to 5 (completely agree)) and the descriptive norm (range 1 (never) to 4 (always)). We based both mean scores on the questions that were filled out by a respondent. Only respondents with missing values on all six questions measuring a norm were excluded (excluded subjective 
norm: $\mathrm{N}=46$; excluded descriptive norm: $\mathrm{N}=61$ ). Higher scores indicated more 'conservative' social norms, i.e. leaving the decision to the physician.

Table 4.1 Questions used to measure involvement in medical decision-making, the subjective norm and the descriptive norm

Questions
Involvement in medical decision-making
How often do you think that your doctor make the decisions about what's
best for your health?
How often do you think that the important medical decisions will be taken
by your doctor and not by yourself?

\section{Answer categories}

Never (score 1),

sometimes (score 2),

often (score 3), always

(score 4)

Completely disagree

(score 1 ) to completely agree (score 5) + not applicable, I don't have...
The people I consider important think that I should let the doctor decide what is best for my health. The people I consider important would prefer that to me having to make a choice.

My partner thinks that the most important medical decisions should be taken by my doctor and not by me.

My family thinks that the most important medical decisions should be taken by my doctor and not by me.

The people I consider important think that the most important medical decisions should be taken by my doctor and not by me.

\section{Descriptive norm}

How often do you think that your partner allows the doctor to decide what is best for his or her health?

How often do you think that your family allows the doctor to decide what is best for their health?

How often do you think that the people you consider important allow the doctor to decide what is best for their health?

How often do you think that the most important medical decisions will be taken by the doctor and not by your partner?

How often do you think that the most important medical decisions will be taken by the doctor and not by your family?

How often do you think that the most important medical decisions will be taken by the doctor and not by the people you consider important? 
Correlation between the two composite variables was 0.63 . This can be explained by the fact that both variables measure social norms, although in a different way. Additionally, a likelihood ratio (LR)-test was conducted to examine whether a more complex model (including both social norms) fits significantly better than a simple model (including one social norm) for explaining involvement in medical decisionmaking. The LR-test confirmed that a more complex model fits better. Therefore, both the subjective and the descriptive norm were included in our analyses.

\section{Socio-demographics}

The following socio-demographics were included: age (continuous), gender ( $0=$ man, $1=$ woman), highest level of education completed (1=low, $2=$ middle and $3=$ high), ethnicity ( $1=$ non-migrant, $2=$ western migrant and $3=$ non-western migrant) and self-reported general health ( $1=$ excellent/very good, $2=$ good and $3=$ fair/bad).

\section{Statistical analyses}

First, we performed descriptive statistics to describe the characteristics of the study population. Secondly, we tested whether our data were consistent with empirical studies showing that involvement in medical decision-making is associated with socio-demographics. We conducted a multiple linear regression analysis (model-I) in which we included involvement in medical decision-making as a dependent variable, and the socio-demographics (gender, age, educational level, ethnicity and self-reported general health) as independent variables. Thirdly, we examined whether social norms are an explanation for the association between socio-demographics and involvement in medical decision-making. We conducted two multiple linear regression analyses in which we included the subjective norm and the descriptive norm, respectively, as dependent variables, and the sociodemographics as independent variables. Finally, we tested the association between social norms and involvement in medical decision-making and added the subjective and descriptive norm as additional independent variables to model-I (model-II). We controlled all models for whether a respondent filled out the questionnaire through the internet (1), or by post (0). In the regression analyses, categorical variables (educational level, ethnicity and self-reported general health) were recoded into dummy variables. The level of statistical significance was fixed at 0.05. All statistical analyses were carried out using STATA, version 13.1. 


\subsection{Results}

Approximately half (53\%) of the respondents were women, and the mean age of the respondents was 63 years (range 19-90 years; Table 4.2). About half (51\%) had a middle level of education. Table 4.2 shows that $55 \%$ of the respondents were non-migrant, 36\% western migrant and $9 \%$ non-western migrant. General health was self-reported as excellent/very good in $28 \%$ of the cases. When compared with the general Dutch population aged 18 years and older, mainly elderly (65 years and older) and western migrants were over-represented in the group of respondents [17]. The reason for this is that these groups were also over-represented in the study sample due to the fact that the questionnaire was also used for other studies focusing on migrant groups.

Table 4.2 Descriptive statistics of the respondents

\begin{tabular}{lcc}
\hline & $\mathbf{N}$ & \% or mean (SD) \\
\hline Gender & 974 & \\
male & 461 & 47.3 \\
female & 513 & 52.7 \\
Age & 974 & 63 (15.7) \\
Level of education & 955 & \\
low (none, primary school or pre-vocational education) & 154 & 16.1 \\
middle (secondary or vocational education) & 485 & 50.8 \\
high (professional higher education or university) & 316 & 33.1 \\
Ethnicity & 974 & \\
non-migrant & 532 & 54.6 \\
western migrant & 353 & 36.2 \\
non-western migrant & 89 & 9.1 \\
Self-reported general health & 925 & \\
excellent/very good & 257 & 27.8 \\
good & 454 & 49.1 \\
fair/bad & 214 & 23.1 \\
Questionnaire & 974 & $2.69(1.06)$ \\
post & 499 & 2.51 (0.82) \\
internet & 47.2 \\
Subjective norm (range 1-5) & 956 & 48.8 \\
Descriptive norm (range 1-4) & 928 & 2.60 (0.78) \\
\hline
\end{tabular}


The mean score for involvement in medical decision-making was 2.60 (SD 0.78) on a scale from 1 (more involvement) to 4 (less involvement) (Table 4.2). Almost half (49\%) of the respondents had a score of 3 or higher. This means that on average respondents were slightly more inclined not to be involved in the decision-making process. The mean scores for the subjective and descriptive norm were 2.69 (SD 1.06 , range $1-5$, higher scores indicated more conservative norms) and 2.51 (SD 0.82 , range $1-4$, higher scores indicated more conservative norms), respectively (Table 4.2). This means that, on average, the social norms of the respondents were slightly more focused on leaving the decision to the physician.

Our data were consistent with empirical studies showing that involvement in medical decision-making is associated with socio-demographic characteristics. Younger people and women stated to be more involved in medical decision-making (model-I Table 4.3). Also, people with a high level of education stated to be more involved in medical decision-making compared with people with a low level of education. No significant association was observed for ethnicity and self-reported general health. The explained variance of the model was low: $7 \%$.

We found an association between socio-demographics and social norms (not shown in Table 4.3). Women and people with a high level of education have less conservative norms compared with men and people with low level of education. No significant association was observed for age, ethnicity and self-reported general health.

In model-II, we added the subjective and descriptive norms as explanatory variables in order to examine the association between social norms and involvement in medical decision-making. Table 4.3 shows that both social norms were significantly related to involvement in such decision-making. The more conservative subjective and descriptive norms were, the fewer respondents reported being involved in medical decision-making, confirming our hypotheses. The effects of both norms were comparable (see standardised coefficients in Table 4.3). In model-II, age and gender were no longer significantly associated with involvement in medical decision-making. Just as in model-I, people with a high level of education were more involved in medical decision-making, although the effect is smaller. The explained variance of model-II was $48 \%$. 


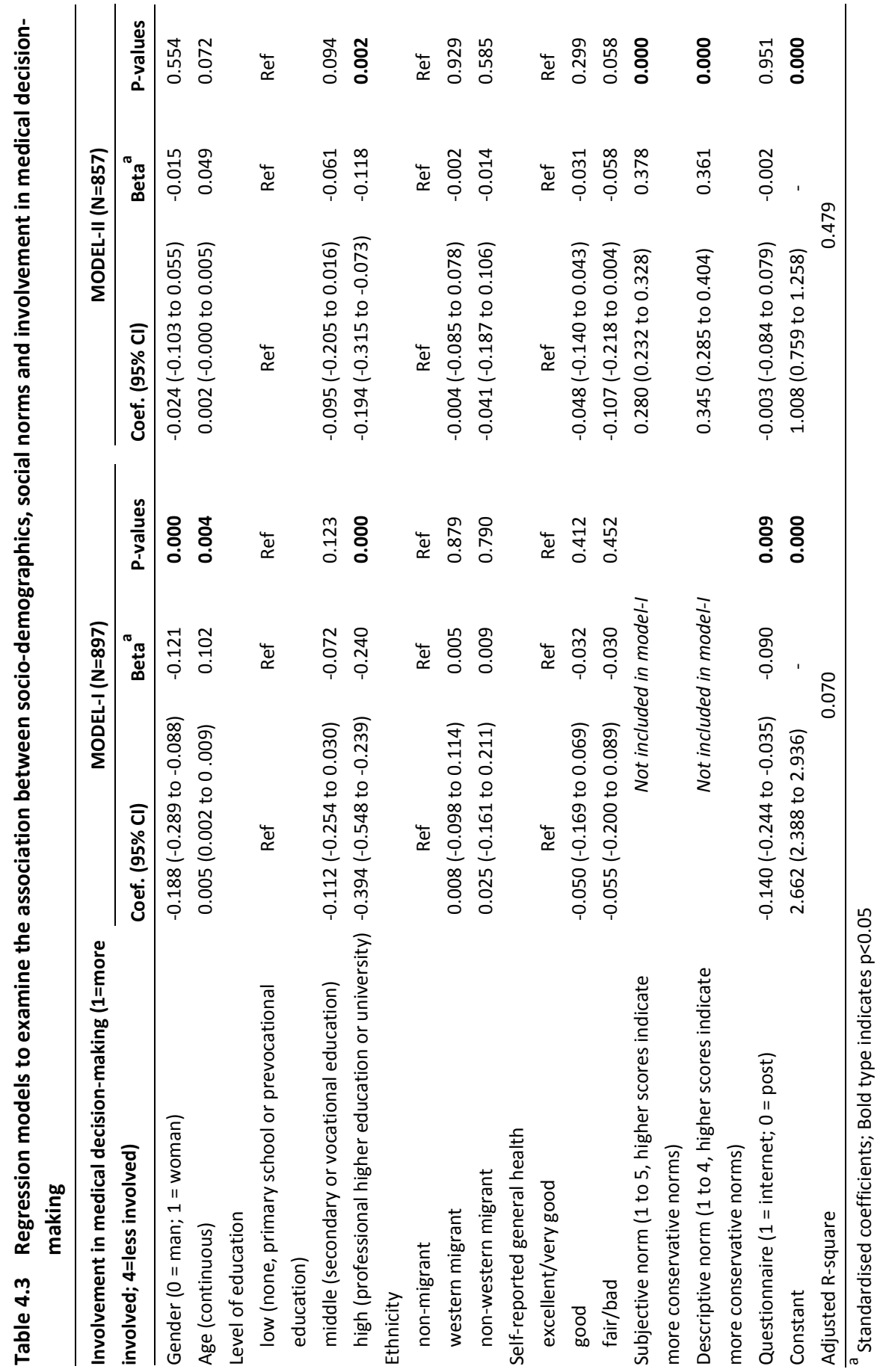




\subsection{Discussion}

This study explored the relationship between social norms and involvement in medical decision-making. In line with our hypotheses, we found that social norms are associated with involvement in such decision-making. With regards to the subjective norm, we found that the more a person thinks that according to significant others he or she has to leave the decision to the physician, the less that person reports being involved in medical decision-making. The same results were found for the descriptive norm: the more people think that significant others leave the decision to the physician, the less they report being involved in the decisionmaking process. An explanation for this is that people behave according to the norms of their social environment, as this will result in social approval. For instance, it can be common in someone's social environment to leave medical decisions to physicians, since there is great deal of respect for them. If this is the situation, then people are expected to leave the decision to physicians in order to obtain social approval. Social norms might thus be a barrier against people participating in medical decision-making.

Consistent with previous empirical studies [6, 10-12], we found that involvement in medical decision-making is associated with individual patient characteristics. However, when social norms are included as an explanatory mechanism, most individual patient characteristics are no longer associated with involvement in such decision-making. This means that social norms are related to individual patient characteristics, as was confirmed in our analyses. Furthermore, we observed that people with a high level of education stated to be more involved in medical decision-making than people with a low level even when social norms are included as an explanatory mechanism. However, here, the effect of educational level on involvement is then much smaller. Based on this, we argue that social norms are less decisive for people with a high level of education and they are less dependent on others in their decision to be involved in medical decision-making compared with people with a low level. Our study gives a first insight into the idea that the decision to be involved in medical decision-making is not as individual as it first seems; someone's social context also plays a role. Our results suggest that differences in patient involvement have also to be examined at the level of the patient's social context, and not just at the individual patient level. 
Our model including social norms explains much, but not all, variation in whether patients are actively involved in medical decision-making. This means that there are other mechanisms besides social norms that too influence patient involvement. One possible mechanism is the availability of social support in someone's social network. It would be interesting for further research to examine whether social support is related to involvement in medical decision-making, as well as whether the mechanisms of social support and social norms enhance each other, or are in conflict with each other, e.g. a situation where conservative norms and receiving support both exist. Another possible mechanism might be someone's health literacy. This is 'the degree to which individuals have the capacity to obtain, process and understand basic health information and services needed to make appropriate health decisions' [22]. In the context of medical decision-making, it can be reasoned that those who are better able to obtain information, and to understand and judge it, are better prepared and more able to take an active role in such decision-making. It would be interesting to include health literacy in future research on patient involvement in medical decision-making.

The strengths of this study are the fact that the questionnaire was both sent by post and through the internet and the large sample size, even though there was a relatively low response rate. Our respondents were not representative of the general Dutch population aged 18 years and older [17]. When compared with this population, people aged 65 and over and western migrants were especially overrepresented. We expect that this does not affect our regression results, since all subgroups are of sufficient size to perform association analyses. Nevertheless, we performed sensitivity analyses in which we analysed model-Il for non-migrants and migrants, respectively. The sensitivity analyses showed the same results. For both non-migrants and migrants, social norms are strongly related to their involvement in medical decision-making. Furthermore, it can be argued that health care panel members are more interested in health care, and, for instance, are more involved in the decision-making process. This might have affected our results. In addition, a limitation might be that we examined self-reported involvement in medical decision-making, instead of actual observed behaviour. It remains unclear from this study whether people participate in the decision-making process in real life. Another limitation is the correlation between the measurements we used for the dependent and independent variables. The questions of the different concepts resembled each other, and therefore it is debatable whether the questions were sufficiently distinctive for the respondents. Moreover, there might be the 
possibility of same-source bias, since we measured involvement in medical decision-making and social norms in the same questionnaire. Thus, the way we measured our questions might have had an impact on our results. Further research is recommended to examine what happens when social norms are measured in a different way. One possible option is measuring the actual norms of network members, instead of measuring the network norms as perceived by the actor [23]. For future research, it would be interesting to ask network members themselves about their norms. Nevertheless, to our knowledge, no standardised measurements are available to measure social norms in the context of our study. We, therefore, believe that we provide a good starting point for developing such measures. Lastly, our data were obtained using a cross-sectional study design, and therefore, do not give insight into the question of causality. From the literature, it is known that people choose network members who are similar to them (selection). On the other hand, network members influence the way people think about various aspects (contagion) [24]. In our context, this might imply that people choose network members who think the same about patient involvement, and that the way they think about this is influenced by their network members. Further research would have to make use of longitudinal data to gain insight into the question of causality.

\subsection{Conclusion}

This study indicates that social norms do play a role as a mechanism in explaining involvement in medical decision-making. We found that the more conservative social norms are, the less likely it is that people are involved in such decisionmaking. Our study offers a first insight into the idea that the decision to be involved in medical decision-making is not as individual as it first seems; someone's social context also plays a role. Strategies aimed at emphasising patient involvement have to address this social context. 


\section{References}

1. Institute of Medicine. Crossing the quality chasm: a new health system for the 21st century. Washington, DC: National Academies Press, 2001

2. Ouwens $M$, Van der Brug S, Faber M, et al. Shared decision making \& Zelfmanagement. Literatuuronderzoek naar begrippen. Nijmegen: UMC St Radboud, IQ healthcare, 2012

3. Charles C, Gafni A, Whelan T. Decision-making in the physician-patient encounter: revisiting the shared treatment decision-making model. Social Science \& Medicine 1999; 49:651-61

4. Emanuel EJ, Emanuel LL. Four models of the physician-patient relationship. JAMA 1992; 267:2221-6

5. Elwyn G, Laitner S, Coulter A, et al. Implementing shared decision making in the NHS. The BMJ 2010; 341:c5146

6. Chewning B, Bylund $\mathrm{CL}$, Shah B, et al. Patient preferences for shared decisions: a systematic review. Patient Education \& Counseling 2012; 86:9-18

7. Van den Brink-Muinen A, Van Dulmen SM, De Haes HC, et al. Has patients' involvement in the decision-making process changed over time? Health Expectations 2006; 9:333-42

8. Arora NK, McHorney CA. Patient preferences for medical decision making: who really wants to participate? Medical Care 2000; 38:335-41

9. Degner LF, Sloan JA. Decision making during serious illness: what role do patients really want to play? Journal of Clinical Epidemiology 1992; 45:941-50

10. Brom L, Hopmans W, Pasman HR, et al. Congruence between patients' preferred and perceived participation in medical decision-making: a review of the literature. BMC Medical Informatics and Decision Making 2014; 14:25

11. Ende J, Kazis L, Ash A, et al. Measuring patients' desire for autonomy: decision making and information-seeking preferences among medical patients. Journal of General Internal Medicine 1989; 4:23-30 
12. Say R, Murtagh $M$, Thomson R. Patients' preference for involvement in medical decision making: a narrative review. Patient Education \& Counseling 2006; 60:102-14

13. Burke NJ, Joseph G, Pasick RJ, et al. Theorizing social context: rethinking behavioral theory. Health Education \& Behavior 2009; 36:55s-70s

14. Coleman J. Foundations of Social Theory. Cambridge, MA: Belknap, 1990

15. Cialdini RB, Kallgren CA, Reno RR. A focus theory of normative conduct: A theoretical refinement and reevaluation of the role of norms in human behavior. Advances in Experimental Social Psychology 1991; 24:1-243

16. Rivis A, Sheeran P. Descriptive norms as an additional predictor in the theory of planned behaviour: a meta-analysis. Current Psychology 2003; 22:218-33

17. Brabers A, Reitsma-Van Rooijen M, De Jong J. Consumentenpanel Gezondheidszorg: Basisrapport met informatie over het panel (2015). Utrecht: NIVEL, 2015

18. CCMO. Your research: does it fall under the WMO? The Hague. Available at: http://www.ccmo.nl/en/your-research-does-it-fall-under-the-wmo (26 August, 2015, date last accessed)

19. Flynn KE, Smith MA, Vanness D. A typology of preferences for participation in healthcare decision making. Social Science \& Medicine 2006; 63:1158-69

20. Sieverding $M$, Matterne $U$, Ciccarello $L$. What role do social norms play in the context of men's cancer screening intention and behavior? Application of an extended theory of planned behavior. Health Psychology 2010; 29:72-81

21. Mackie G, Moneti F, Denny E, et al. What are social norms? How are they measured. University of California at San Diego-UNICEF Working Paper, San Diego, 2012

22. Institute of Medicine. Health Literacy: A Prescription to End Confusion. Washington, DC: The National Academies Press, 2004

23 Van Dijk L, Siegers J. Norms of Networks Members and Labour Supply by Dutch Mothers with Young Children. Child Care and Female Labour Supply in the Netherlands. Amsterdam: Thesis Publishers, 1998; 57-80 
24. Leenders RTAJ. Structure and influence: statistical models for the dynamics of actor attributes, network structure and their interdependence. PhD thesis. University of Groningen, 1995 


\section{Part B}

\section{Patient involvement and medical practice variation}




\section{5}

Does a strategy to promote shared decision-making reduce medical practice variation in the choice of either single or double embryo transfer after in vitro fertilisation?

A secondary analysis of a randomised controlled trial

This article is published as:

Brabers AEM, Van Dijk L, Groenewegen PP, Van Peperstraten AM, De Jong JD. Does a strategy to promote shared decision-making reduce medical practice variation in the choice of either single or double embryo transfer after in vitro fertilisation? A secondary analysis of a randomised controlled trial. BMJ Open 2016; 6:e010894 doi: 10.1136/bmjopen-2015-010894 


\begin{abstract}
Objectives

The hypothesis that shared decision-making (SDM) reduces medical practice variations is increasingly common, but no evidence is available. We aimed to elaborate further on this, and to perform a first exploratory analysis to examine this hypothesis. This analysis, based on a limited data set, examined how SDM is associated with variation in the choice of single embryo transfer (SET) or double embryo transfer (DET) after in vitro fertilisation (IVF). We examined variation between and within hospitals.
\end{abstract}

\title{
Design
}

A secondary analysis of a randomised controlled trial.

\section{Setting}

5 hospitals in the Netherlands.

\section{Participants}

222 couples (woman aged $<40$ years) on a waiting list for a first IVF cycle, who could choose between SET and DET (i.e., $\geq 2$ embryos available).

\section{Intervention}

SDM via a multifaceted strategy aimed to empower couples in deciding how many embryos should be transferred. The strategy consisted of decision aid, support of IVF nurse and the offer of reimbursement for an extra treatment cycle. Control group received standard IVF care.

\section{Outcome measure}

Difference in variation due to SDM in the choice of SET or DET, both between and within hospitals.

\section{Results}

There was large variation in the choice of SET or DET between hospitals in the control group. Lower variation between hospitals was observed in the group with SDM. Within most hospitals, variation in the choice of SET or DET appeared to increase due to SDM. Variation particularly increased in hospitals where mainly DET was chosen in the control group. 


\section{Conclusions}

Although based on a limited data set, our study gives a first insight that including patients' preferences through SDM results in less variation between hospitals, and indicates another pattern of variation within hospitals. Variation that results from patient preferences could be potentially named the informed patient rate. Our results provide the starting point for further research.

\section{Trial registration number}

NCT00315029; Post-results. 


\subsection{Introduction}

Considerable variation exists in medical treatment [1-4]. In a paternalistic model, the physician is the dominant actor deciding on this treatment $[5,6]$. This approach is widely practiced and is embedded in the idea that physicians decide on treatment based on medical science and what is best for an individual patient [3], that is, the belief 'the doctor knows best'. As such, physicians' professional judgements rather than patients' preferences often determine which treatment a patient receives [7, $3 \mathrm{p} 9$ ]. As a result, medical practice variation is found to be related to physicians rather than to patients $[3,8,9]$. In explaining this variation research, therefore, focuses on the role of physicians and the patients' influence receives little attention $[10,11]$. Research showed that variation, among others, can be explained by differences in opinions on or enthusiasm for certain procedures between individual physicians, and by differences in constraints and social influences on groups of physicians, for example, between hospitals [9, 1114]. In the past decades, however, the paternalistic model has been questioned. Also, the position of patients in healthcare has significantly altered. On an individual level, they are supposed to take up an active role in their health [15], and are expected to be involved in decisions about their health [16]. There is, thus, an increased emphasis on including patients and their preferences in medical decisionmaking $[17,18]$. Since medical decision-making is decisive for variation in medical practice, it is questioned whether patients can still be ignored in theories about variation. Providing care that is respectful of, and responsive to an individual patient's preferences, so-called patient-centeredness, is regarded as being of primary importance to healthcare alongside dimensions such as being safe, effective, timely, efficient and equitable [19].

Medical decisions regarding treatment may change through the inclusion of patients' preferences as these preferences may deviate from physicians' professional judgements [20]. Including patients' preferences may result in different treatment choices, and patterns of variation. It has been hypothesised that patients' involvement may reduce variation in medical practice because research shows that patients, through a combination of education and participation, were less ready to accept certain procedures [21]. This also assumes that physicians are more diverse in their preferences than patients despite the fact that they have a shared training and socialisation that has no parallel among patients [21]. One specific approach to patient involvement is shared decision- 
making (SDM) [22, 23]. SDM is especially important in case of preference sensitive care, that is, when there is more than one clinically appropriate treatment option. SDM is defined as an approach where physicians and patients take decisions together using the best available evidence. Patients are helped to make informed choices by considering the options, and the likely benefits and disadvantages of each option [24, 25]. This is important as informed patients often prefer other treatments than those chosen by their physician [3]. Research shows that, in general, informed patients prefer less invasive treatment options [3, 26]. For example, a study of Deyo et al. [27] showed that patients with herniated disks who watched a video programme chose less surgery. On the other hand, variation exists between physicians, since some of them prefer invasive treatments and others conservative treatments [28]. As such, it has been suggested that SDM - as a case of patient involvement - reduces medical treatment variation [23, 29-31]. However, no clear evidence about the association between SDM and medical practice variation is available as yet [11]. There is no research which has identified exactly how or why SDM might reduce this variation. Therefore, this study further elaborates on the mechanisms that may explain why SDM reduces medical practice variation. In addition, we aim to perform a first explorative analysis on a limited data set to examine the hypothesis that SDM reduces medical practice variation. Here we make use of a clear example of a decision which depends on patients' preferences, the choice of either a single embryo transfer (SET) or double embryo transfer (DET) after in vitro fertilisation (IVF) [32].

SET prevents a multiple pregnancy with associated higher risks. DET results in higher live birth rates per treatment cycle [33, 34] (see Box 5.1 for more information). The percentage of SET varies considerably between countries [35-37]. For example, rates of SET ranged from $8.7 \%$ in Moldova to $70.7 \%$ in Sweden [37]. Likewise, major differences exist in how this complex decision is taken. These differences exist between countries, and between hospitals within the same country. In some hospitals, the decision is based solely on clinical parameters, while in other hospitals the patients are fully involved in the decision and physicians act as their advisor [38]. If the physician decides on SET or DET, this decision is mainly based on the physicians' professional judgements. As such, decision variation is likely. When patients are involved, decisions may differ; informed patients often prefer less invasive treatments $[3,26]$. The data from the randomised controlled trial (RCT) analysed in this study, in which a strategy for SDM was used as intervention, showed that educated couples, who understood the 
risks of twin pregnancies, were more inclined to choose SET; this is as compared with couples receiving standard care [32].

We examine how a strategy to promote SDM is associated with variation in choosing SET or DET both between and within hospitals. We hypothesise that SDM is associated with less variation between hospitals since we expect that, due to SDM, SET is chosen more often both in hospitals where physicians already preferred SET and in hospitals where physicians preferred DET as educated couples prefer this (H1). We also hypothesise that if DET is mainly preferred within a hospital and there is thus hardly any variation, then SDM is expected to increase variation because SET will be chosen more often due to SDM (H2). Whereas, if SET is mainly preferred within a hospital and there is thus hardly any variation, then SDM is expected not to change variation since SET is still preferred due to SDM (H3). Furthermore, we hypothesise that if DET and SET are both chosen within a hospital and there is thus large variation, SDM is expected to decrease variation because, due to SDM, SET is likely to be chosen more often than DET (H4).

Box 5.1 The choice of single embryo transfer (SET) or double embryo transfer (DET): a complex decision-making problem

\footnotetext{
The choice of a SET or DET after in vitro fertilisation (IVF) is a complex decision-making problem because of the need to find a balance between the risk of complications of multiple birth and the best chance of pregnancy [32]. Some subfertile couples and professionals regard twin pregnancies as a success; however, this could also be considered as a side effect or even a complication [45]. Twin pregnancies are associated with higher morbidity and mortality rates for mother and child compared with singleton pregnancies [34]. Moreover, complications of twin pregnancies cause substantial use of medical budgets $[46,47]$. Subsequently, twin pregnancies are increasingly regarded as undesirable. To prevent twin pregnancies, professionals and couples could choose SET instead of DET $[34,45]$. However, this may be disadvantageous since it could result in a lower pregnancy rate per IVF cycle [33]. The choice of SET or DET is ideally decided through shared decision-making [48].
} 


\subsection{Methods}

\section{Description of the data}

Data for this research were obtained from the RCT by Van Peperstraten et al. [32]. The choice for SET or DET should ideally be decided in a SDM process by an educated and empowered couple. In the RCT study of Van Peperstraten et al. [32], a multifaceted strategy was used to promote SDM. To promote SDM, Van Peperstraten et al developed a decision aid (DA; see Box 5.2 for more information).

Box 5.2 The choice of single or double embryo transfer: an evidence-based decision aid (DA)

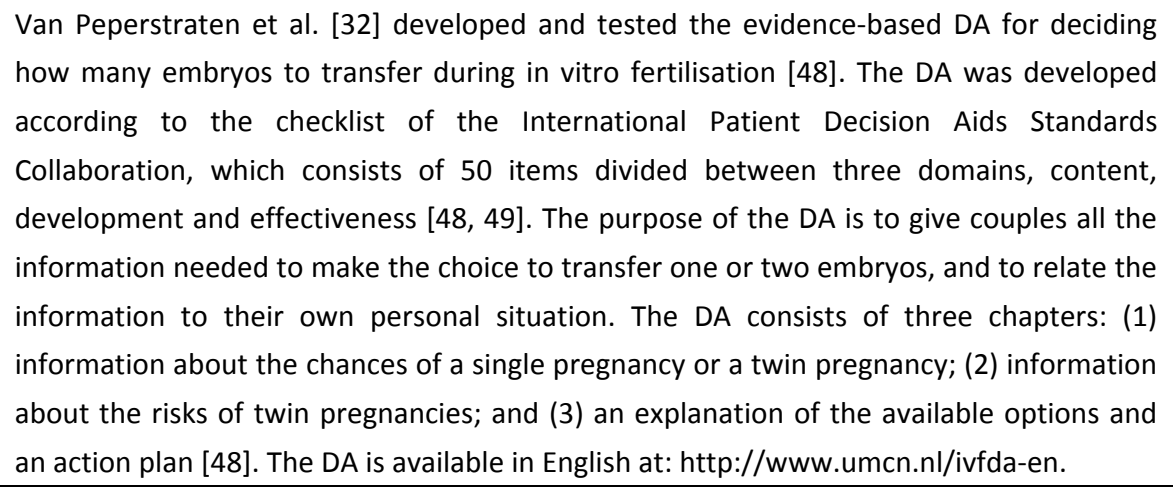

DAs are standardised evidence-based tools intended to promote SDM [23]. Besides the evidence-based DA, this strategy consisted of the support of an IVF nurse, and reimbursement for an additional cycle of IVF for couples for whom the choice of SET caused a reduced chance of pregnancy [32]. In the Netherlands, up to three IVF cycles are covered by the basic (but extensive) health insurance. The content of the DA and the reimbursement offer were discussed in person with a trained IVF nurse. All three elements of the strategy were provided before the counselling session that was part of standard care [32]. The control group received standard IVF care, including a session discussing the choice of SET or DET. Next to this standard care, the intervention group received the multifaceted empowerment strategy [32]. In the original RCT study, participating women completed three questionnaires (at inclusion, after intervention (but before starting treatment), and 5 weeks after embryo transfer) to measure decision-making outcomes and knowledge. Results showed that the proportion of couples in the intervention group who wanted to decide for themselves on the number of embryos to be transferred increased, 
while this percentage remained the same in the control group $(p<0.001)$. Levels of experienced knowledge $(p=0.001)$ and actual knowledge $(p<0.001)$ were higher in the intervention group compared with the control group [32]. For further detailed information, see Van Peperstraten et al. [32].

Before the study, in 2005, 39\% of the couples underwent SET after the first cycle [39]. The RCT was performed in five hospitals in the Netherlands. It included couples on the IVF waiting list between November 2006 and July 2007. The followup was continued until December 2008. Couples with women under 40 years of age were included if they were on the waiting list for their first IVF cycle ever or a first cycle after a previous successful IVF. Couples were excluded if SET was mandatory due to a strict medical indication. Written informed consent was provided by the couples before participation [32].

\section{Selection of the data}

In total, 308 couples at the beginning of their first IVF cycle were included in the intention-to-treat (ITT) analysis of Van Peperstraten et al. [32]. In all five hospitals, approximately half of the couples received standard care, while the other half received the intervention. In this study, only couples who had the opportunity to choose between SET and DET were included. We, therefore, omitted from the 308 couples included in the ITT all the couples: (1) where the woman was pregnant before starting IVF ( $N=20)$; (2) who had never started IVF ( $N=13)$ and (3) who had none or just one embryo available ( $N=39, N=14$, respectively). Our sample included 222 couples, 113 in the control group and 109 in the intervention group. The outcome measure used in this study was the choice of either SET or DET. The data on this outcome were collected by Van Peperstraten et al. [32] from local IVF registries. Other variables included were whether a couple was involved in the intervention or in the control groups, and the hospital in which a couple was treated. In addition, we included four variables that are of medical relevance and might, therefore, affect the choice of SET or DET, and thus in medical practice variation. For example, the older the woman is, the less likely she will become pregnant and the more likely she will have twins. The four variables included were: (1) the age of the woman (in years); (2) the duration of infertility (in years); (3) the presence of a good quality embryo (yes/no) and (4) any previous pregnancies (yes/no). Data on the presence of a good quality embryo were collected by Van Peperstraten et al. [32] from local IVF registries. Data for the other three variables were collected through a patient questionnaire which couples received when 
included into the study [32]. The woman's age and duration of infertility were calculated in this study on 31 December 2008 (=end of follow-up).

\section{Statistical analyses of the data}

We examined whether the control and intervention group were comparable for the characteristics included by performing descriptive statistics, and $\chi 2$-tests (categorical variables) and t-tests (continuous variables; $p<0.05$ ). We then examined whether the five hospitals included did significantly differ with respect to the four variables that are of medical relevance. If there were differences between the five hospitals then we had to take these into account through the rest of our analyses since these may have an impact on the choice of SET or DET. We performed descriptive statistics per hospital for the four variables. By $\chi 2$-tests (categorical variables) and one-way analyses of variance (ANOVA) (continuous variables), we tested if there were significant differences between the five hospitals for the woman's age, the duration of infertility, the presence of a good quality embryo and for previous pregnancies $(p<0.05)$. If a significant difference was found between the hospitals for one of the aforementioned variables, we then performed an additional analysis to examine if there was an association between that variable and the outcome measure.

We then calculated, for each hospital, the percentage of couples who chose SET or DET, both in the control and in the intervention groups. We examined this in order to confirm that educated couples are inclined to choose SET.

Next, we examined the variation between the hospitals. We first calculated for each hospital the percentage of SET in the control group, and then in the intervention group. Thereafter, we calculated the range of SET percentages for the control and the intervention groups. A smaller range or difference between the highest and the lowest percentage of SET implies less variation. Thus, if a strategy to promote SDM is associated with less variation between hospitals, then the range of SET percentages for the intervention group is smaller than that for the control group.

We now examined the variation within the hospitals by looking at the differences in variation between the control and the intervention groups in each hospital. We calculated for each hospital the absolute difference between SET and DET in the control as well as in the intervention groups. For example, if $40 \%$ chose SET and 
$60 \% \mathrm{DET}$, the absolute difference is 20 . There is no medical practice variation if the proportion of SET to DET is $0 \%$ compared with $100 \%$, or vice versa. Thus, there is no variation if the absolute difference is 100 . On the other hand, the most variation is observed if the proportion of SET to DET is $50 \%$ to $50 \%$. Thus, there is an absolute difference of 0 . We can thus create a scale ranging from 0 to 100 , where a score closer to 100 means less medical practice variation. We compared the scores of the control and the intervention groups for each hospital. If the score in a hospital is higher in the intervention group than in the control group, and thus closer to 100 (=no variation), then a strategy to promote SDM is associated with less variation within that hospital. Complementary to the descriptive statistics, we performed a multilevel analysis (MLA) in MLwiN to examine variation between hospitals. An MLA takes into account the nested structure of the data as well as the differences in the number of patients per hospital. All statistical analyses were carried out using STATA, V.13.1.

\subsection{Results}

\section{Characteristics of the couples included}

A description of the 222 couples included is given in Table 5.1. The number of couples included ranged from 12 couples in hospital 5 to 153 couples in hospital 1 (see Table 5.1). The control and intervention groups did not differ significantly with respect to the characteristics included. Furthermore, no significant differences were observed between the five hospitals for the mean duration of infertility $(p=0.256)$, the presence of a good quality embryo $(p=0.406)$ and for previous pregnancies ( $p=0.403$; see Table 5.2 ). ANOVA showed a significant difference $(p=0.032)$ for the variable, woman's age. An additional t-test showed no difference between woman's age and the choice of SET or DET $(p=0.346)$. Thus, we decided not to include these four variables throughout the rest of the analyses.

\section{Choice of SET}

Table 5.3 shows the numbers and percentages of SET and DET for the control and intervention groups, in total and per hospital. In total, $52 \%$ of the couples included in the intervention group chose SET, in comparison with $39 \%$ of the couples in the control group $(p=0.046)$. To be more specific, in four of the five hospitals, couples in the intervention groups more often chose SET than DET. In hospital 4, however, couples in the intervention group more often chose DET than SET (80\% vs $20 \%$ ). 
Although in hospital 4, couples in the intervention group more often chose DET, they more often chose SET (20\%) than couples in the control group (0\%).

\section{Variation between hospitals}

The range of SET in the control and intervention groups can also be observed in Table 5.3. The percentages of SET in the control groups ranged from $0 \%$ to $85.7 \%$, while the percentages of SET in the intervention groups ranged from $20.0 \%$ to $87.5 \%$. Therefore, the range of SET is smaller in the intervention group than in the control group, which is an indication that a strategy to promote SDM reduced variation in the choice of SET or DET between hospitals. The MLA also indicated that the variation between hospitals was lower in the intervention group than in the control group. However, the difference was not significant.

Table 5.1 Characteristics of the couples included ( $N=222)$

\begin{tabular}{|c|c|c|c|c|}
\hline Characteristics & $\begin{array}{l}\text { Control } \\
\text { group (N=113) }\end{array}$ & $\begin{array}{l}\text { Intervention } \\
\text { group ( } N=109)\end{array}$ & $\begin{array}{l}\text { Total } \\
\text { (N = 222) }\end{array}$ & P-value \\
\hline \multicolumn{5}{|l|}{ Hospital } \\
\hline hospital 1 & 79 & 74 & 153 & NA \\
\hline hospital 2 & 7 & 7 & 14 & \\
\hline hospital 3 & 7 & 8 & 15 & \\
\hline hospital 4 & 13 & 15 & 28 & \\
\hline hospital 5 & 7 & 5 & 12 & \\
\hline $\begin{array}{l}\text { Mean (sd) age of woman } \\
\text { (years) }^{\text {a }}\end{array}$ & $\begin{array}{l}33.9(3.85) \\
\text { (range } 21-41 \text { years) }\end{array}$ & $\begin{array}{l}33.5(3.88) \\
\text { (range } 25-41 \text { years) }\end{array}$ & $\begin{array}{l}33.7(3.86) \\
\text { (range } 21-41 \text { years) }\end{array}$ & 0.475 \\
\hline $\begin{array}{l}\text { Mean (sd) duration of } \\
\text { infertility (years) }\end{array}$ & $\begin{array}{l}4.03(2.08) \\
\text { (range } 1-13 \text { years) } \\
(\mathrm{N}=101)\end{array}$ & $\begin{array}{l}3.94(1.91) \\
\text { (range } 1-12 \text { years) } \\
(\mathrm{N}=98)\end{array}$ & $\begin{array}{l}3.98(2.00) \\
\text { (range } 1-13 \text { years) } \\
(\mathrm{N}=199)\end{array}$ & 0.749 \\
\hline \multicolumn{5}{|l|}{$\begin{array}{l}\text { Presence of a good quality } \\
\text { embryo }\end{array}$} \\
\hline $\begin{array}{l}\text { no } \\
\text { yes } \\
\text { Previous pregnancies }\end{array}$ & $\begin{array}{l}41 \\
72 \\
(N=113)\end{array}$ & $\begin{array}{l}28 \\
81 \\
(N=108)\end{array}$ & $\begin{array}{l}69 \\
153 \\
(N=221)\end{array}$ & 0.088 \\
\hline $\begin{array}{l}\text { no } \\
\text { yes }\end{array}$ & $\begin{array}{l}63 \\
50 \\
\end{array}$ & $\begin{array}{l}63 \\
45 \\
\end{array}$ & $\begin{array}{r}126 \\
95 \\
\end{array}$ & 0.698 \\
\hline $\begin{array}{l}\text { Values are numbers unles } \\
\text { a Calculated on Decembe } \\
\text { result, we have a higher } \\
2010[32] . \\
\text { b Based on the question: } \\
\text { c } p<0.05 \text { is significant }\end{array}$ & $\begin{array}{l}\text { herwise stated } \\
2008 \text { based on infor } \\
\text { ean for age and durati } \\
\text { ve you ever been pre }\end{array}$ & $\begin{array}{l}\text { mation filled out in } \\
\text { on of infertility than } \\
\text { snant?" }\end{array}$ & $\begin{array}{l}\text { tients' questionnaires } \\
\text { an Peperstraten et al. }\end{array}$ & $\begin{array}{l}\text { As a } \\
\text { BMJ, }\end{array}$ \\
\hline NA, not applicable & & & & \\
\hline
\end{tabular}


Table 5.2 Characteristics of the couples included per hospital

\begin{tabular}{|c|c|c|}
\hline Characteristics & Total $(\mathrm{N}=222)$ & P-value ${ }^{c}$ \\
\hline Mean (sd) age of woman (years) ${ }^{a}$ & $33.7(3.86)(21-41)$ & \\
\hline hospital 1 ( $N=153)$ & $33.8(3.63)(21-41)$ & \\
\hline hospital $2(N=14)$ & $30.9(4.54)(25-39)$ & 0.032 \\
\hline hospital $3(\mathrm{~N}=15)$ & $34.6(3.96)(28-40)$ & \\
\hline hospital $4(\mathrm{~N}=28)$ & $33.4(4.53)(25-41)$ & \\
\hline hospital $5(\mathrm{~N}=12)$ & $35.2(2.86)(30-38)$ & \\
\hline Mean (sd) duration of infertility (years) ${ }^{a}$ & $4.0(2.00)(1-13)$ & \\
\hline hospital 1 ( $N=139)$ & $4.1(2.20)(1-13)$ & \\
\hline hospital $2(\mathrm{~N}=11)$ & $4.0(1.26)(2-6)$ & 0.256 \\
\hline hospital $3(\mathrm{~N}=11)$ & $4.3(1.85)(2-8)$ & \\
\hline hospital $4(\mathrm{~N}=26)$ & $3.2(1.22)(1-6)$ & \\
\hline hospital $5(\mathrm{~N}=12)$ & $4.0(1.13)(2-6)$ & \\
\hline Presence of a good quality embryo (\% yes) & $68.9 \%$ & \\
\hline hospital 1 ( $N=153)$ & $72.6 \%$ & \\
\hline hospital $2(N=14)$ & $64.3 \%$ & 0.406 \\
\hline hospital $3(N=15)$ & $66.7 \%$ & \\
\hline hospital $4(\mathrm{~N}=28)$ & $60.7 \%$ & \\
\hline hospital $5(\mathrm{~N}=12)$ & $50.0 \%$ & \\
\hline Previous pregnancies (\% yes) ${ }^{b}$ & $43.0 \%$ & \\
\hline hospital 1 ( $N=153)$ & $45.8 \%$ & \\
\hline hospital $2(N=14)$ & $21.4 \%$ & 0.403 \\
\hline hospital $3(N=14)$ & $50.0 \%$ & \\
\hline hospital $4(\mathrm{~N}=28)$ & $39.3 \%$ & \\
\hline hospital $5(\mathrm{~N}=12)$ & $33.3 \%$ & \\
\hline \multicolumn{3}{|c|}{$\begin{array}{l}\text { Calculated on December 31, } 2008 \text { based on information filled out in patients' questionnaires. As a } \\
\text { result, we have a higher mean for age and duration of infertility than Van Peperstraten et al., BMJ, } \\
2010 \text { [32]. }\end{array}$} \\
\hline
\end{tabular}


Table 5.3 The choice of single embryo transfer (SET) or double embryo transfer (DET) total group, and per hospital

\begin{tabular}{|c|c|c|c|c|c|}
\hline \multirow{2}{*}{ Total } & \multicolumn{2}{|c|}{ Control group } & \multicolumn{2}{|c|}{ Intervention group } & \multirow[t]{2}{*}{ P-value $^{a}$} \\
\hline & & & & & \\
\hline SET & 44 & $(38.9 \%)$ & 57 & $(52.3 \%)$ & 0.046 \\
\hline DET & 69 & (61.1\%) & 52 & $(47.7 \%)$ & \\
\hline \multicolumn{6}{|c|}{ Hospital 1} \\
\hline SET & 31 & $(39.2 \%)$ & 40 & (54.1\%) & 0.066 \\
\hline DET & 48 & $(60.8 \%)$ & 34 & $(46.0 \%)$ & \\
\hline \multicolumn{6}{|c|}{ Hospital 2} \\
\hline SET & 3 & $(42.9 \%)$ & 4 & (57.1\%) & 0.593 \\
\hline DET & 4 & (57.1\%) & 3 & $(42.9 \%)$ & \\
\hline \multicolumn{6}{|c|}{ Hospital 3} \\
\hline SET & 4 & (57.1\%) & 7 & $(87.5 \%)$ & 0.185 \\
\hline DET & 3 & $(42.9 \%)$ & 1 & $(12.5 \%)$ & \\
\hline \multicolumn{6}{|c|}{ Hospital 4} \\
\hline SET & 0 & $(0.0 \%)$ & 3 & $(20.0 \%)$ & 0.088 \\
\hline DET & 13 & $(100.0 \%)$ & 12 & $(80.0 \%)$ & \\
\hline \multicolumn{6}{|c|}{ Hospital 5} \\
\hline SET & 6 & $(85.7 \%)$ & 3 & $(60.0 \%)$ & 0.310 \\
\hline DET & 1 & $(14.3 \%)$ & 2 & $(40.0 \%)$ & \\
\hline
\end{tabular}

Values are numbers (\%) unless otherwise stated

$\mathrm{p}<0.05$ is significant

\section{Variation within hospitals}

Figure 5.1 shows the differences in variation within hospitals by illustrating, per hospital, the absolute difference between SET and DET in the control group (standard care) and the intervention group (strategy to promote SDM). In one hospital (hospital 2), the absolute difference in the control and the intervention groups is the same. This means that the variation within hospital 2 is the same with or without a strategy to promote SDM. Within hospital 3, the strategy to promote SDM appears to be associated with less variation, since the absolute difference in the control group is lower than in the intervention group (14 and 75, respectively). On the other hand, within the other three hospitals, hospitals 1, 4 and 5, the strategy to promote SDM appears to be associated with more variation. Within these three hospitals, the absolute difference in the control group is higher than that in the intervention group (see Figure 5.1). Therefore, within some of the hospitals included, a strategy to promote SDM appears to be associated with more variation, while within other hospitals a strategy to promote SDM appears to be associated with less or the same level of variation. 
Figure 5.1 Variation within hospitals. A measure of variation for the control and intervention groups per hospital. DET, double embryo transfer; SET, single embryo transfer.

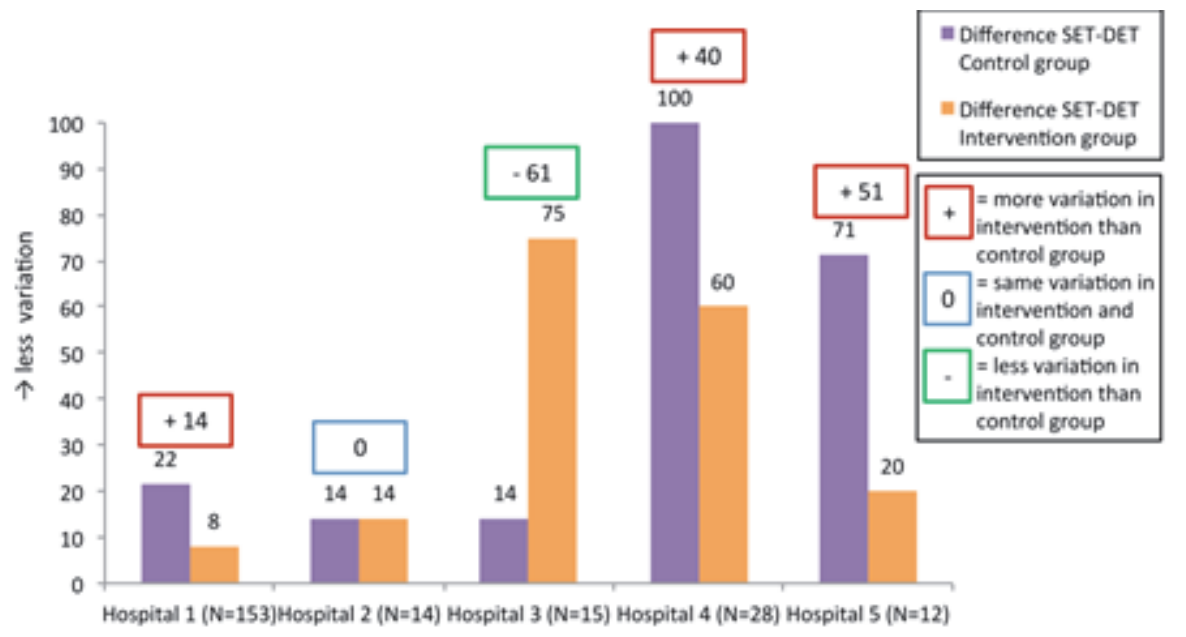

\subsection{Discussion and conclusions}

\section{Principal findings}

This study further elaborated on and explored the association between SDM and variation in the choice of SET or DET both between and within hospitals. There was large variation in the choice of SET or DET between hospitals in the control group. Lower variation between hospitals was observed in the group with a strategy to promote SDM. Furthermore, we observed that within most hospitals, the variation in the choice of SET or DET appeared to increase due to a strategy to promote SDM. This was particularly so in hospitals where mainly DET was chosen in the control group.

\section{What this study adds}

Literature suggests that SDM reduces variation [23, 29-31]. To date, there is no clear evidence about this association. This study is the first that explored this association based on a case concerning the choice of SET or DET after IVF. We noticed that a strategy to promote SDM reduces variation between hospitals (confirming $\mathrm{H} 1$ ), while the variation within most hospitals appears to increase. The hypothesis in literature that SDM reduces variation is based on the observation 
that informed patients more often prefer less invasive treatments $[3,26]$. We found that in most hospitals, couples in the intervention group more often chose SET. However, this does not imply that there will be less variation since our results indicate that variation within most hospitals increased. This is due to the fact that the level of variation without SDM differed between hospitals. For example, in some of the hospitals included mainly DET was preferred and there was, thus, almost no variation. Owing to the strategy to promote SDM, however, SET was chosen more often, and thus the variation increased within such hospitals, since now both SET and DET are chosen (confirming H2). In one hospital, SET was mainly chosen in the control group and we, therefore, expected no change in variation since we expected SET was still preferred due to the strategy to promote SDM (H3). However, we observed an increase in variation in that hospital, rejecting $\mathrm{H} 3$. In the two hospitals with the largest variation in the control group, the variation decreased or remained equal, confirming H4. A subsequent implication is that an overall decrease in variation between hospitals provides no indication about the change in variation within an individual hospital. Although based on a limited data set, this study gives a first insight that SDM results in less variation between hospitals while suggesting another pattern of variation within hospitals.

\section{Further research}

This research focused on just one decision-making situation in obstetrics, and had only access to a limited data set. The results, therefore, have to be interpreted with caution and further research is necessary to underpin our results and examine questions that remain unanswered. Nevertheless, our study provides a starting point for further empirical research within this area. For many medical problems, no absolute best treatment option is available, and so there are significant tradeoffs among the available options [40,41]. We expect, however, that our results apply generally to medical problems with no absolute best treatment option. Decisions concerning such problems are defined as preference sensitive, since they depend on considerations of the benefits, disadvantages and uncertainties of each treatment. For example, some patients will prefer to accept a small risk of death in order to attempt to improve their function, while others will not [23, 41]. Therefore, the best decisions cannot be made without including patients' preferences $[40,41]$. Well-known examples include chronic back pain, early-stage breast cancer and prostate cancer. For examples such as these it is believed that variation will change as a result of SDM. Future research has to confirm this by making use of data from multicentre RCT studies that applied intervention 
strategies (like a DA) to increase SDM in a specific consultation. Such RCT studies have been carried out [26] but have focused, comparable to the study we used, on outcome measures other than variation. Therefore, we decided in this study to perform a secondary analysis. Any possible multicentre studies should include a control and an intervention group which could thus measure actual treatment choices with and without SDM. This will allow researchers to examine whether SDM changes the pattern of variation by, for example, using the same method as we did. Another possibility for further research is to conduct a new multicentre RCT study specifically aimed at analysing the relationship between SDM and medical practice variation.

Our results show that a strategy to promote SDM results in less variation between hospitals and indicates another pattern of variation within hospitals, confirming our hypotheses. These results appear to show that the decisions made by informed patients have a pattern too. Choices made by informed patients appear to have a rate which deviates from baseline rates, irrespective of whether those are 'low' or 'high'. This could be potentially named the informed patient rate. However, it can be questioned whether the rates we observed are indeed the informed patient rate, that is, the results of what the couples want. It is possible that not all patients were able or preferred to take a shared decision about the choice of SET or DET. Nevertheless, results of the original RCT study show that levels of experienced knowledge $(p=0.001)$ and actual knowledge $(p<0.001)$ were higher in the intervention group compared with the control group [32]. Further research has to examine whether the actual choice was indeed the patients' preference and whether there are differences between groups of patients for this. In addition, a different pattern of variation due to SDM might be a positive indication for the quality of care. Good healthcare requires, among others, providing care that is respectful of and responsive to individual patients' preferences [19]. This is particularly true for preference sensitive decisions, since these decisions depend on patients' preferences regarding the benefits, disadvantages, and uncertainties of each treatment. Further research has to examine whether SDM results in better quality of care for preference sensitive decisions.

The broad context of this study is about the influence of patients and their preferences on variation in medical practice. SDM is one option for including patients' preferences in medical decision-making. There are other options through which patients can express their preferences, and thus influence the pattern of 
variation. For example, patients differ in how much pressure they are able to put on physicians $[13,42]$. They differ in their ability to take part in discussions over treatment with their physicians. Some patients are expected to be able to ask their physician for another treatment than, for example, the treatment that is recommended in a guideline or the one that is preferred by the physician $[13,43]$. If this is the case, then patients' preferences appear to influence the treatment chosen, and thus the variation. Further research is recommended regarding these situations.

\section{The strengths and weaknesses of the study}

A strength of our study is that we are the first to elaborate further on and explore the association between SDM and variation in medical treatment. We examined this association to get insight into whether including patients' preferences through a strategy to promote SDM results in another pattern of variation in medical treatment. Another strength is the use of data from a RCT. We had the opportunity to compare the variation in the choice of SET or DET with and without SDM. It might be possible that the choice of SET or DET in the control group is influenced by physicians, since they treated both couples in the intervention and in the control group. Ideally, data would have been available about the percentage of SET and DET before the RCT, allowing us to compare the intervention and control groups with these percentages. Though another study showed that in 2005, before the RCT, 39\% of twin-prone couples in two Dutch hospitals chose SET [39], which is comparable to the percentage of SET in the control group. It seems plausible to use the control group as the situation before SDM. We performed descriptive statistics to analyse our data because of the low numbers of couples included in the hospitals. We have taken into account the nested structure of the data by performing our analyses per hospital. However, we did not take into account the differences in the number of patients per hospital. We, therefore, also performed an MLA to examine the variation between hospitals. The MLA supported the results of the descriptive statistics; however, the difference was not significant. From the data set it was only known in which hospital a couple was treated, and not by which physician within that hospital. However, only one or two physicians per hospital treated all couples in that hospital; therefore, we do not expect that this will affect our conclusions. Further research should ideally be performed with a larger data set, preferably using MLA in order to test the hypothesis of this study. This would acknowledge that patients are nested hierarchically within physicians and physicians within hospitals. In addition, further research has to include into the 
analyses the socio-demographics that might have an influence on treatment decision. Another limitation might be that the original RCT did not assess whether more SDM actually took place. As such, it is unclear whether the strategy really led to more SDM. A final limitation might be that the intervention consisted of different elements, and thus it is difficult to assess separately the effects of these elements. Despite the fact that at the end of the follow-up period only $4 \%$ of the couples qualified for reimbursement of a fourth cycle, reimbursement might have played a role in the decision [32]. However, a follow-up study showed that compared with the other elements - the reimbursement offer was rated least important by the couples in choice for SET or DET [44].

\section{Conclusions}

This study was the first to elaborate further on and explore the relationship between including patients' preferences in medical decision-making and practice variation. Although based on a limited data set, our study gives a first insight that including patients' preferences through SDM results in less medical practice variation between hospitals, and indicates another pattern of variation within hospitals. The variation that results from patient preferences could be potentially named the informed patient rate. The results of this study provide the starting point for further empirical research within this area. 


\section{References}

1. Paul-Shaheen P, Clark JD, Williams D. Small area analysis: a review and analysis of the North American literature. Journal of health politics, policy and law 1987; 12:741-809

2. Wennberg JE. Understanding geographic variations in health care delivery. New England Journal of Medicine 1999; 340:52-3

3. Wennberg JE. Tracking medicine: a researcher's quest to understand health care. Oxford University Press, 2010

4. Corallo AN, Croxford R, Goodman DC, et al. A systematic review of medical practice variation in OECD countries. Health Policy 2014; 114:5-14

5. Emanuel EJ, Emanuel LL. Four models of the physician-patient relationship. JAMA $1992 ; 267: 2221-6$

6. Charles C, Gafni A, Whelan T. Shared decision-making in the medical encounter: what does it mean? (or it takes at least two to tango). Social Science \& Medicine 1997; 44:681-92

7. Wennberg JE. Unwarranted variations in healthcare delivery: implications for academic medical centres. The BMJ 2002; 325:961

8. McPherson K. Why do variations occur? In: Andersen TF, Mooney G, eds. The challenges of medical practice variations. London: The Macmillan Press, 1990; 16-35

9. Wennberg JE, Gittelsohn A. Health care delivery in Maine I: patterns of use of common surgical procedures. The Journal of the Maine Medical Association 1975; 66(5):123-30, 49

10. Mercuri M, Gafni A. Medical practice variations: what the literature tells us (or does not) about what are warranted and unwarranted variations. Journal of Evaluation in Clinical Practice 2011; 17(4):671-7

11. De Jong JD, Groenewegen PP, Westert GP. Sociological Model for Understanding Medical Practice Variations. In: Sobolev B (Series ed), Johnson A, Stukel T (eds). Health Services Research Series. Medical Practice Variations. New York: Springer, 2015; 25-39 
12. Chassin MR. Explaining geographic variations. The enthusiasm hypothesis. Medical Care 1993; 31(5 Suppl):Ys37-44

13. De Jong JD. Explaining medical practice variation. Social organization and institutional mechanisms. NIVEL, 2008

14. Westert GP, Groenewegen PP. Medical practice variations: changing the theoretical approach. Scandinavian journal of public health 1999; 27(3):173-80

15. Van de Bovenkamp HM, Trappenburg MJ, Grit KJ. Patient participation in collective healthcare decision making: the Dutch model. Health Expectations 2010; 13(1):73-85

16. Guadagnoli E, Ward P. Patient participation in decision-making. Social Science \& Medicine 1998; 47(3):329-39

17. Frosch DL, Kaplan RM. Shared decision making in clinical medicine: past research and future directions. American Journal of Preventive Medicine 1999; 17:285-94

18. Fraenkel L. Incorporating patients' preferences into medical decision making. Medical Care Research and Review 2013; 70(1 Suppl):80s-93s

19. Institute of Medicine. Crossing the quality chasm: a new health system for the 21st century. National Academies Press, 2001

20. Wennberg JE. Variation in Use of Medicare Services among Regions and Selected Academic Medical Centers: Is More Better? Commonwealth Fund, 2005

21. Greer AL, Goodwin JS, Freeman JL, et al. Bringing the patient back in. Guidelines, practice variations, and the social context of medical practice. International Journal of Technology Assessment in Health Care 2002; 18(4):747-61

22. Charles C, Gafni A, Whelan T. Decision-making in the physician-patient encounter: revisiting the shared treatment decision-making model. Social Science \& Medicine 1999; 49:651-61

23. O'Connor AM, Llewellyn-Thomas HA, Flood AB. Modifying unwarranted variations in health care: shared decision making using patient decision aids. Health Affairs 2004; Var63-72 
24. Elwyn G, Frosch D, Thomson R, et al. Shared decision making: a model for clinical practice. Journal of General Intern Medicine 2012; 27(10):1361-7

25. Elwyn G, Laitner S, Coulter A, et al. Implementing shared decision making in the NHS. The BMJ 2010; 341:c5146

26. Stacey D, Bennett CL, Barry MJ, et al. Decision aids for people facing health treatment or screening decisions. The Cochrane Database of Systematic Reviews 2011; (10):Cd001431

27. Deyo RA, Cherkin DC, Weinstein J, et al. Involving patients in clinical decisions: impact of an interactive video program on use of back surgery. Medical Care 2000; 38:959-69

28. McClure W. Toward development and application of a qualitative theory of hospital utilization. Inquiry 1982; 19:117-35

29. O'Connor AM, Wennberg JE, Legare F, et al. Toward the 'tipping point': decision aids and informed patient choice. Health Affairs 2007; 26:716-25

30. Stiggelbout AM, Van der Weijden T, De Wit MP, et al. Shared decision making: really putting patients at the centre of healthcare. The BMJ 2012; 344:e256

31. Weinstein JN, Bronner KK, Morgan TS, et al. Trends and geographic variations in major surgery for degenerative diseases of the hip, knee, and spine. Health Affairs 2004; Var81-9

32. Van Peperstraten A, Nelen W, Grol R, et al. The effect of a multifaceted empowerment strategy on decision making about the number of embryos transferred in in vitro fertilisation: randomised controlled trial. The BMJ 2010; 341:c2501

33. Pandian Z, Marjoribanks J, Ozturk O, et al. Number of embryos for transfer following in vitro fertilisation or intra-cytoplasmic sperm injection. The Cochrane Database of Systematic Reviews 2013; 7:Cd003416

34. Pinborg A. IVF/ICSI twin pregnancies: risks and prevention. Human Reproduction Update 2005; 11:575-93

35. Andersen AN, Goossens V, Ferraretti AP, et al. Assisted reproductive technology in Europe, 2004: results generated from European registers by ESHRE. Human Reproduction 2008; 23:756-71 
36. De Mouzon J, Goossens V, Bhattacharya S, et al. Assisted reproductive technology in Europe, 2006: results generated from European registers by ESHRE. Human Reproduction 2010; 25:1851-62

37. Ferraretti AP, Goossens V, Kupka M, et al. Assisted reproductive technology in Europe, 2009: results generated from European registers by ESHRE. Human Reproduction 2013; 28:2318-31

38. Van Peperstraten A. Implementation of single embryo transfer: a patient directed strategy. Radboud Universiteit Nijmegen, 2009

39. Van Peperstraten AM, Kreuwel IA, Hermens RP, et al. Determinants of the choice for single or double embryo transfer in twin prone couples. Acta Obstetricia et Gynecologica Scandinavica 2008; 87:226-31

40. Barry MJ. Shared decision making: informing and involving patients to do the right thing in health care. The Journal of Ambulatory Care Management 2012; 35:90-8

41. Dartmouth Atlas. A Dartmouth Atlas project topic brief preference-sensitive care. Lebanon: The Dartmouth Atlas of Health Care, 2007

42. Westert GP, Groenewegen PP, Lindenberg SM. De invloed van ziekenhuispatiënten op de duur van de hospitalisatie. Tijdschrift voor gezondheidswetenschappen 1991; 69:184-94

43. Hajjaj FM, Salek MS, Basra MK, et al. Non-clinical influences on clinical decisionmaking: a major challenge to evidence-based practice. Journal of the Royal Society of Medicine 2010; 103:178-87.

44. Kreuwel IA, Van Peperstraten AM, Hulscher ME, et al. Evaluation of an effective multifaceted implementation strategy for elective single-embryo transfer after in vitro fertilization. Human Reproduction 2013; 28:336-42

45. No authors listed. Prevention of twin pregnancies after IVF/ICSI by single embryo transfer. ESHRE Campus Course Report. Human Reproduction 2001; 16:790-800

46. Wolner-Hanssen $\mathrm{P}$, Rydhstroem $\mathrm{H}$. Cost-effectiveness analysis of in-vitro fertilization: estimated costs per successful pregnancy after transfer of one or two embryos. Human Reproduction 1998; 13:88-94 
47. Lukassen HG, Schönbeck $Y$, Adang EM, et al. Cost analysis of singleton versus twin pregnancies after in vitro fertilization. Fertility and Sterility 2004; 81:1240-6

48. Van Peperstraten AM, Hermens RP, Nelen WL, et al. Deciding how many embryos to transfer after in vitro fertilisation: development and pilot test of a decision aid. Patient Education \& Counseling 2010; 78:124-9

49. Elwyn G, O'Connor A, Stacey D, et al. Developing a quality criteria framework for patient decision aids: online international Delphi consensus process. The BMJ 2006; 333:417 


\section{Is there a conflict between general practitioners applying guidelines for antibiotic prescribing and including their patients' preferences?}

This article is published as:

Brabers AEM, Van Esch TEM, Groenewegen PP, Hek K, Mullenders P, Van Dijk L, De Jong JD. Is there a conflict between general practitioners applying guidelines for antibiotic prescribing and including their patients' preferences? Patient Preference and Adherence 2018; 12:9-19 https://doi.org/10.2147/PPA.S147616 


\begin{abstract}
Objectives

One perceived barrier to guideline adherence is the existence of conflicting patient preferences. We examined whether patient preferences influence the prescription of antibiotics in general practice, and how this affects guideline adherence. We hypothesised that preferences play a larger role in prescribing antibiotics if the guideline allows for preferences to be taken into account, i.e., if prescribing antibiotics is an option which can be considered rather than a clear recommendation to prescribe or not. We included three guidelines: acute cough, acute rhinosinusitis, and urinary tract infections.
\end{abstract}

\title{
Methods
}

Data from NIVEL (the Netherlands Institute for Health Services Research) Primary Care Database (NIVEL-PCD) were used to assess antibiotic indications and prescriptions. These data were combined with a questionnaire among members of NIVEL's Dutch Health Care Consumer Panel to examine patient preferences. According to NIVEL-PCD, 286 of these members contacted their general practitioner (GP) in 2015 for acute cough, acute rhinosinusitis or urinary tract infections. A logistic multilevel regression analysis was performed to test our hypothesis.

\section{Results}

Patient preferences do play a role in GPs' prescribing of antibiotics only in situations where, in accordance with the guideline, their use is an option which could be considered (interaction between indication and preference: $p=0.049$ ). If patients ask for antibiotics themselves in such situations, then GPs prescribe antibiotics more often.

\section{Conclusions}

Patient preferences only play a role if the guideline provides room to take preferences into account. Therefore, our results do not suggest a conflict between applying guidelines and including patient preferences. Further research is recommended to examine this possible conflict in other situations. 


\subsection{Introduction}

Clinical practice guidelines give recommendations about appropriate health care. As such they have the potential to reduce inappropriate practice variation, enhance the translation of research into practice, and maintain and improve health care quality and safety [1-4]. The extent to which physicians adhere to guidelines can be regarded as an indicator of the quality of care delivered [5]. Adherence to guidelines varies considerably, both between physicians and practices and between different guidelines [6-10]. One perceived barrier to adherence to guidelines, mentioned by physicians, is the existence of patient preferences [11]. Yet, another key indicator of good quality of care is providing care that is respectful of, and responsive to, an individual patient's preferences, needs, and values [12]. This requires that patient preferences are incorporated into the decision-making process.

In theory, the decision-making process involves physicians bringing in the recommendations of the guideline and the clinically relevant characteristics of their patients, while the patients bring in their preferences. In making medical decisions, there might, however, be a conflict between applying these guidelines and including patient preferences $[13,14]$.

An area where adherence to guidelines can be improved is in the prescription of antibiotics. Wide variations exist in the rates of antibiotic prescribing [15-17]. Inappropriate prescribing of antibiotics is directly related to higher rates of antimicrobial resistance [17-19]. This is now globally recognised as a major threat to human health $[20,21]$. The Netherlands, the setting of this study, has comparatively low and stable antibiotic use in primary care [17, 22]. Still, there are large variations among Dutch general practitioners (GPs) in the adherence to guidelines when prescribing antibiotics [7-9, 23]. These guidelines are developed by the Dutch College of General Practitioners (NHG). The NHG strives to ensure that its guidelines are widely accepted. This is encouraged by involving GPs in the development process (Box 6.1). This study focuses on the prescription of antibiotics by Dutch GPs for three conditions for which guidelines were published more than 10 years ago and which were recently updated: 1) acute cough, last version 2013; 2) acute rhinosinusitis, last version 2014; and 3) urinary tract infections, last version 2013. These guidelines were chosen for two reasons. Firstly, wide variations in antibiotic prescribing rates have been observed in the Netherlands for these 
conditions [24, 25]. Secondly, they involve different recommendations about the prescription of antibiotics. These recommendations range from an indication for antibiotics, to an "unsure" indication for antibiotics - that is that antibiotics may be considered by the GP - to no indication for antibiotics. For example, for both acute cough and rhinosinusitis antibiotics are generally not indicated in otherwise healthy patients, whereas antibiotics can be considered in vulnerable groups such as people aged over 75 . For healthy women with a urinary tract infection antibiotics may be considered, while antibiotics are always indicated for men with urinary tract infection. Extensive recommendations are shown in Table 6.1.

\section{Box 6.1 Procedure to develop guidelines for GPs in the Netherlands}

The Dutch College of General Practitioners (NHG) develops guidelines for GPs. It selects a topic for which a guideline should be formulated. A working group, mainly consisting of GPs, develops the guideline using a predetermined procedure. Comments are made about this concept guideline in two phases, one internal and one external round. After the guideline is revised, it is sent to the appropriate NHG committee for authorisation. As a final step, the NHG publishes the guideline on the NHG website and in the Dutch journal for GPs "Huisarts \& Wetenschap" [47]. The first guideline appeared in 1989 and around 100 guidelines for different diagnoses are currently available [48].

Table 6.1 Recommendations about the prescribing of antibiotics for the guidelines acute cough, acute rhinosinusitis, and urinary tract infections

\begin{tabular}{|c|c|c|c|}
\hline Guideline & $\begin{array}{c}\text { Acute cough, } \\
\text { last version } 2013^{49}\end{array}$ & $\begin{array}{l}\text { Acute rhinosinusitis, } \\
\text { last version } 2014^{50}\end{array}$ & $\begin{array}{l}\text { Urinary tract infections, } \\
\text { last version } 2013^{51}\end{array}$ \\
\hline $\begin{array}{l}\text { Diagnoses } \\
\text { (ICPC) }\end{array}$ & $\begin{array}{l}\text { Acute cough (R05), } \\
\text { Whooping cough (R71), } \\
\text { Laryngitis / tracheitis acute } \\
\text { (R77), Acute bronchitis / } \\
\text { bronchiolitis (R78) }\end{array}$ & $\begin{array}{l}\text { Sinus symptom / complaint } \\
\text { (R09), Upper respiratory } \\
\text { infection acute (R74), } \\
\text { Sinusitis acute / chronic } \\
\text { (R75) }\end{array}$ & $\begin{array}{l}\text { Dysuria / painful urination } \\
\text { (U01), Urinary frequency / } \\
\text { urgency (U02), Cystitis / } \\
\text { urinary tract infection (U71) }\end{array}$ \\
\hline $\begin{array}{l}\text { Antibiotics } \\
\text { recommen- } \\
\text { dations in } \\
\text { guideline }\end{array}$ & $\begin{array}{l}\text { No antibiotics if } \\
\text { pneumonia is not } \\
\text { considered likely. } \\
\text { Exceptions in which } \\
\text { antibiotics should be } \\
\text { considered are patients } \\
\text { with one or more risk } \\
\text { factors: } \\
\text { - Age }<3 \text { months or }>75 \\
\text { years } \\
\text { - Relevant comorbidity: }\end{array}$ & $\begin{array}{l}\text { In principle, no antibiotics. } \\
\text { Antibiotics are indicated in } \\
\text { patients who are seriously } \\
\text { ill. Antibiotics can be } \\
\text { considered in patients with } \\
\text { poor immune response: } \\
\text { - Chronic use of } \\
\text { corticosteroids or other } \\
\text { immunosuppressive } \\
\text { medicines } \\
\text { - HIV infection with a }\end{array}$ & $\begin{array}{l}\text { - Healthy women aged } 12 \\
\text { years and older who are } \\
\text { not pregnant: The GP [...] } \\
\text { discusses the possibility of } \\
\text { wait and see [...] and a } \\
\text { postponed antibiotics } \\
\text { prescription. } \\
\text { - Recurrent cystitis in } \\
\text { healthy women (12 years } \\
\text { and older) who are not } \\
\text { pregnant: [...] (three or }\end{array}$ \\
\hline
\end{tabular}




\begin{tabular}{|c|c|c|c|}
\hline Guideline & $\begin{array}{c}\text { Acute cough, } \\
\text { last version } \mathbf{2 0 1 3 ^ { 4 9 }}\end{array}$ & $\begin{array}{l}\text { Acute rhinosinusitis, } \\
\text { last version } 2014^{50}\end{array}$ & $\begin{array}{l}\text { Urinary tract infections, } \\
\text { last version } 2013^{51}\end{array}$ \\
\hline & $\begin{array}{l}\text { heart failure, severe } \\
\text { COPD, diabetes mellitus } \\
\text { (in particular when using } \\
\text { insulin), neurological } \\
\text { diseases, severe kidney } \\
\text { diseases. } \\
\text { - Poor immune response } \\
\text { CRP in adults: }<20 \mathrm{mg} / \mathrm{L} \\
\text { no indication for } \\
\text { antibiotics, } 20-100 \mathrm{mg} / \mathrm{L} \\
\text { indication for antibiotics } \\
\text { depends on the clinical } \\
\text { presentation, }>100 \mathrm{mg} / \mathrm{L} \\
\text { indication for antibiotics. }\end{array}$ & $\begin{array}{l}\text { reduced number of T- } \\
\text { cells } \\
\text { - Chemotherapy or } \\
\text { radiotherapy } \\
\text { - Immune disorders } \\
\text { - Frail elderly who are sick } \\
\text { - Patients with diabetes } \\
\text { mellitus } \\
\text { Antibiotics can be } \\
\text { considered for patients } \\
\text { who have had fever for } \\
\text { more than } 5 \text { days, or for } \\
\text { patients who have } \\
\text { recurrent fever after a few } \\
\text { fever-free days within one } \\
\text { episode of rhinosinusitis. }\end{array}$ & $\begin{array}{l}\text { more yearly) the following } \\
\text { options: self-treatment } \\
\text { with a postponed } \\
\text { antibiotics prescription, or } \\
\text { prophylactic treatment } \\
\text { with [...] continuous } \\
\text { antibiotic prophylaxis. } \\
\text { - Cystitis in risk groups: } \\
\text { Patients in risk groups } \\
\text { have an increased risk for } \\
\text { complications of cystitis. } \\
\text { In those patients, cystitis } \\
\text { should be treated with } \\
\text { antibiotics, in anticipation } \\
\text { of the test results. Risk } \\
\text { groups include: pregnant } \\
\text { women, men, patients } \\
\text { with diabetes mellitus, } \\
\text { patients with poor } \\
\text { immune response and } \\
\text { patients with } \\
\text { abnormalities of the } \\
\text { kidneys or urinary tract. } \\
\text { Urine tract infection with } \\
\text { signs of tissue invasion: } \\
\text { explain [...] that antibiotic } \\
\text { treatment is necessary. } \\
\text { [...] }\end{array}$ \\
\hline $\begin{array}{l}\text { Antibiotics not } \\
\text { indicated... }\end{array}$ & $\begin{array}{l}\text { in patients with cough } \\
\text { (R05, R77, R78) between } \\
18 \text { and } 75 \text { years, without } \\
\text { indications for poor } \\
\text { immune response }{ }^{a} \text {, with } \\
\text { CRP <20 and without } \\
\text { relevant comorbidity. }\end{array}$ & $\begin{array}{l}\text { in patients with sinus } \\
\text { complaints (R09, R74, R75) } \\
\text { without indications for } \\
\text { poor immune response. }\end{array}$ & $\begin{array}{l}\text { in patients with urinary } \\
\text { complaints (U01, U02). }\end{array}$ \\
\hline $\begin{array}{l}\text { Antibiotics can } \\
\text { be considered... }\end{array}$ & $\begin{array}{l}\text { in patients with cough } \\
\text { (R05, R77, R78) over } 75 \\
\text { years, or with indications } \\
\text { for poor immune response, } \\
\text { or with CRP > } 20 \text { or with } \\
\text { relevant comorbidity and } \\
\text { in patients with whooping } \\
\text { cough (R71). }\end{array}$ & $\begin{array}{l}\text { in patients with sinus } \\
\text { complaints (R09, R74, R75) } \\
\text { with an indication for poor } \\
\text { immune response. }\end{array}$ & $\begin{array}{l}\text { in healthy women, who are } \\
\text { not pregnant, with urinary } \\
\text { tract infection (U71) without } \\
\text { abnormalities of the kidneys } \\
\text { or urinary tract and without } \\
\text { indications for poor immune } \\
\text { response. }\end{array}$ \\
\hline
\end{tabular}




\begin{tabular}{|c|c|c|c|}
\hline Guideline & $\begin{array}{c}\text { Acute cough, } \\
\text { last version } \mathbf{2 0 1 3 ^ { 4 9 }}\end{array}$ & $\begin{array}{l}\text { Acute rhinosinusitis, } \\
\text { last version } 2014^{50}\end{array}$ & $\begin{array}{l}\text { Urinary tract infections, } \\
\text { last version } 2013^{51}\end{array}$ \\
\hline $\begin{array}{l}\text { Antibiotics are } \\
\text { indicated... }\end{array}$ & $\begin{array}{l}\text { in patients with cough } \\
\text { (R05, R77, R78) and CRP } \\
>100 \text {. }\end{array}$ & $\begin{array}{l}\text { in patients with sinus } \\
\text { complaints (R09, R74, R75) } \\
\text { and CRP >100. }\end{array}$ & $\begin{array}{l}\text { in patients with urine tract } \\
\text { infection (U71) who are } \\
\text { male, or pregnant, or have } \\
\text { abnormalities of the kidneys } \\
\text { or urinary tract, or } \\
\text { indications for poor immune } \\
\text { response. }\end{array}$ \\
\hline Remarks & $\begin{array}{l}\text { Not all measured CRP } \\
\text { values are recorded. CRP } \\
\text { limits for indications are } \\
\text { only applied if CRP values } \\
\text { were recorded. } \\
\text { Relevant comorbidity } \\
\text { includes: heart failure, } \\
\text { COPD, neurological } \\
\text { diseases and severe kidney } \\
\text { diseases. }\end{array}$ & $\begin{array}{l}\text { Being seriously ill and } \\
\text { having prolonged or } \\
\text { recurrent fever cannot be } \\
\text { retrieved from NIVEL } \\
\text { Primary Care Database and } \\
\text { are consequently not taken } \\
\text { into account. }\end{array}$ & $\begin{array}{l}\text { Signs of tissue invasion } \\
\text { cannot be retrieved from } \\
\text { NIVEL Primary Care } \\
\text { Database and are } \\
\text { consequently not taken into } \\
\text { account. No distinction } \\
\text { between a single bout of } \\
\text { cystitis or recurrent cystitis } \\
\text { is made, because in both } \\
\text { cases antibiotic can be } \\
\text { considered in healthy } \\
\text { women who are not } \\
\text { pregnant. }\end{array}$ \\
\hline
\end{tabular}

$\bar{a}$ Patients are considered as having a poor immune response if at least one of the following drugs were prescribed: corticosteroids (chronic use), cytostatic drugs, DMARDs, biologicals, anti-thyroid drugs, phenytoin, neuroleptics, antivirals for systemic use, or if at least one of the following diseases was recorded: HIV infection, cancer, diabetes mellitus, severe alcohol abuse, sickle cell disease, (functional) asplenic, severe renal insufficiency.

Patient expectations, as well as patient demand or "pressure", have been mentioned by GPs as major factors in the decision to prescribe antibiotics and are associated with increased antibiotic prescribing [26-30]. Patient expectations can be defined as the patient's perception of what their GP might do in a specific situation. Expectations differ from hoping for, or preferring, an antibiotic prescription and from explicitly expressing the hope, or preference, for an antibiotic - i.e., asking for an antibiotic prescription [30]. In addition, patients might explicitly express a preference not to be given a prescription for an antibiotic. Yet, few studies have examined the direct relationship between patient expectations or preferences on the one hand, and the GP's decision to prescribe antibiotics on the other [30]. For instance, Coenen et al. found that both patient expectation and hope were positively associated with antibiotic prescribing by GPs for acute cough [30]. The present study aims to examine further the relationship between patient preferences and the GP's decision to prescribe an antibiotic. By examining this, we 
aim to achieve further insight into the possible conflict between applying guidelines and including patient preferences in decision-making. We answer the following research question: Do patient preferences influence the GP's decision to prescribe antibiotics, and how does this affect adherence to guidelines by GPs? We hypothesise that patient preferences have a larger role in the GP's decision to prescribe an antibiotic if the guideline provides room to take patient preferences into account. In other words, if the prescribing of antibiotics is an option which can be considered - that is an "unsure" indication - rather than a clear recommendation to prescribe or not.

\subsection{Materials and methods}

\section{Study design}

To answer our research question, we used a combined set of data from the NIVEL (the Netherlands Institute for Health Services Research) Primary Care Database (NIVEL-PCD) and data from the Dutch Health Care Consumer Panel of NIVEL. Data from NIVEL-PCD were used to assess the GP's prescription of antibiotics. A questionnaire among members of the Dutch Health Care Consumer Panel of NIVEL was conducted in order to examine patient preferences for antibiotics. All the members of the consumer panel included are registered patients of 15 general practices which participate in the NIVEL-PCD. As such, we were able to combine, at the patient level, the GP's prescription of antibiotics with patient preferences for antibiotics.

\section{NIVEL PCD}

NIVEL-PCD collects, over time, data from the routine electronic health records of a large and dynamic pool of general practices across the Netherlands [31]. These data comprise information on consultations, morbidity, and prescriptions. Morbidity is registered using the International Classification of Primary Care version 1 (ICPC-codes) [32, 33] in constructed illness episodes [34]. Prescription data are classified according to the Anatomical Therapeutic and Chemical (ATC) classification. We used data from 2015.

\section{Dutch Health Care Consumer Panel}

The Dutch Health Care Consumer Panel aims to measure the attitude toward, and the knowledge of, health care as well as the expectations and experiences of health 
care among a cross-section of the Dutch population [35]. All 2,816 panel members selected for this study were recruited via the previously mentioned 15 general practices participating in the NIVEL-PCD. The panel members selected received a questionnaire about antibiotics early in March 2016. According to their previously stated preference, 1,069 panel members received a questionnaire by post and 1,747 through the internet. Panel members were free to answer the questions. They did not have to fill out all the questions; they were able to skip a question if they could not answer that specific question. One postal reminder (after 2 weeks) and two electronic reminders (after 1 and 2 weeks) were sent to panel members who had not yet responded. After 4 weeks, the questionnaire had been returned by 1,310 panel members (response rate $47 \%$ ).

\section{Data protection NIVEL-PCD and Dutch Health Care Consumer Panel}

Dutch law permits, under certain conditions, the use of extracts from electronic health records for research purposes. According to Dutch legislation, neither obtaining informed consent nor approval by a medical ethics committee is obligatory for this kind of observational study containing no directly identifiable data [36]. With respect to NIVEL-PCD, participating general practices were contractually obliged to inform their patients about their participation in the NIVELPCD, and to inform patients about the possibility of opting out if they objected to their data being included in the database. This study has been approved by the governance bodies applicable to the NIVEL-PCD under nr. NZR-00315.069. The data from the Dutch Health Care Consumer Panel are processed anonymously and the data collection is registered with the Dutch Data Protection Authority (nr. 1262949). In addition, a privacy regulation applies to the consumer panel in general, as well as for the recruitment of patients via general practices participating in the NIVEL-PCD. According to Dutch legislation, neither obtaining informed consent nor approval by a medical ethics committee is obligatory for carrying out research through the panel [36]. All panel members included in this study gave written informed consent to combine their answers from the questionnaires with the data about their use of health care, as registered by their GP participating in the NIVEL-PCD. For the present study, data from the NIVEL-PCD and the questionnaire were linked by an employee of NIVEL who is not working for either the NIVEL-PCD, or the Dutch Health Care Consumer Panel. In the resulting research file patients were marked with a random ID specific to the project in order to guarantee patients' privacy. 


\section{Study sample}

The study sample consisted of the respondents to the questionnaire, who contacted their GP in 2015 for acute cough, acute rhinosinusitis, or urinary tract infection according to the NIVEL-PCD (Table 6.1 shows the ICPC-codes which were included). If there were patients with multiple relevant episodes then one episode was selected randomly.

\section{Measurements}

\section{Antibiotics prescription (dependent variable)}

The prescription data from the NIVEL-PCD were used to determine whether or not antibiotics were prescribed by the GP for each episode of illness selected. All prescriptions from the ATC subgroup J01 (antibacterials for systemic use) were included and were assigned to illness episodes based on the prescription dates and prescription ICPCS. The variable "antibiotics prescription" was coded as $0=$ no prescription for antibiotics, $1=$ prescription for antibiotics.

\section{Antibiotics indication (independent variable)}

The NIVEL-PCD data were used to determine the indication for antibiotics. For each episode of illness selected, the indication for antibiotics was estimated according to the definitions in Table 6.1. Patients' age, sex, morbidity data, test results, and prescription data were used to estimate whether antibiotics were indicated, not indicated, or could be considered ("unsure" indication) for each illness episode. The variable "antibiotics indication" was coded as $0=$ an indication for antibiotics, $1=$ antibiotics could be considered ("unsure" indication), and $2=$ no indication for antibiotics.

\section{Patient preferences (independent variable)}

Patient preferences for antibiotics were assessed in the questionnaire of the consumer panel. We defined patient preferences as preferences that were explicitly expressed; that is asking for an antibiotic prescription. They were measured using the question: "When you contacted your GP regarding your [acute cough, acute rhinosinusitis, or urinary tract infection], did you ask the GP for a prescription for an antibiotic?" Answer options were: 1) not at all; 2) actually not; 3) actually, and; 4) totally. For patients who answered in the questionnaire that they had not contacted their GP in 2015 for acute cough, acute rhinosinusitis, or urinary tract infection, more general preferences were used. These were assessed using the question: "If you were to have an [acute cough, acute rhinosinusitis, or 
urinary tract infection] then to what extent would you be inclined to ask the GP for an antibiotic prescription?" The answer options were the same. The answer options were recoded into two categories "preference for antibiotics" (coded as 1, actually and totally) and "no preference for antibiotics" (coded as 0 , not at all and actually not).

\section{Statistical analyses}

In the first instance, descriptive statistics were performed in order to gain insight into patient preferences for antibiotics, the indication for antibiotics, and the GP's prescription of antibiotics. Secondly, a logistic multilevel regression analysis was performed in order to test the role of patient preferences in the GP's prescription of an antibiotic. The model contained two levels as the data are structured hierarchically, with patients nested in general practices. A multilevel analysis took into account the nested structure of the data as well as the differences in the number of patients per practice. We included the GP's prescription of antibiotics as a dependent variable, and patient preferences and indication for antibiotics as independent variables. To examine whether the role of patient preferences is modified by the indication for antibiotics, an interaction effect between patient preferences and indication was included in the model. In the multilevel analysis, categorical variables (such as the indication for antibiotics) were recoded into dummy variables. All analyses were performed using STATA, version 14.0.

\subsection{Results}

\section{Descriptive statistics}

According to data registered in the NIVEL-PCD, 286 respondents to the questionnaire contacted their GP in 2015 for acute cough (38\%, N=109), acute rhinosinusitis $(25 \%, \mathrm{~N}=72)$ or urinary tract infections $(37 \%, \mathrm{~N}=105)$ (Table 6.2$)$. The number of patients per practice ranged from $\mathrm{N}=5$ to $\mathrm{N}=44$ (data not shown). In half $(50 \%, N=144)$ of the cases prescribing antibiotics could be considered. In $17 \%$ $(\mathrm{N}=48)$ of the cases there was an indication for antibiotics, whereas there was no indication for antibiotics in 33\% ( $N=94)$ of the cases (Table 6.2$)$. In $42 \%(N=120)$ of the cases the GP did indeed prescribe antibiotics. Where there was an indication for antibiotics, the GP prescribed them in $81 \%(\mathrm{~N}=39)$ of the cases; if the indication for antibiotics was "unsure" - that is when antibiotics can be considered - then the GP prescribed them in $38 \%(N=55)$ of the cases. Where there was no indication for 
antibiotics, the GP prescribed them in $28 \%(\mathrm{~N}=26)$ of the cases (data not shown). One out of five $(21 \%, \mathrm{~N}=50)$ patients stated that they asked, or would ask, for an antibiotic prescription when contacting their GP (Table 6.2). In half of these cases (50\%, $N=25)$ the GP did indeed prescribe an antibiotic (data not shown).

Table 6.2 Results of descriptive statistics

\begin{tabular}{|c|c|c|c|c|}
\hline & Data source & $\mathbf{N}$ & $\mathbf{N}$ & $\%$ \\
\hline Number of patients who contacted their GP in 2015 for... & NIVEL-PCD & 286 & & \\
\hline acute cough & & & 109 & 38.1 \\
\hline acute rhinosinusitis & & & 72 & 25.2 \\
\hline urinary tract infections & & & 105 & 36.7 \\
\hline Antibiotics prescribed by GP & NIVEL-PCD & 286 & & \\
\hline yes & & & 120 & 42.0 \\
\hline no & & & 166 & 58.0 \\
\hline Indication for antibiotics ${ }^{a}$ & NIVEL-PCD & 286 & & \\
\hline yes & & & 48 & 16.7 \\
\hline 'unsure' (i.e., antibiotics can be considered) & & & 144 & 50.4 \\
\hline no & & & 94 & 32.9 \\
\hline Patient preference for antibiotics & Consumer Panel & 240 & & \\
\hline yes & & & 50 & 20.8 \\
\hline no & & & 190 & 79.2 \\
\hline
\end{tabular}

a Based on the recommendations in the three guidelines (see Table 6.1 for extensive recommendations).

\section{The role of patient preferences in the GP's prescription of antibiotics}

Table 6.3 shows that the indication for antibiotics is significantly associated with the GP's prescribing of them. GPs more often prescribe antibiotics in cases with an indication for antibiotics compared to cases in which antibiotics can be considered and in cases with no indication for antibiotics. No significant association was found between patient preferences and the GP's prescribing of antibiotics. However, the interaction effect between indication and patient preferences was significant $(p=0.049)$. The results indicate that the relationship between patient preferences and the GP's prescribing of antibiotics varies according to the indication for antibiotics. Patient preferences have a role in the GP's prescribing of antibiotics in situations where, according to the guideline, antibiotics can be considered; that is that there is an "unsure" indication. If in such situations patients ask for antibiotics then GPs will more often prescribe them. 
Table 6.3 Results of logistic multilevel regression analysis to examine the relationship between patient preferences and the GP's prescription of antibiotics $(N=240)$

\begin{tabular}{|c|c|c|c|}
\hline GP's prescription of antibiotics ( $1=\mathrm{Yes}, 0=\mathrm{No})$ & Odds Ratio & $95 \% \mathrm{Cl}$ & P-value \\
\hline \multicolumn{4}{|l|}{ Indication for antibiotics ${ }^{a}$} \\
\hline yes & Ref & Ref & Ref \\
\hline 'unsure' (i.e., antibiotics can be considered) & 0.067 & $0.018-0.245$ & 0.000 \\
\hline no & 0.053 & $0.014-0.203$ & 0.000 \\
\hline \multicolumn{4}{|l|}{ Patient preference for antibiotics } \\
\hline no & Ref & Ref & Ref \\
\hline yes & 0.401 & $0.067-2.411$ & 0.318 \\
\hline \multicolumn{4}{|l|}{$\begin{array}{l}\text { Patient preference for antibiotics \# Indication for } \\
\text { antibiotics }\end{array}$} \\
\hline preference no \& indication yes & Ref & Ref & Ref \\
\hline preference yes \& indication 'unsure' & 7.696 & $1.009-58.679$ & 0.049 \\
\hline preference yes \& indication no & 0.973 & $0.087-10.851$ & 0.982 \\
\hline Constant & 7.558 & $2.224-25.683$ & 0.001 \\
\hline
\end{tabular}

\subsection{Discussion}

This study sought to achieve insight into the potential conflict in making medical decisions regarding the prescription of antibiotics by GPs. On the one hand GPs should apply the guidelines and on the other include their patient preferences. Our results show that there is no real conflict. The reason for this is that in cases where the guideline provides a clear recommendation to prescribe or not, we did not find a significant relationship between patient preferences and the GP's decision to prescribe antibiotics. Patient preferences appear only to play a role in the GP's decision if prescribing an antibiotic was an option that could be considered. However, in those situations there is no conflict between applying the guidelines and including patient preferences. In such situations, antibiotics are justified since the guideline provides room for taking patient preferences into account.

This study has been performed in the Netherlands, a country with comparatively low and stable antibiotic use in primary care [17, 22]. Furthermore, around nine out of ten Dutch people agree that bacteria can become less susceptible (resistant) to antibiotics [37] and that prescribing antibiotics for minor ailments is not necessary [24]. It might be that in countries with a higher antibiotic use, patient 
preferences do play a role in the GP's decision to prescribe antibiotics, even if the guideline provides a clear recommendation not to prescribe them. Moreover, this study focused on just one type of decision: the prescription of antibiotics by GPs. Further research is recommended into whether, in other situations, there is a conflict between applying the guidelines and including patient preferences. Patient preferences may play a role in the failure to adhere to guidelines in other situations.

Although including patient preferences in medical decision-making is regarded as an indicator of good quality of care [12], it could be questioned whether patient preferences have to play a role in all situations. In some situations, there is one treatment, which on the basis of reasonably sound medical evidence is known to work better than any alternative, and for which the benefits of treatment exceed the side effects or unintended consequences (i.e., effective care). As such, in general, all eligible patients have to receive that treatment [38]. It has to be recognised, however, that also in situations of effective care patients have a choice, even if it is not wanting treatment. An example of effective care in the context of this study is that antibiotics are always indicated for men in the case of urinary tract infections (Table 6.1) and thus, in general, they have to receive an antibiotic prescription.

Preferences are more likely to play a role if there is no absolute best treatment option. For this so-called preference-sensitive care the right treatment for an individual patient should depend on the patient's preference [38]. An example in the context of this study is that antibiotics can be considered for otherwise healthy women with urinary tract infections who are not pregnant (Table 6.1). In the case of preference-sensitive care, however, professional judgments rather than patients' own preferences often determine which treatment a patient receives. The reason for this is that patients often delegate medical decision-making to their physician [38]. Also, in the context of antibiotics, it has been argued that clinicians, on their own, do not know whether or not antibiotics are best for individual patients; clinicians commonly misinterpret patients' expectations of antibiotic treatment [39]. An approach which promotes the uptake of patient preferences in the decision-making process, is shared decision-making (SDM). Here, physicians and patients make decisions together using the best available evidence. Patients are helped to make informed choices by considering each option and its possible benefits and disadvantages $[40,41]$. Well-informed patients are known to prefer 
more conservative treatment options [42]. In the context of this study, this would mean not using antibiotics. SDM has been recognised as a framework for enhancing the appropriate use of antibiotics and hence for controlling resistance to antibiotics [39, 43]. Research showed that SDM reduces antibiotic prescribing rates for acute respiratory infections in primary care [44]. Furthermore, it has been reasoned that SDM results in fewer inappropriate demands for antibiotics in the future [43].

A strength of this study is that we combined data about patient preferences for antibiotics and the GP's prescription of antibiotics at the level of the patient. Moreover, we could individually estimate the indication for antibiotics using the NIVEL-PCD. We only found one other study which directly combined patient views about antibiotics with the antibiotic prescribing behaviour of GPs [30]. Coenen et al collected data in 13 different European countries and found that a patient's expectations and hopes were positively associated with antibiotic prescribing by GPs for acute cough. They did not find an association with asking for antibiotics [30]. However, they focused solely on acute cough and did not examine whether the role of the patient's views differed according to the indication for antibiotics. Another strength is that we took into account the nested structure of our data by performing a multilevel analysis. However, from the data set, it was only possible to know at which general practice a patient had a consultation, but not with which GP within that general practice. Earlier research shows that Dutch GPs working in the same practice show more similarity in their attitudes and behaviour than GPs who do not work in the same practice [45]. Therefore, we do not expect this to affect our conclusions. Although we had a large sample size $(N=1,310)$, a potential limitation is the relatively low response rate of $47 \%$. A multidisciplinary research team including experts in the field of antibiotics developed the questionnaire. The draft questionnaire was also commented upon by the program committee of the Dutch Health Care Consumer Panel, consisting of representatives of different actors in the health care sector, including the Dutch Ministry of Health, Welfare and Sport, the Dutch Consumers Association, and the Dutch Health Care Inspectorate. Nevertheless, a limitation is that the questionnaire has not been tested in a pilot study among panel members. It is therefore debatable whether all questions and answer options were sufficiently clear for the panel members. Another limitation of the present study is the recall bias of the respondents to the questionnaire. Not all respondents answered in the questionnaire that they had contacted their GP in 2015 for acute cough, acute rhinosinusitis or urinary tract infections. As such, for 
this part $(\mathrm{N}=149)$, the patients' preference, in general, for antibiotics was used. Furthermore, if patients remember that they had contacted their GP, we do not know whether this necessarily refers to the same contact as that in the NIVEL-PCD. Another limitation is that we defined preferences as those preferences which were expressed explicitly; that is asking for an antibiotic prescription. We did not consider preferences which were not explicitly expressed, nor the option to state to prefer not to have an antibiotic prescription. In addition, we did not study whether groups of patients differ in their preferences for antibiotics. It can be reasoned that patients differ in their ability to ask their physician for an antibiotic prescription [46]. Further research is recommended to examine possible differences between groups of patients.

The results of this study do not suggest a conflict between applying guidelines and including patient preferences in medical decision making in the case of antibiotics prescribing by Dutch GPs. Further research is recommended to examine whether this conflict exists in other decision-making situations. 


\section{References}

1. Graham R, Mancher M, Wolman DM, Greenfield S, Steinberg E. Clinical practice guidelines we can trust: National Academies Press, 2011

2. Grimshaw JM, Russell IT. Effect of clinical guidelines on medical practice: a systematic review of rigorous evaluations. The Lancet 1993; 342(8883):1317-22

3. Woolf SH, Grol R, Hutchinson A, Eccles M, Grimshaw J. Clinical guidelines: potential benefits, limitations, and harms of clinical guidelines. The BMJ 1999; 318(7182):527-30

4. Grilli R, Magrini N, Penna A, Mura G, Liberati A. Practice guidelines developed by specialty societies: the need for a critical appraisal. The Lancet 2000; 355(9198):103-6

5. Mainz J. Defining and classifying clinical indicators for quality improvement. International Journal for Quality in Health Care 2003; 15(6):523-30

6. De Jong JD, Groenewegen PP, Spreeuwenberg P, Schellevis F, Westert GP. Do guidelines create uniformity in medical practice? Social Science \& Medicine 2010; 70(2):209-16

7. Van Dijk L, De Jong JD, Westert GP, de Bakker DH. Variation in formulary adherence in general practice over time (2003-2007). Family Practice 2011; 28(6):624-31

8. Ivanovska V, Hek K, Mantel Teeuwisse AK, et al. Antibiotic prescribing for children in primary care and adherence to treatment guidelines. Journal of Antimicrobial Chemotherapy 2016; 71(6):1707-14

9. Braspenning J, Schellevis F, Grol R. Tweede Nationale Studie naar ziekten en verrichtingen in de huisartspraktijk: kwaliteit huisartsenzorg belicht. Utrecht/ Nijmegen: NIVEL/ WOK, 2004

10. Van den Berg MJ, De Bakker DH, Spreeuwenberg P, et al. Labour intensity of guidelines may have a greater effect on adherence than GPs' workload. BMC Family Practice 2009; 10(1):74

11. Lugtenberg M, Burgers JS, Besters CF, Han D, Westert GP. Perceived barriers to guideline adherence: a survey among general practitioners. BMC Family Practice 2011; $12: 98$ 
12. Institute of Medicine. Crossing the quality chasm: A new health system for the 21st century: National Academies Press, 2001

13. Greer AL, Goodwin JS, Freeman JL, Wu ZH. Bringing the patient back in. Guidelines, practice variations, and the social context of medical practice. International Journal of Technology Assessment in Health Care 2002; 18(4):747-61

14. Krahn M, Naglie G. The next step in guideline development: incorporating patient preferences. JAMA 2008; 300(4):436-8

15. Butler CC, Hood K, Verheij T, et al. Variation in antibiotic prescribing and its impact on recovery in patients with acute cough in primary care: prospective study in 13 countries. The BMJ 2009; 338:b2242

16. Cordoba G, Siersma V, Lopez-Valcarcel B, et al. Prescribing style and variation in antibiotic prescriptions for sore throat: cross-sectional study across six countries. BMC Family Practice 2015; 16(1):7

17. Goossens H, Ferech M, Van der Stichele R, Elseviers M, ESAC Project Group. Outpatient antibiotic use in Europe and association with resistance: a cross-national database study. The Lancet 2005; 365(9459):579-87

18. Van Bijnen EM, Paget J, de Lange-de Klerk ES, et al. Antibiotic Exposure and Other Risk Factors for Antimicrobial Resistance in Nasal Commensal Staphylococcus aureus: An Ecological Study in 8 European Countries. PLoS One 2015; 10(8):e0135094

19. Riedel S, Beekmann SE, Heilmann KP, et al. Antimicrobial use in Europe and antimicrobial resistance in Streptococcus pneumoniae. European Journal of Clinical Microbiology \& Infectious Diseases 2007; 26(7):485-90

20. WHO. Antimicrobial resistance: 2014 global report on surveillance: World Health Organization, 2014

21. Cecchini M, Langer J, Slawomirski L. Antimicrobial Resistance in G7 Countries and Beyond: Economic Issues, Policies and Options for Action. Paris: Organization for Economic Co-operation and Development 2015

22. Adriaenssens N, Coenen S, Versporten A, et al. European Surveillance of Antimicrobial Consumption (ESAC): outpatient antibiotic use in Europe (1997-2009). Journal of Antimicrobial Chemotherapy 2011; 66(suppl 6):vi3-vi12 
23. Van Bergeijk $H$, Berger $M$. Behandeling van urineweginfecties binnen en buiten praktijkuren. Huisarts en wetenschap 2008; 51(9):430-34

24. Van Esch T, Mullenders P, Brabers A, Hek K, De Jong J. De rol van patiënten bij het afwijken van richtlijnen door huisartsen: een onderzoek naar het voorschrijven van antibiotica. Utrecht: NIVEL, 2016

25. Van Esch T, Van Dijk L, Weesie Y, et al. Antibioticagebruik bij luchtweginfecties in de eerste lijn. Utrecht: NIVEL, 2016

26. Coenen S, Michiels B, Renard D, Denekens J, Van Royen P. Antibiotic prescribing for acute cough: the effect of perceived patient demand. British Journal of General Practice 2006; 56(524):183-90

27. Butler CC, Rollnick S, Pill R, Maggs-Rapport F, Stott N. Understanding the culture of prescribing: qualitative study of general practitioners' and patients' perceptions of antibiotics for sore throats. The BMJ 1998; 317(7159):637-42

28. Macfarlane J, Holmes W, Macfarlane R, Britten N. Influence of patients' expectations on antibiotic management of acute lower respiratory tract illness in general practice: questionnaire study. The BMJ 1997; 315(7117):1211-14

29. Britten $N$, Ukoumunne $\mathrm{O}$. The influence of patients' hopes of receiving a prescription on doctors' perceptions and the decision to prescribe: a questionnaire survey. The BMJ 1997; 315(7121):1506-10

30. Coenen $S$, Francis $N$, Kelly $M$, et al. Are patient views about antibiotics related to clinician perceptions, management and outcome? A multi-country study in outpatients with acute cough. PLoS One 2013; 8(10):e76691

31. NIVEL. NIVEL Primary Care Database. Utrecht. Available at: http://www.nivel.nl/ en/nivel-primary-care-database (3 November, 2016, date last accessed)

32. Hofmans-Okkes I, Lamberts H. The International Classification of Primary Care (ICPC): new applications in research and computer-based patient records in family practice. Family Practice 1996; 13(3):294-302

33. Lambert H, Woods M. The International Classification of Primary Care (ICPC): Oxford: Oxford University Press, 1987 
34. Nielen $M$, Spronk I, Davids $R$ et al. A new method for estimating morbidity rates based on routine electronic medical records in primary care. In: Abstractbook 21st WONCA Europe Conference 15-18 juni 2016, Kopenhagen; 2016

35. Brabers A, Reitsma-Van Rooijen M, De Jong J. Consumentenpanel Gezondheidszorg: Basisrapport met informatie over het panel (2015). Utrecht: NIVEL, 2015

36. CCMO. Your research: does it fall under the WMO? The Hague. Available at: http://www.ccmo.nl/en/your-research-does-it-fall-under-the-wmo (26 August, 2015, date last accessed)

37. Cals JW, Boumans D, Lardinois RJ, et al. Public beliefs on antibiotics and respiratory tract infections: an internet-based questionnaire study. British Journal of General Practice 2007; 57(545):942-7

38. Wennberg JE. Tracking medicine: a researcher's quest to understand health care: Oxford University Press, 2010

39. Butler CC, Kinnersley $\mathrm{P}$, Prout $\mathrm{H}$, et al. Antibiotics and shared decision-making in primary care. Journal of Antimicrobial Chemotherapy 2001; 48(3):435-40.

40. Elwyn G, Laitner S, Coulter A, et al. Implementing shared decision making in the NHS. The BMJ 2010; 341:c5146

41. Elwyn G, Frosch D, Thomson R, et al. Shared decision making: a model for clinical practice. Journal of General Intern Medicine 2012; 27(10):1361-7

42. Stacey $\mathrm{D}$, Bennett $\mathrm{CL}$, Barry MJ, et al. Decision aids for people facing health treatment or screening decisions. The Cochrane Database of Systematic Reviews 2011; (10):Cd001431

43. Davey P, Pagliari C, Hayes A. The patient's role in the spread and control of bacterial resistance to antibiotics. Clinical Microbiology and Infection 2002;8 Suppl 2:43-68

44. Coxeter P, Del Mar CB, McGregor L, Beller EM, Hoffmann TC. Interventions to facilitate shared decision making to address antibiotic use for acute respiratory infections in primary care. The Cochrane Database of Systematic Reviews 2015; (11):Cd010907

45. De Jong JD, Groenewegen PP, Westert GP. Mutual influences of general practitioners in partnerships. Social Science \& Medicine 2003; 57(8):1515-24 
46. Hajjaj FM, Salek MS, Basra MK, et al. Non-clinical influences on clinical decisionmaking: a major challenge to evidence-based practice. Journal of the Royal Society of Medicine 2010; 103:178-87.

47. NHG. Handleiding. Ontwikkelen van NHG-Standaarden. Utrecht: NHG, 2015

48. NHG. Richtlijnen en praktijk (guidelines and practice). Available at: https://www.nhg. org/richtlijnen-praktijk (20 October, 2016, date last accessed)

49. Nederlands huisartsen genootschap. Acuut hoesten. [Acute coughing]. Available at: https://www.nhg.org/standaarden/samenvatting/acuut-hoesten (5 December, 2017, date last accessed)

50. Nederlands huisartsen genootschap. Acuut rhinosinusitis. [Acute rhinosinusitis]. Available at: https://www.nhg.org/standaarden/samenvatting/acute-rhinosinusitis (5 December, 2017, date last accessed)

51. Nederlands huisartsen genootschap. Urineweginfecties. [Urinary tract infections]. Available at: https://www.nhg.org/standaarden/samenvatting/urineweginfecties (5 December, 2017, date last accessed) 
7

General discussion 


\subsection{Introduction}

The role of patients is largely ignored in theories about variation [1]. Variation is explained in current research by focussing mainly on physicians and the organisations they work in [2]. This approach might be adequate in cases where physicians are the dominant actor deciding on the treatment. In the past decades, however, this paternalistic model has become questioned. In parallel, there is an increased emphasis towards including patients and their preferences in medical decision-making [3, 4]. Moreover, providing care that is respectful of, and responsive to, an individual patient's preferences is regarded as one aspect of a good quality of care [5]. Since medical decision-making is a decisive factor for practice variation, this raises the question of whether patients can be ignored in theories about variation. This question was the central subject of this thesis. In order to gain insight into this subject, we examined under which circumstances the interaction between physician and patient is not dominated by the physician. We explored several mechanisms explaining patient involvement in medical decisionmaking. We examined, too, how this involvement influences medical decisionmaking, and thus practice variation. It has been suggested that patient involvement, and more specifically shared decision-making (SDM), decreases variation [6-10]. However, empirical data showing this was lacking.

The two research questions addressed in this thesis were:

1. Which mechanisms explain differences in patient involvement in medical decision-making?

2. How does patient involvement, and more specifically shared decision-making, influence medical practice variation?

\section{An outline of this chapter}

This chapter starts by providing answers to the research questions addressed in this thesis. Next, several overarching methodological problems are discussed. After that, we place our findings in a broader context and mention several recommendations for further research. We also highlight several implications of our findings. This chapter ends with an overall conclusion. 


\subsection{Answers to the research questions}

\section{Which mechanisms explain differences in patient involvement in medical decision-making?}

Firstly, we examined under which circumstances the physician-patient interaction is not dominated by the physician. It is only if patients share medical decision-making with their physician that they should be modelled as actors in theories about variation. Previous studies have shown that there is variation in patient involvement in medical decision-making [e.g. 11]. However, no clear explanation for this observed variation has been given. We therefore examined three mechanisms, both at the micro (patient) and the meso (social context) level, which may explain patient involvement in medical decision-making. These were: 1 ) health literacy, 2) social support, and 3) social norms. We found that these three mechanisms are all associated with patient involvement in medical decisionmaking. Our results suggest that, in general, high critical health literacy, the availability of medical informational support, and non-conservative social norms are positively related to patient involvement in medical decision-making. As such, patients have to be modelled as actors in theories about variation.

\section{Health literacy}

Health literacy can be considered as a resource that is integrated into people's daily lives and includes information and decision-making skills which are necessary in a range of different contexts [12]. We hypothesised that people with higher health literacy are more involved in medical decision-making (hypothesis 1, Table 7.1). This is because we can assume these people are better able to obtain, understand, appraise, and apply information required for medical decision-making. However, we only found that the higher respondents scored on the health literacy scale 'appraisal of health information', the more they reported being involved in medical decision-making. As such, hypothesis 1 is only partly confirmed (see Table 7.1). Our results suggest that higher order competences, that is to say 'critical' health literacy, appear to be more relevant for reporting involvement in medical decisionmaking than functional competences, such as a basic knowledge of reading and writing [13, 14], and communicative/interactive competences, such as more advanced cognitive and literacy skills which can be used in everyday activities and to apply new information to changing circumstances [13, 14]. 'Information appraisal' is one component of critical health literacy. It refers to cognitive skills in managing and interpreting information, as well as to assessing the personal 
relevance of information [15]. In the context of this thesis, it appears that in order to be involved in medical decision-making, patients have to be able to interpret information and weigh this information against their own preferences.

\section{Social support}

Our findings also imply that the decision to be involved in medical decision-making is not as individual as it first seems; someone's social context also plays a role. Firstly, we found that someone's social context can enhance involvement by providing social support. One reason for patients to leave medical decision-making to their physician is the information asymmetry between them and the physician [16]. Patients believe that medical decision-making requires knowledge they do not have [17]. We hypothesised that getting informational support from others may compensate for this lack of knowledge (hypothesis 2, Table 7.1). We found that people to whom more medical informational support is available, that is knowing people who are medical professionals (general practitioner, medical specialist, or nurse), are more positive towards taking an active role in medical decision-making. An explanation for this might be that they are able to contact someone who is a medical professional within their network more easily and thus seek medical information necessary for decision-making. On the other hand, we found no relationship between the availability of lay informational support, that is having lay people in your network to seek information from, and taking an active role in decision-making. Another reason to delegate decision-making to the physician is that people who are ill feel vulnerable and therefore do not want to, or cannot, take a decision [18, 19]. We hypothesised that emotional support, in the form of having someone to take with you to a medical consultation, can compensate for this (hypothesis 2, Table 7.1). Patients are expected to feel less vulnerable when receiving emotional support as it has been suggested that patients feel more confident when a companion is present [20]. We found, however, that it was only with regard to people who are low educated that the availability of emotional support was positively related to the attitude towards taking an active role. Also, we found that irrespective of the level of emotional support available, people with a middle and high level of education have a more positive attitude towards taking an active role in decision-making. In conclusion, our results showed that social support does play a role in patient involvement, however, not all forms of support play a role in all groups of patients. As such, hypothesis 2 is only partly confirmed (see Table 7.1). 


\section{Social norms}

We also found that someone's social context can enhance as well as impair involvement due to the social norms that apply. Social norms define what actions are regarded as normal by a group of people and what actions are regarded as deviant [21]. We distinguished two norms. These were: 1) the subjective norm, that is doing what others think one ought to do, and 2) the descriptive norm, that is doing what others do [22]. For both norms, we hypothesised that the more it is common in someone's social context to leave decisions to a physician, the less someone is involved in medical decision-making (hypothesis 3, Table 7.1). The reason for this is that we expected that people will behave according to the norms of their social environment, as this will result in social approval. Our results confirmed hypothesis 3 . With regards to the subjective norm, our findings showed that the more a person thinks that, according to significant others, he or she has to leave decisions to the physician, the less that person reports being involved in medical decision-making. The same was found for the descriptive norm. The more people think that significant others will leave decisions to the physician, the less they report being involved in medical decision-making.

\section{How does patient involvement, and more specifically shared decision-making, influence medical practice variation?}

Treatment decisions may change as a result of patient involvement in medical decision-making. The reason for this is that patients' preferences for treatment may differ from physicians' judgements [23]. Medical decision-making is decisive for variation, therefore patterns of variation may also change through patient involvement. It has been hypothesised that patient involvement, and more specifically SDM, decreases practice variation [6-10]. However, empirical data confirming a decrease was lacking. We aimed, therefore, to examine how patient involvement, and more specifically SDM, influences medical practice variation. The findings of this thesis showed that patients taking an active role in the decisionmaking process influence the decision taken, and thus the variation.

Firstly, we found, based on a limited data set in one decision-making situation in obstetrics, that SDM reduces variation. We hypothesised that SDM is associated with less variation between units such as hospitals, as we expected that, due to SDM, a more conservative treatment option will be chosen in units where physicians already prefer the more conservative option, as well as in units where physicians prefer the invasive option. This is because informed patients prefer the 
more conservative option. Our study looked at the choice of a single embryo transfer (SET) or double embryo transfer (DET) after in vitro fertilisation. Here, we found large variation in the choice of SET or DET between hospitals in the control group, while less variation was found between hospitals in the group with a strategy to promote SDM. As such, hypothesis 4 is confirmed (see Table 7.1). In addition to this, we found that within most hospitals the variation in the choice of SET or DET appeared to increase due to a strategy to promote SDM. While in other hospitals the variation in the choice of SET or DET decreased, or remained equal. This can be explained by the fact that the level of variation without SDM differed between the hospitals. For instance, in several of the hospitals we studied, DET was the main preference and as such there was almost no variation. However, SET was chosen more often due to a strategy to promote SDM and the variation thus increased in these hospitals as now both DET and SET are chosen. An implication of our results is that an overall decrease in variation between hospitals gives no indication about the change in variation within an individual hospital.

Secondly, we found that two mechanisms, guidelines and patient involvement, that both have the potential to decrease practice variation do not have to conflict with each other. On the one hand, physicians are expected to apply guidelines, and on the other they should include the preferences of their patients. This raises the question of whether, in making decisions, there will be a conflict. We hypothesised that patient preferences have a larger role in decision-making if the guideline provides room to take patient preferences into account (hypothesis 5, Table 7.1). Or, in other words, if the guideline provides an option for treatment which can be considered rather than a clear recommendation for a specific treatment or not. In our study about the prescribing of antibiotics in general practice, we found that patient preferences appear only to play a role in the decision if prescribing an antibiotic was an option that could be considered. In those situations there is no conflict between applying the guidelines and including patient preferences. The reason for this is that, in such situations, antibiotics are justified as the guideline provides room for taking patient preferences into account. As such, hypothesis 5 was confirmed (see Table 7.1). In our study, we were not able to link these results to variation in the prescribing of antibiotics between general practices because of the small number of general practices included in our sample. However, medical decision-making is a decisive factor for practice variation and patient preferences appear to play a role in the decision if prescribing an antibiotic was an option that could be considered. Thus, it can be reasoned that this will result in another 
pattern of variation between practices. Further research has to examine whether the inclusion of patient preferences indeed results in another pattern of variation.

Table 7.1 Hypotheses tested in this thesis and their test results

\begin{tabular}{lll}
\hline Hypothesis tested & Chapter & Test result \\
\hline H1: & Chapter 2 & Partly confirmed \\
People with higher health literacy are more involved in & \\
medical decision-making. & \\
H2: & \\
The more informational and emotional support people have available & Chapter 3 & Partly confirmed \\
in their social network, the more they are involved in medical & \\
decision-making. & \\
H3: & \\
The more common it is in someone's social context to leave the & Chapter 4 & Confirmed \\
decision to a physician, the less someone is involved in medical & \\
decision-making. & \\
H4: & \\
SDM reduces variation in medical treatment between units & \\
(e.g. hospitals). & Chapter 5 & Confirmed \\
H5: & & \\
$\begin{array}{l}\text { Patient preferences have a larger role in medical decision-making if } \\
\text { the guideline provides room to take patient preferences into account. }\end{array}$ & Chapter 6 & Confirmed \\
\hline
\end{tabular}

\subsection{Methodological problems}

This thesis consists of five different studies. The strengths and weaknesses of every study have already been discussed. Within this section several overarching methodological problems will be discussed. These are the problems of: 1) selectivity, 2) using self-reported behaviour instead of actual behaviour, and 3) having access to a limited data set focusing on one decision-making situation.

\section{Selectivity}

All three studies in the first part of this thesis are based on data collected through NIVEL's Dutch Health Care Consumer Panel (see [24] for more information). The Consumer Panel is a so-called access panel, which consists of a large number of people who have agreed to answer questions on a regular basis. As of August 2017, the Consumer Panel consisted of approximately 12,000 people aged 18 years and 
older. The use of an access panel usually generates a large sample size and high response rate. However, the degree to which the results are applicable to the general population in the Netherlands aged 18 years and older may be problematic. By comparison with this population, people aged 65 years and older were overrepresented in all three studies [24]. However, we do not expect this to affect our results as we tested associations in the three studies by using subgroups of sufficient size.

In addition, it can be argued that members of a health care panel are more interested in health care, and for instance, are more likely to be involved in medical decision-making. To minimise this bias, people are not allowed to sign up for the Consumer Panel on their own initiative. Possible new panel members are recruited in two ways. Firstly, we buy an address file from an address supplier. In this way, potential new panel members are sampled at random from the general population in the Netherlands. Secondly, we recruit potential new panel members via general practices participating in the NIVEL Primary Care Database. Nevertheless, it can be argued that people who are more interested in health care are more likely to respond when they are invited to join the panel. Moreover, it can be reasoned that people with low, or very low, levels of health literacy will not participate in a health care panel due to the nature of collecting data through written questionnaires. Our findings in Chapter 2 support this, as we found that, except for the appraisal of health information, the respondents scored relatively well on the other health literacy scales we included, such as being able to understand health information well enough. This might also be an explanation for the fact that, in Chapter 2, we only observed a relationship between critical health literacy and involvement and not between functional and communicative/interactive health literacy and involvement. However, such response biases are expected to apply to other written questionnaire studies conducted outside of an access panel as well.

\section{Self-reported behaviour instead of actual behaviour}

Another problem is that we examined self-reported patient involvement instead of actual behaviour in part $A$ of this thesis. In the questionnaires, we did not refer to a specific treatment decision, but asked about involvement in general. It remains unclear from these studies whether people actually participate in the medical decision-making process in real life. Earlier research already showed that the type of care people have to decide upon has an impact upon the importance they attach to SDM, as well as upon their involvement in the decision-making process [25]. On 
the other hand, using self-reported involvement in medical decision-making as an outcome might also be a strength, as this gives insight into how people themselves experience their involvement. In addition, the physicians' role in the decisionmaking process was not included in part $A$ of this thesis. To resolve these problems, medical decision-making has to be studied in practice.

\section{A limited data set focusing on one decision-making situation}

Both studies in part B of this thesis are based on a limited data set focusing on just one decision-making situation. This is the choice of a single or double embryo transfer after in vitro fertilisation in Chapter 5 , and the prescribing of antibiotics in general practice in Chapter 6 . However, the data sets we used were the best we had at our disposal and were helpful in gaining insight into our research questions. Nevertheless, a problem might be the extent to which our findings are applicable to other decision-making situations. Further research has to confirm our results in other decision-making contexts, preferably by making use of larger data sets.

\subsection{Broader context of our results}

Variation in medical practice is in itself not a bad thing, as without practice variation there may not be any advancement in health care [26]. The problem is, however, that it is unclear what is behind variation in medical practice as physicians are not able to clarify why there is variation. For policy makers and health insurance companies, practice variation is a sign of physicians using unnecessary treatments [26]. For patients, practice variation gives, at least in theory, the possibility of choosing a physician based on their treatment preferences [26]. However, in general, as stated by Richards et al. (2013), "patients lack information on practice variation, the effectiveness of their care, and the extent of medical uncertainty" [27 p1].

The existence of variation in medical practice was, besides the growing health care costs, one of the motives for the development of guidelines [28]. Guidelines provide recommendations about appropriate health care, and are able, potentially, to decrease inappropriate practice variation [29-31]. In the past decades, they have been a cornerstone in the support of professional decision-making and have come to play a key role in clinical practice [32]. Furthermore, the extent to which physicians adhere to guidelines is considered as an indicator of the quality of care 
delivered [33]. However, although guidelines may influence physicians' behaviour, there is no empirical evidence confirming whether they reduce practice variation [28].

In parallel with the use of guidelines, there was a growing awareness that medical decision-making does not lie solely with the physicians [32]. And yet individual patients might not receive a treatment that accompanies their personal situation and preferences without having information on practice variation and with the physician being the dominant actor who decides upon the treatment. In order for patients to receive their preferred treatment, they have to be involved in decisions about their health [4]. Including patients in decision-making is especially important in the case of preference sensitive care. This is care about which there is a high level of uncertainty because the clinical evidence does not clearly support one treatment option and where choice of treatment should depend on patient preferences [34]. Moreover, providing care that is respectful of, and responsive to, the preferences, needs and values of an individual patient is regarded as one of the key elements of good quality of care [5].

SDM is an approach which promotes the involvement of patients and their preferences in medical decision-making. Both the physician and the patient take decisions together taking into account the best available evidence and the preferences of the patient $[35,36]$. Both in the Netherlands, the context of this thesis, but also in other countries, SDM is on the agenda of policy makers, professional bodies, patient representative groups, and health insurers $[37,38]$. Van der Weijden et al. (2017) argue that there is a strong patient participation movement at both the macro and the meso level in the Netherlands, however, there is room for improvement in daily practice, in other words at the micro level [38]. The findings of this thesis provide some directions which might help to improve SDM in daily practice. Previous studies have shown that there are differences between groups of people in their degree of involvement in medical decisions. However, no clear explanation for this observed variation was given by these studies. This thesis aimed to try to close this gap in the knowledge by showing that mechanisms at both the micro and the meso level explain patient involvement in medical decision-making. Firstly, our results suggest that to take up an active role, patients need to have access to information, for instance from people within their social network who are medical professionals. But in addition to this, they also have to be able to interpret this information and weigh this 
information against their own preferences. This is what is meant by critical health literacy. For policy and practice, it is recommended that patients are supported in this. A decision aid might be an option to help patients in daily practice. According to O'Connor et al. (2004; 2007), these decision aids differ from traditional educational materials as they present balanced personalised information about the options in sufficient detail for patients to arrive at informed judgments about the personal value of those options $[7,8]$. As of now, they are increasingly used to enhance patient involvement in the decision-making process. A literature review already showed that when patients use these decision aids they participate more in decision-making [39]. An international example of a decision aid for patients is 'the Option Grid". Option Grids are defined by Elwyn et al. (2013) as "summary tables, using one side of paper to enable rapid comparisons of options, using questions that patients frequently ask (FAQs) and designed for face-to-face clinical encounters" [40 p207]. A Dutch initiative, inspired by the Option Grids, is the 'Consultkaart', which also gives a brief overview of the different options using a question and answer format [41].

Our findings also imply that the decision to be involved in medical decision-making is not as individual as it first seems. Both social support and social norms also play a role. This confirms that people do not make decisions in a 'vacuum' even in the context of SDM. Strategies aimed at emphasising SDM in daily practice have to address this social context too. An example might be the use of a 'buddy' system, which would be supported by our finding that, for low educated people, taking someone with you to a medical consultation is positively related to involvement. Such a 'buddy', for example a family member, volunteer, or medical professional, can, for example, ask questions during the medical consultation, or discuss the possible treatment options with the patient.

In conclusion, on the one hand, guidelines have been developed to support physician decision-making, and on the other hand decision aids have been developed to support patient decision-making. Although both are aimed at supporting the decision-making process, their origins are different [32]. This raises the question of whether there will be a conflict in making decisions. At first sight, it can be reasoned that applying guidelines and including patient preferences are incompatible. Burgers (2017), however, argues that there is no contradiction, but rather that there is a paradox [42]. The results of this thesis support this argument, by showing empirically that in one decision-making situation, the prescribing of 
antibiotics in general practice, there is no real conflict between applying guidelines and including patient preferences. We found that patient preferences only play a role in the decision if prescribing an antibiotic was an option that could be considered. Van der Weijden et al. (2012) suggest that in order to increase the quality of decision-making between the physician and patient, it is important to establish closer links between guidelines and decision aids [32]. The authors argue that although no practical strategies have yet been described for linking guidelines with decision aids, one option might be to incorporate types of formats such as balanced information about benefits and harms in the guidelines. These may encourage greater deliberation about the different treatment options. Such formats also form the basis of the decision aids [32]. As mentioned, guidelines are introduced for, among other things, to decrease practice variation. An interesting question is what a closer link between guidelines and decision aids implies for practice variation. It can be argued that incorporating formats into the guidelines in order to stimulate deliberation about treatment options might result in different treatment choices, as patient preferences might differ, and thus variation. However, as hypothesised in the literature, and confirmed empirically in one decision-making situation in this thesis, SDM appears to reduce variation. This can be explained by the fact that informed patients, in general, prefer the conservative treatment option more often [e.g. 34, 43-46].

\subsection{Proposal for further research}

The scientific implications of this thesis are to be found within our theoretical model. This thesis was the first to include the physician-patient interaction in testing a theoretical model explaining medical practice variation. We derived several new hypotheses from our theoretical model which we tested empirically in five different studies. All our hypotheses were confirmed, or partially confirmed (see Table 7.1). As such, our model proved to be valuable for gaining insight into the question of under which circumstances the physician is not the dominant actor deciding on the treatment. And, if patients are involved in the decision-making process, how this influences the decision-taken, and thus variation. We believe this thesis provides sufficient insight that, under certain circumstances, patients cannot be ignored in theories about variation. However, there are still areas which have not been investigated. Therefore, we recommend several of these for further research. The first set of recommendations focuses on testing those parts of the 
model that have not yet been tested. These include the interaction between the mechanisms explaining patient involvement and the influence which the structure and institutions of the health care system - that is at the macro level - have upon patient involvement. The second set of recommendations focuses on testing those hypotheses further which may not have been tested thoroughly enough so far, for instance the hypotheses that were tested in just one decision-making situation.

\section{Other mechanisms explaining patient involvement}

This thesis studied three different mechanisms, at both the micro and the meso level, which explain patient involvement in medical decision-making. Although the mechanism of social norms, in particular, explains much, the three mechanisms studied do not explain all variation in whether patients are actively involved in medical decision-making. This indicates that there are other mechanisms besides the ones studied that influence patient involvement too. One mechanism that might play a role is trust. Hereby, it is reasoned that trust might both foster and impair patient involvement. According to Entwistle (2004), trust can increase patient involvement because people feel more confident in honest discussions with their physicians, but trust can also impair patient involvement and foster a more passive role [47]. The few studies examining the relationship between trust and patient involvement found either a bidirectional relationship between trust and SDM, or that a lower degree of trust is related to more patient involvement. However, all these studies were conducted among specific patient groups instead of among a more general sample of health care users [48-50]. Further research is therefore recommended to examine, among a more general sample of health care users, whether trust fosters, or impairs patient involvement, or whether there is a bidirectional relationship.

Furthermore, this thesis only examined mechanisms at the micro, the patient, and the meso, the social context, level. Mechanisms at the macro level were not part of this thesis, as all patients in the Netherlands are subject to the same health care system, namely a system of managed competition. However, at the macro level, patients might, just as with physicians, be subject to influences from the structure and institutions of the health care system [2]. Based on Scott (2001), De Jong et al. (2015) distinguished three mechanisms at the macro level that influence the physician-patient interaction at the micro level. These are the regulative, the normative, and the cultural-cognitive mechanisms. For instance, there are differences in patients' views on the authority of physicians between countries [2]. 
It can be hypothesised that patients leave medical decision-making to physicians more often in countries where there is greater respect towards physicians compared to countries where there is a more equal relationship between physicians and patients. Future research is recommended to examine the role of the three institutional mechanisms in patient involvement in medical decisionmaking.

\section{Interaction between the mechanisms which may explain patient involvement}

Each of the three mechanisms has been examined in a separate study. However, there could also be an interaction between these mechanisms. How they interact, and what their relative importance is, was not studied in this thesis. It would be interesting in future to examine whether the mechanisms studied enhance each other, or are in conflict. It would be of value, for instance, to examine what happens in a situation where receiving medical informational support and conservative norms coexist.

\section{Patient preferences}

As argued in Chapter 1, the hypothesis that patient involvement reduces variation in medical practice assumes that patients are less diverse in their preferences than physicians. Next to this, it assumes that patients do not select a physician based on their treatment preferences. This thesis did not test these two assumptions empirically. From this thesis, however, we know that a strategy to promote SDM consisting among other things of a decision aid, may influence variation in medical practice. It can be argued on the basis of earlier research [e.g. 34, 43-46] that the presence of a decision aid appears, in general, to result in patients having the same preference more often. That is to say a preference for a more conservative option and thus resulting in less variation between units. It can be reasoned that, initially, patients strive to be healthy, and thus prefer a more invasive option such as surgery to remove an organ. However, they might consider other goals, prompted by the information in the decision aid about the pros and cons of different treatment options. For example they might also consider the quality of life and consequently prefer a less invasive option such as watchful waiting. This is supported by the example of Edward who we referred to in the introduction of this thesis. If Edward had been informed about the side effects of surgery beforehand, he would have probably opted for watchful waiting as surgery seriously affected his sex life. Although it appears that, in general, informed patients prefer the more conservative option, research showed that in some cases, for example, in the 
choice of prenatal screening, there is no difference in the choice of treatment with or without a decision aid. However, there were mixed results in other situations, for example in the choice of screening for colon cancer [51]. It is recommended that, for future research, it would be best not only to test empirically the above mentioned two assumptions, but, in particular, to elaborate further on mechanisms which explain how patient preferences for treatment are formed and under which circumstances patients are expected to choose a physician based on their treatment preferences. Earlier research showed that, in general, most of the patients do not actively choose a physician [52]. However, it is known that in some cases, for example in the case of lower back pain, part of the patients choose a private hospital as they know that they will get surgery there sooner [53].

The relationship between treatment decisions at the micro level and practice variation at the meso and macro level

Chapter 6 showed that patient preferences have a role in the prescribing of antibiotics in general practice as antibiotics can be considered according to a guideline. Due to the small number of general practices included in our study, we were not able to link these results to variation in antibiotic prescribing rates between practices. Further research is recommended to link treatment decisions at the micro level to practice variation at the meso and macro level. This can be done by making use of simulations. Hereby, behaviour at the micro level is modelled upon empirical data. Subsequently, the resulting patterns at the meso and macro levels are simulated. Simulations are used before to estimate variation. For example, Moore and Roland (1989) used simulations to examine the variation expected in referral rates among general practitioners [54]. And Garcia et al. (2000) used simulations to analyse the impact of several factors on variation in medical practice, such as the experience accumulated by the doctor in clinical practice and waiting lists [55].

We also found that the mechanisms of health literacy, social support and social norms have a role in whether patients take up an active role in the decision-making process. We did not examine, however, how this influences the decision taken, and thus the variation. It can be argued that if these mechanisms differ between units, for example among general practices, then this influences the variation between these units. Further research is recommended to examine this by using simulations too. One could ask, for example, what happens with the variation between general practices if it is assumed that in all practices patients have the same level of health 
literacy, and the physicians act in the same way, but with the exception of one practice in which patients have a high level of health literacy and thus are expected to take up an active role in the decision-making process.

\section{Other decision-making situations}

As argued in the section on methodological problems, both studies in part B of this thesis are based on a limited data set and focus on just one decision-making situation. Furthermore, in our study about the role of patient preferences in the prescribing of antibiotics in general practice, we focused on preferences that were explicitly expressed by patients, namely that patients ask for the more invasive treatment option - an antibiotic prescription. A relevant question is, to what extent our results are applicable to other decision-making situations. Future research is recommended to test this. In order to test further the hypothesis that SDM reduces practice variation, researchers can make use of, for example, data from multicentre randomised controlled trial (RCT) studies that applied intervention strategies to increase SDM in a specific consultation. These studies should include a control and an intervention group and measure actual treatment choice with and without SDM. Furthermore, ideally, future research should be performed with a larger data set, preferably using a multilevel analysis, and including in the analysis, the sociodemographic characteristics, which might have an influence upon the decision taken.

\section{Decision-making situations in practice}

All studies in the first part of this thesis were conducted by using a questionnaire. As argued before in the section on methodological problems, this method was appropriate to test our hypotheses. However, it remains unclear whether people are actually involved in the medical decision-making process in real life. We would, therefore, recommend studying decision-making situations in practice in any future research. One possibility would be to do this by observing medical consultations in which a decision will be taken. The study of Van den Brink-Muinen et al. (2006) is an example of a study that observed the extent to which patients are involved in medical decision-making in practice. Van den Brink-Muinen et al. (2006) analysed videotaped consultations in general practice from two years, 1987 and 2001. They concluded that patient involvement in the decision-making process has increased over time, although not in every respect. In addition, the authors concluded that older patients were involved the least [56]. 


\subsection{Conclusions}

In conclusion, this thesis was the first to include the physician-patient interaction in testing a theoretical model explaining medical practice variation. We aimed to gain insight into under which circumstances the physician-patient interaction is not dominated by the physician, and if this is the case, how patient involvement influences the decision taken, and thus practice variation. We found that health literacy, social support, and social norms are all three mechanisms associated with patient involvement in medical decision-making. Our results suggest that, in general, high critical health literacy, the availability of medical informational support, and non-conservative social norms are positively related to patient involvement in medical decision-making. As such, patients have to be modelled as actors in theories about variation. An implication of our results is that the decision to be involved in medical decision-making is not as individual as it first seems. A person's social context also plays a role. This thesis also proved that patient involvement in medical decision-making influences the decision taken, and thus practice variation. We found that SDM results in less variation between hospitals. As such, we confirmed, empirically, the hypothesis from the literature that SDM reduces medical practice variation. Until now empirical data showing such a decrease was lacking. In addition, we found that SDM results in another pattern of variation within hospitals. An implication of our results is that an overall decrease in variation between hospitals gives no indication about the change in variation within an individual hospital. Lastly, we found that two mechanisms - guidelines and patient involvement - which both have the potential to reduce practice variation, do not conflict each other. Our results suggest that patient preferences only play a role if the guideline provides room to take preferences into account. In conclusion, our model proved to be valuable in order to gain insight into circumstances under which the physician-patient interaction is not dominated by the physician. If this is the case then insight is also gained into how this influences the decision taken, and thus practice variation. We believe this thesis provides sufficient insight to argue that, under certain circumstances, patients cannot be ignored in theories about variation. However, some questions remain unanswered. 


\section{References}

1. Mercuri M, Gafni A. Medical practice variations: what the literature tells us (or does not) about what are warranted and unwarranted variations. Journal of Evaluation in Clinical Practice 2011; 17(4):671-7

2. De Jong JD, Groenewegen PP, Westert GP. Sociological Model for Understanding Medical Practice Variations. In: Sobolev B (Series ed), Johnson A, Stukel T (eds). Health Services Research Series. Medical Practice Variations. New York: Springer, 2015;25-39

3. Guadagnoli E, Ward P. Patient participation in decision-making. Social Science \& Medicine 1998; 47(3):329-39

4. RVZ. De participerende patiënt. Den Haag, 2013

5. Institute of Medicine. Crossing the quality chasm: A new health system for the 21st century: National Academies Press, 2001

6. Greer AL, Goodwin JS, Freeman JL, Wu ZH. Bringing the patient back in. Guidelines, practice variations, and the social context of medical practice. International Journal of Technology Assessment in Health Care 2002; 18(4):747-61

7. O'Connor AM, Llewellyn-Thomas HA, Flood AB. Modifying unwarranted variations in health care: shared decision making using patient decision aids. Health Affairs 2004; Var63-72

8. O'Connor AM, Wennberg JE, Legare F, Llewellyn-Thomas HA, Moulton BW, Sepucha KR, et al. Toward the 'tipping point': decision aids and informed patient choice. Health Affairs 2007; 26(3):716-25

9. Stiggelbout AM, Van der Weijden T, De Wit MP, Frosch D, Legare F, Montori VM, et al. Shared decision making: really putting patients at the centre of healthcare. The BMJ 2012; 344:e256

10. Weinstein JN, Bronner KK, Morgan TS, Wennberg JE. Trends and geographic variations in major surgery for degenerative diseases of the hip, knee, and spine. Health Affairs 2004; Suppl Variation:Var81-9 
11. Say R, Murtagh M, Thomson R. Patients' preference for involvement in medical decision making: a narrative review. Patient Education \& Counseling 2006; 60(2):10214

12. Peerson A, Saunders M. Health literacy revisited: what do we mean and why does it matter? Health Promotion International 2009; 24(3):285-96

13. Nutbeam D. Health literacy as a public health goal: a challenge for contemporary health education and communication strategies into the 21st century. Health Promotion International 2000; 15(3):259-67

14. Nutbeam D. The evolving concept of health literacy. Social Science \& Medicine 2008; $67(12): 2072-8$

15. Chinn D. Critical health literacy: a review and critical analysis. Social Science \& Medicine 2011; 73(1):60-7

16. Arrow KJ. Uncertainty and the welfare economics of medical care. The American economic review 1963:941-73

17. Charles C, Whelan T, Gafni A, Reyno L, Redko C. Doing Nothing is No Choice: Lay Constructions of Treatment Decision-making Among Women with Early-stage Breast Cancer. Sociology of Health \& IIIness 1998; 20(1):71-95

18. Marzuk PM. The right kind of paternalism. New England Journal of Medicine 1985; 313(23):1474-6

19. Pellegrino ED. Patient and physician autonomy: conflicting rights and obligations in the physician-patient relationship. Journal of Contemporary Health Law \& Policy 1994; $10: 47$

20. Wolff JL, Roter DL. Family presence in routine medical visits: a meta-analytical review. Social Science \& Medicine 2011; 72(6):823-31

21. Coleman J. Foundations of social theory. Cambridge, MA: Belknap 1990

22. Cialdini RB, Kallgren CA, Reno RR. A focus theory of normative conduct: A theoretical refinement and reevaluation of the role of norms in human behavior. Advances in experimental social psychology 1991; 24(20):1-243 
23. Wennberg JE. Variation in Use of Medicare Services among Regions and Selected Academic Medical Centers: Is More Better? Commonwealth Fund, 2005

24. Brabers A, Reitsma-Van Rooijen M, De Jong J. Consumentenpanel Gezondheidszorg: Basisrapport met informatie over het panel (2015). Utrecht: NIVEL, 2015

25. Van den Brink-Muinen A, Spreeuwenberg P, Rijken M. Preferences and experiences of chronically ill and disabled patients regarding shared decision-making: does the type of care to be decided upon matter? Patient Education \& Counseling 2011;84(1):111-7

26. De Jong JD. Explaining medical practice variation. Social organization and institutional mechanisms. NIVEL, 2008

27. Richards T, Montori VM, Godlee F, Lapsley P, Paul D. Let the patient revolution begin. The BMJ 2013; 346:f2614

28. De Jong JD, Groenewegen PP, Spreeuwenberg P, Schellevis F, Westert GP. Do guidelines create uniformity in medical practice? Social Science \& Medicine 2010; 70(2):209-16

29. Graham R, Mancher M, Wolman DM, Greenfield S, Steinberg E. Clinical practice guidelines we can trust: National Academies Press, 2011

30. Grimshaw JM, Russell IT. Effect of clinical guidelines on medical practice: a systematic review of rigorous evaluations. The Lancet 1993; 342(8883):1317-22

31. Woolf SH, Grol R, Hutchinson A, Eccles M, Grimshaw J. Clinical guidelines: potential benefits, limitations, and harms of clinical guidelines. The BMJ 1999; 318(7182):527-30

32. Van der Weijden T, Boivin A, Burgers J, Schunemann HJ, Elwyn G. Clinical practice guidelines and patient decision aids. An inevitable relationship. Journal of Clinical Epidemiology 2012; 65(6):584-9

33. Mainz J. Defining and classifying clinical indicators for quality improvement. International Journal for Quality in Health Care 2003; 15(6):523-30

34. Wennberg JE. Tracking medicine: a researcher's quest to understand health care. Oxford: Oxford University Press, 2010 
35. Elwyn G, Frosch D, Thomson R, Joseph-Williams N, Lloyd A, Kinnersley P, et al. Shared decision making: a model for clinical practice. Journal of General Internal Medicine 2012; 27(10):1361-7

36. Elwyn G, Laitner S, Coulter A, Walker E, Watson P, Thomson R. Implementing shared decision making in the NHS. The BMJ 2010; 341:c5146

37. Harter M, Moumjid N, Cornuz J, Elwyn G, van der Weijden T. Shared decision making in 2017: International accomplishments in policy, research and implementation. Zeitschrift für Evidenz, Fortbildung und Qualität im Gesundheitswesen 2017; 123124:1-5

38. Van der Weijden T, Post H, Brand PLP, Van Veenendaal H, Drenthen T, Van Mierlo LA, et al. Shared decision making, a buzz-word in the Netherlands, the pace quickens towards nationwide implementation. Zeitschrift für Evidenz, Fortbildung und Qualität im Gesundheitswesen 2017; 123-124:69-74

39. Stacey D, Bennett CL, Barry MJ, Col NF, Eden KB, Holmes-Rovner M, et al. Decision aids for people facing health treatment or screening decisions. The Cochrane Database of Systematic Reviews 2011; (10):Cd001431

40. Elwyn G, Lloyd A, Joseph-Williams N, Cording E, Thomson R, Durand MA, et al. Option Grids: shared decision making made easier. Patient Education \& Counseling 2013;90(2):207-12

41. No authors listed. Consultkaart. Available at: http://consultkaart.nl/ (3 August, 2017, date last accessed)

42. Burgers J. Persoonsgerichte zorg in richtlijnen: contradictie of paradox? Maastricht: Universiteit Maastricht, 2017

43. Deyo RA, Cherkin DC, Weinstein J, Howe J, Ciol M, Mulley AG, Jr. Involving patients in clinical decisions: impact of an interactive video program on use of back surgery. Medical Care 2000; 38(9):959-69

44. Stacey D, Legare F, Col NF, Bennett CL, Barry MJ, Eden KB, et al. Decision aids for people facing health treatment or screening decisions. The Cochrane Database of Systematic Reviews 2014; 1:Cd001431 
45. Van Peperstraten A, Nelen W, Grol R, Zielhuis G, Adang E, Stalmeier P, et al. The effect of a multifaceted empowerment strategy on decision making about the number of embryos transferred in in vitro fertilisation: randomised controlled trial. The BMJ 2010; 341:c2501

46. Coxeter P, Del Mar CB, McGregor L, Beller EM, Hoffmann TC. Interventions to facilitate shared decision making to address antibiotic use for acute respiratory infections in primary care. The Cochrane Database of Systematic Reviews 2015; (11):Cd010907

47. Entwistle V. Trust and shared decision-making: an emerging research agenda. Health Expectations 2004; 7(4):271-3

48. Goggins KM, Wallston KA, Nwosu S, Schildcrout JS, Castel L, Kripalani S. Health literacy, numeracy, and other characteristics associated with hospitalized patients' preferences for involvement in decision making. Journal of Health Communication 2014; 19 Suppl 2:29-43

49. Kraetschmer N, Sharpe N, Urowitz S, Deber RB. How does trust affect patient preferences for participation in decision-making? Health Expectations 2004; 7(4):31726

50. Peek ME, Gorawara-Bhat R, Quinn MT, Odoms-Young A, Wilson SC, Chin MH. Patient trust in physicians and shared decision-making among African-Americans with diabetes. Health Communication 2013; 28(6):616-23

51. Stacey D, Legare F, Lewis K, Barry MJ, Bennett CL, Eden KB, et al. Decision aids for people facing health treatment or screening decisions. The Cochrane Database of Systematic Reviews 2017; 4:Cd001431

52. Victoor A. (How) do patients choose a healthcare provider? Tilburg: Tilburg Universiteit, 2015

53. No authors listed. Privékliniek opereert eerder dan ziekenhuis. Available at: https://www.nationalezorggids.nl/ziekenhuizen/nieuws/8892-privekliniek-opereerteerder-dan-ziekenhuis.html (3 August, 2017, date last accessed)

54. Moore AT, Roland MO. How much variation in referral rates among general practitioners is due to chance? The BMJ 1989; 298(6672):500-2 
55. Garcia R, Gonzalez-Busto B, Alvarez Y. Medical practice variations: reflections from the complex systems perspective. International Journal of Healthcare Technology and Management 2000; 2(5-6):477-97

56. Van den Brink-Muinen A, Van Dulmen SM, De Haes HC, Visser AP, Schellevis FG, Bensing JM. Has patients' involvement in the decision-making process changed over time? Health Expectations 2006; 9(4):333-42 


\section{Summary}




\section{Introduction and research questions}

Medical practice variation is a well-known phenomenon that has been extensively described in the literature [e.g. 1-3]. Variation in medical treatment means that similar, or apparently similar patients with a similar health status or medical condition do not receive the same treatment. Variation is explained in current research by focussing mainly on physicians and the organisations they work in [4]. This approach might be adequate in cases where physicians are the dominant actor deciding on the treatment. In the past decades, however, this paternalistic model has become questioned. In parallel, there is an increased emphasis towards including patients and their preferences in medical decision-making $[5,6]$. Moreover, providing care that is respectful of, and responsive to, an individual patient's preferences is regarded as one aspect of a good quality of care [7]. Since medical decision-making is a decisive factor for practice variation, this raises the question whether patients can be ignored in theories about variation. This question was the central subject of this thesis. In order to gain insight into this subject, we examined under which circumstances the interaction between physician and patient is not dominated by the physician. We explored several mechanisms explaining patient involvement in medical decision-making. We examined, too, how this involvement influences medical decision-making, and thus practice variation. It has been suggested that patient involvement, and more specifically shared decision-making (SDM), decreases variation [8-12]. However, empirical data showing this was lacking.

The two research questions addressed in this thesis were:

\section{Which mechanisms explain differences in patient involvement in medical decision-making?}

2. How does patient involvement, and more specifically shared decision-making, influence medical practice variation?

In line with our two research questions, this thesis is divided into two parts. Part A aims to achieve insight into three possible mechanisms which might explain patient involvement in medical decision-making, and comprises the Chapters 2 to 4 . Part B, Chapters 5 and 6, seeks to achieve insight into how patient involvement, and more specifically SDM, influences medical practice variation. 


\section{Mechanisms explaining differences in patient involvement in medical decision-making}

We examined under which circumstances the physician-patient interaction is not dominated by the physician. It is only if patients share medical decision-making with their physician that they should be modelled as actors in theories about variation. Previous studies have shown that there is variation in patient involvement in medical decision-making [e.g. 13]. However, no clear explanation for this observed variation has been given. We therefore examined three mechanisms, both at the micro (patient) and the meso level (social context) which may explain patient involvement in medical decision-making. These were: 1 ) health literacy, 2) social support and, 3) social norms.

Chapter 2 examined the relationship between health literacy and self-reported involvement in medical decision-making. Health literacy refers to "personal characteristics and social resources needed for people to access, understand and use information to make decisions about their health" [14 p2, 15 p1]. We hypothesised that people with higher health literacy report that they are more involved in medical decision-making. This, we presume, is because these people are able to obtain, understand, appraise, and apply information required for medical decision-making better. A structured questionnaire was sent to members of NIVEL's Dutch Health Care Consumer Panel in May 2015 (response 46\%, N=974). Health literacy was measured using five scales of the Health Literacy Questionnaire [16]. A regression model was used to estimate the relationship between health literacy and self-reported involvement. In general, our results did not show a relationship between health literacy and self-reported involvement. However, we found that the higher respondents scored on the health literacy scale 'appraisal of health information', the more they reported being involved in medical decisionmaking. As such, our hypothesis was partly confirmed. Our findings suggest that higher order competences, that is to say 'critical' health literacy, in particular, are important in reporting involvement in medical decision-making. 'Information appraisal' is one component of critical health literacy. This refers to cognitive skills in managing and interpreting information, as well as to assessing the personal relevance of information [17]. In the context of this thesis, it appears that in order to be involved in medical decision-making, patients have to be able to interpret information and weigh this information against their own preferences. 
Chapter 3 studied the role of social support, in the form of the availability of informational and emotional support, on the attitude that people have towards taking an active role in medical decision-making. One reason for patients to leave medical decision-making to their physician is the information asymmetry between them and the physician [18]. Patients believe that medical decision-making requires knowledge they do not have [19]. We hypothesised that gaining informational support from others may compensate for this lack of knowledge. Another reason to leave decision-making to the physician is that people who are sick feel vulnerable and thus do not want to, or cannot, take a decision [20, 21]. We hypothesised that emotional support, in the form of having someone to take with you to a medical consultation, can compensate for this. Patients are expected to feel less vulnerable if they receive emotional support as it has been suggested that they feel more confident when a companion is present [22]. A questionnaire was sent to members of NIVEL's Dutch Health Care Consumer Panel (response 70\%, $\mathrm{N}=1,300$ ) in June 2013. A regression model was then used to estimate the relationship between medical and lay informational support and emotional support, on the one hand, and attitudes towards taking an active role in medical decision-making on the other. We found that people to whom more medical informational support is available, that is knowing people who are medical professionals, are more positive towards taking an active role in medical decisionmaking. The reason for this might be that they are able to contact someone who is a medical professional within their network more easily and thus seek medical information necessary for decision-making. On the other hand, we found no relationship between the availability of lay informational support, that is having lay people in your network to seek information from, and taking an active role in decision-making. We also found that it was only in people with a low level of education that the availability of emotional support related positively to their attitude towards taking an active role in medical decision-making. This is not the case in people with a middle or high level of education. The latter have a more positive attitude towards taking an active role in medical decision-making, irrespective of the level of emotional support available. In conclusion, our findings showed that social support does play a role in patient involvement. However, not all forms of support play a role in all groups of patients. As such, our hypothesis was partly confirmed.

Chapter 4 provided insight into how social norms play a role in self-reported involvement in medical decision-making. Social norms define what actions are 
regarded as normal by a group of people, and what actions are regarded as deviant [23]. We made a distinction between subjective norms, that is doing what others think one ought to do, and descriptive norms, that is doing what others do [24]. We hypothesised that for both norms, the more it is common in someone's social context to leave the decision to a physician then the less someone reports being involved in medical decision-making. The reason for this is that we expected that people will behave according to the norms of their social environment, as this will result in social approval. A questionnaire was sent to members of NIVEL's Dutch Health Care Consumer Panel in May 2015 (response 46\%; N=974). A regression model was used to estimate the relationship between social norms and involvement in medical decision-making. Our results confirmed our hypothesis. With regards to the subjective norm, we found that the more a person thinks that, according to significant others, he or she has to leave the decision to the physician, the less that person reports being involved in the decision-making process. The same was found for the descriptive norm. The more people think that significant others leave the decision to the physician, the less they report being involved in the decision-making process.

In conclusion, the results of the Chapters 2, 3 and 4 show that the mechanisms of health literacy, social support, and social norms are all three associated with patient involvement in medical decision-making. Our results suggest that, in general, high critical health literacy, the availability of medical informational support, and non-conservative social norms are positively related to patient involvement in medical decision-making. As such, patients have to be modelled as actors in theories about variation. Our findings also suggest that the decision to be involved in medical decision-making is not as individual as it first would appear. A person's social context also plays a role.

\section{Patient involvement and medical practice variation}

Treatment decisions may change as a result of patient involvement in medical decision-making. The reason for this is that patients' preferences for treatment may differ from physicians' judgements [25]. Medical decision-making is decisive for variation, therefore patterns of variation may also change through patient involvement. It has been hypothesised that patient involvement, and more specifically SDM, decreases variation in practice [8-12]. However, empirical data 
confirming a decrease was lacking. We aimed, therefore, to examine how patient involvement, and more specifically SDM, influences medical practice variation.

In Chapter 5, we tested, empirically, the hypothesis that SDM reduces medical practice variation. We hypothesised that SDM is associated with less variation between units such as hospitals, as we expected that, due to SDM, a more conservative treatment option will be chosen in units where physicians already prefer the more conservative option, as well as in units where physicians prefer the invasive option. This is because informed patients prefer the more conservative option. Based on a limited data set, we examined how SDM is associated with variation in the choice of single embryo transfer (SET) or double embryo transfer (DET) after in vitro fertilisation. We examined variation between and within hospitals. We found a large degree of variation in the choice of SET or DET between hospitals in the control group, while less variation was found between hospitals in the group with a strategy to promote SDM. As such, our hypothesis was confirmed. In addition to this, we found that within most hospitals the variation in the choice of SET or DET appeared to increase due to a strategy to promote SDM. While in other hospitals the variation in the choice of SET or DET decreased, or remained equal. An implication of our results is that an overall decrease in variation between hospitals gives no indication about the change in variation within an individual hospital.

Chapter 6 provided insight into the possible conflict between applying guidelines on the one hand, and including patient preferences in medical decision-making on the other. We examined whether patient preferences have a role in the prescribing of antibiotics in general practice and how this affects adherence to guidelines. We hypothesised that preferences play a larger role in prescribing antibiotics if the guideline allows for preferences to be taken into account. In other words if prescribing antibiotics is an option which can be considered rather than a clear recommendation to prescribe or not. We included three guidelines: acute cough, acute rhinosinusitis, and urinary tract infections. Data from the NIVEL Primary Care Database (NIVEL-PCD) were used to assess antibiotic indications and prescriptions. These data were combined with a questionnaire among members of NIVEL's Dutch Health Care Consumer Panel to examine the patient's preferences. According to NIVEL-PCD, 286 of these members contacted their general practitioner (GP) in 2015 for acute cough, acute rhinosinusitis or urinary tract infections. A logistic multilevel regression analysis was performed to test our hypothesis. We found that patient 
preferences appear only to play a role in the GP's prescribing of antibiotics if prescribing an antibiotic was an option that could be considered (interaction between indication and preference: $p=0.049$ ). If patients ask for antibiotics themselves in such situations then GPs prescribe antibiotics more often. In those situations there is no conflict between applying the guidelines and including the patient's preferences. Antibiotics are justified in such situations as the guideline provides room for taking patient preferences into account. As such, our hypothesis was confirmed.

In conclusion, the results of the Chapters 5 and 6 show that patients taking an active role in the decision-making process influence the decision taken and thus the variation.

\section{Conclusions}

In conclusion, this thesis was the first to include the physician-patient interaction in testing a theoretical model explaining medical practice variation. We aimed to gain insight into under which circumstances the physician-patient interaction is not dominated by the physician, and if this is the case, how patient involvement influences the decision taken, and thus practice variation. We found that health literacy, social support, and social norms are all three mechanisms associated with patient involvement in medical decision-making. Our results suggest that, in general, high critical health literacy, the availability of medical informational support, and non-conservative social norms are positively related to patient involvement in medical decision-making. As such, patients have to be modelled as actors in theories about variation. An implication of our results is that the decision to be involved in medical decision-making is not as individual as it first seems. A person's social context also plays a role. This thesis also proved that patient involvement in medical decision-making influences the decision taken, and thus practice variation. We found that SDM results in less variation between hospitals. As such, we confirmed, empirically, the hypothesis from the literature that SDM reduces medical practice variation. Until now empirical data showing such a decrease was lacking. In addition, we found that SDM results in another pattern of variation within hospitals. An implication of our results is that an overall decrease in variation between hospitals gives no indication about the change in variation within an individual hospital. Lastly, we found that two mechanisms - guidelines 
and patient involvement - which both have the potential to reduce practice variation, do not conflict each other. Our results suggest that patient preferences only play a role if the guideline provides room to take preferences into account. In conclusion, our model proved to be valuable in order to gain insight into circumstances under which the physician-patient interaction is not dominated by the physician. If this is the case then insight is also gained into how this influences the decision taken, and thus practice variation. We believe this thesis provides sufficient insight to argue that, under certain circumstances, patients cannot be ignored in theories about variation. However, some questions remain unanswered. Therefore, several recommendations for future research have been made. 


\section{References}

1. Corallo AN, Croxford R, Goodman DC, Bryan EL, Srivastava D, Stukel TA. A systematic review of medical practice variation in OECD countries. Health Policy 2014; 114(1):5-14

2. Paul-Shaheen P, Clark JD, Williams D. Small area analysis: a review and analysis of the North American literature. Journal of health politics, policy and law 1987; 12(4):741809

3. Wennberg JE. Tracking medicine: a researcher's quest to understand health care. Oxford: Oxford University Press, 2010

4. De Jong JD, Groenewegen PP, Westert GP. Sociological Model for Understanding Medical Practice Variations. In: Sobolev B (Series ed), Johnson A, Stukel T (eds). Health Services Research Series. Medical Practice Variations. New York: Springer, 2015; 25-39

5. Guadagnoli E, Ward P. Patient participation in decision-making. Social Science \& Medicine 1998; 47(3):329-39

6. RVZ. De participerende patiënt. Den Haag, 2013

7. Institute of Medicine. Crossing the quality chasm: A new health system for the 21st century: National Academies Press, 2001

8. Greer AL, Goodwin JS, Freeman JL, Wu ZH. Bringing the patient back in. Guidelines, practice variations, and the social context of medical practice. International Journal of Technology Assessment in Health Care 2002; 18(4):747-61

9. O'Connor AM, Llewellyn-Thomas HA, Flood AB. Modifying unwarranted variations in health care: shared decision making using patient decision aids. Health Affairs 2004; Var63-72

10. O'Connor AM, Wennberg JE, Legare F, Llewellyn-Thomas HA, Moulton BW, Sepucha $K R$, et al. Toward the 'tipping point': decision aids and informed patient choice. Health Affairs 2007; 26(3):716-25

11. Stiggelbout AM, Van der Weijden T, De Wit MP, Frosch D, Legare F, Montori VM, et al. Shared decision making: really putting patients at the centre of healthcare. The BMJ 2012; 344:e256 
12. Weinstein JN, Bronner KK, Morgan TS, Wennberg JE. Trends and geographic variations in major surgery for degenerative diseases of the hip, knee, and spine. Health Affairs 2004; Suppl Variation:Var81-9

13. Say $R$, Murtagh $M$, Thomson R. Patients' preference for involvement in medical decision making: a narrative review. Patient Education \& Counseling 2006; 60(2):10214

14. Beauchamp A, Buchbinder R, Dodson S, Batterham RW, Elsworth GR, McPhee C, et al. Distribution of health literacy strengths and weaknesses across socio-demographic groups: a cross-sectional survey using the Health Literacy Questionnaire (HLQ). BMC Public Health 2015; 15:678

15. Dodson S, Beauchamp A, Batterham RW, Osborne RH. Information sheet 1: What is health literacy? In Ophelia Toolkit: A step-by-step guide for identifying and responding to health literacy needs within local communities. www.ophelia.net.au

16. Osborne RH, Batterham RW, Elsworth GR, Hawkins M, Buchbinder R. The grounded psychometric development and initial validation of the Health Literacy Questionnaire (HLQ). BMC Public Health 2013; 13:658

17. Chinn D. Critical health literacy: a review and critical analysis. Social Science \& Medicine 2011; 73(1):60-7

18. Arrow KJ. Uncertainty and the welfare economics of medical care. The American economic review 1963; 941-73

19. Charles C, Whelan T, Gafni A, Reyno L, Redko C. Doing Nothing is No Choice: Lay Constructions of Treatment Decision-making Among Women with Early-stage Breast Cancer. Sociology of Health \& Illness 1998; 20(1):71-95

20. Marzuk PM. The right kind of paternalism. New England Journal of Medcine 1985; 313(23):1474-6

21. Pellegrino ED. Patient and physician autonomy: conflicting rights and obligations in the physician-patient relationship. Journal of Contemporary Health Law \& Policy 1994; $10: 47$

22. Wolff JL, Roter DL. Family presence in routine medical visits: a meta-analytical review. Social Science \& Medicine 2011; 72(6):823-31 
23. Coleman J. Foundations of social theory. Cambridge, MA: Belknap 1990

24. Cialdini RB, Kallgren CA, Reno RR. A focus theory of normative conduct: A theoretical refinement and reevaluation of the role of norms in human behavior. Advances in experimental social psychology 1991; 24(20):1-243

25. Wennberg JE. Variation in Use of Medicare Services among Regions and Selected Academic Medical Centers: Is More Better? Commonwealth Fund, 2005 


\section{Samenvatting}

(Summary in Dutch) 


\section{Introductie en onderzoeksvragen}

Variatie in medisch handelen is een fenomeen dat uitvoerig is beschreven binnen de wetenschappelijke literatuur [bijv. 1-3]. Variatie in medisch handelen houdt in dat vergelijkbare patiënten met eenzelfde gezondheidstoestand of medische conditie niet dezelfde behandeling krijgen. In het verklaren van deze variatie richt het huidige onderzoek zich vooral op de rol die artsen en de organisaties waarin zij werken hierin hebben [4]. Deze aanpak is geschikt als je er van uit gaat dat de arts de dominante persoon is die besluit welke behandeling een patiënt krijgt. Echter, in de afgelopen decennia, is dit paternalistische model met de arts als dominante beslisser steeds meer bekritiseerd. Tegelijkertijd is er een beweging gaande om patiënten en hun preferenties een grotere rol te laten spelen in de medische besluitvorming $[5,6]$. Ook wordt het leveren van zorg met inachtneming van de preferenties van een individuele patiënt gezien als onderdeel van kwalitatief goede zorg [7]. Omdat de medische besluitvorming een bepalende factor is voor variatie in medisch handelen, is het de vraag of patiënten nog kunnen worden genegeerd in theorieën over variatie. Deze vraag stond dan ook centraal in dit proefschrift. Om deze vraag te kunnen beantwoorden, onderzochten we onder welke omstandigheden de arts de interactie tussen hem en de patiënt niet domineert. We onderzochten verschillende mechanismen die de betrokkenheid van patiënten in de medische besluitvorming verklaren. Ook onderzochten we hoe de betrokkenheid van patiënten de medische besluitvorming beïnvloedt, en dus variatie. In de literatuur wordt verondersteld dat door de betrokkenheid van de patiënt, en in het bijzonder door gezamenlijke besluitvorming tussen arts en patiënt, praktijkvariatie zal afnemen [8-12]. Tot nu toe was er echter geen empirisch bewijs voor deze aanname.

Dit proefschrift beantwoordt de volgende twee onderzoeksvragen:

1. Welke mechanismen verklaren verschillen in de betrokkenheid van patiënten in de medische besluitvorming?

2. Hoe beïnvloedt de betrokkenheid van patiënten, en in het bijzonder gezamenlijke besluitvorming, variatie in medisch handelen?

In lijn met bovenstaande twee onderzoeksvragen is dit proefschrift onderverdeeld in twee delen. Deel A heeft als doel om inzicht te krijgen in drie mechanismen die 
mogelijk verklaren waarom patiënten betrokken zijn in de medische besluitvorming. Dit deel bestaat uit de hoofdstukken 2, 3 en 4. Deel B gaat in op hoe de betrokkenheid van patiënten, en in het bijzonder gezamenlijke besluitvorming, van invloed is op variatie in medisch handelen. Dit deel bestaat uit de hoofdstukken 5 en 6 .

\section{Mechanismen die verschillen verklaren in de betrokkenheid van patiënten in de medische besluitvorming}

We onderzochten onder welke omstandigheden de interactie tussen arts en patiënt niet wordt gedomineerd door de arts. Alleen als artsen en patiënten gezamenlijk de medische beslissing nemen, moeten patiënten worden opgenomen als actor in theorieën over variatie. Eerdere studies lieten zien dat er variatie is tussen patiënten in de mate waarin zijn betrokken zijn in de medische besluitvorming [bijv. 13]. Deze studies gaven hiervoor echter geen verklaring. Wij onderzochten daarom drie mechanismen, zowel op het micro (patiënt) als het meso (sociale omgeving) niveau, die mogelijk de betrokkenheid van patiënten in de medische besluitvorming verklaren. De onderzochte mechanismen zijn: 1) gezondheidsvaardigheden, 2) sociale steun en 3) sociale normen.

Hoofdstuk 2 onderzocht de relatie tussen gezondheidsvaardigheden en zelfgerapporteerde betrokkenheid in de medische besluitvorming. Gezondheidsvaardigheden kunnen worden gezien als persoonlijke kenmerken en sociale hulpbronnen die mensen nodig hebben om toegang te kunnen krijgen tot informatie, deze informatie te kunnen begrijpen en te kunnen gebruiken bij beslissingen over hun gezondheid [14, 15]. Onze hypothese was dat mensen met hogere gezondheidsvaardigheden aangeven dat zij meer betrokken zijn in de medische besluitvorming, omdat we verwachtten dat deze mensen informatie die nodig is voor de medische besluitvorming beter kunnen verkrijgen, begrijpen, beoordelen en toepassen. Data zijn verzameld door middel van het versturen van een gestructureerde vragenlijst naar een steekproef van panelleden van het Consumentenpanel Gezondheidszorg van het NIVEL (respons 46\%, N=974). Gezondheidsvaardigheden zijn gemeten door middel van vijf schalen van de 'Health Literacy Questionnaire' [16]. Met behulp van een regressie model hebben we de relatie tussen gezondheidsvaardigheden en zelf-gerapporteerde betrokkenheid in de medische besluitvorming geschat. Over het algemeen vonden we geen relatie 
tussen beide concepten. Wel vonden we dat hoe hoger respondenten scoorden op de vaardigheid 'het beoordelen van gezondheidsinformatie', hoe meer ze aangaven betrokken te zijn in de medische besluitvorming. Onze hypothese is dus deels bevestigd. Onze resultaten suggereren dat met name vaardigheden van een hoger niveau, ook wel 'kritische' gezondheidsvaardigheden genoemd, belangrijk zijn in het rapporteren van betrokkenheid in de medische besluitvorming. Het beoordelen van informatie is een onderdeel van kritische gezondheidsvaardigheden. Dit heeft betrekking op het hebben van cognitieve vaardigheden om informatie te verwerken en te interpreteren, alsmede om de persoonlijke relevantie van deze informatie te kunnen beoordelen [17]. In de context van dit proefschrift lijkt het er op dat patiënten om deel te kunnen nemen aan de medische besluitvorming in staat moeten zijn om informatie te kunnen interpreteren en deze te kunnen afwegen tegen hun eigen voorkeuren.

Hoofdstuk 3 onderzocht de relatie tussen de beschikbaarheid van sociale steun en de houding die mensen hebben ten aanzien van het hebben van een actieve rol in de medische besluitvorming. Een reden voor patiënten om de beslissing over te laten aan de arts is de informatie ongelijkheid tussen artsen en patiënten [18]. Patiënten denken dat om een medische beslissing te kunnen nemen je informatie nodig hebt die zij niet hebben [19]. Onze hypothese was dat het krijgen van steun van anderen in de vorm van informatie dit gebrek aan kennis kan compenseren. Een andere reden voor patiënten om de medische besluitvorming aan artsen over te laten is dat zij zich kwetsbaar voelen en dus geen beslissing kunnen of willen nemen $[20,21]$. Onze hypothese was dat emotionele steun, in de vorm van het hebben van iemand die je mee kan nemen naar een consult, dit kan compenseren. We veronderstelden dat patiënten door het krijgen van emotionele steun zich minder kwetsbaar voelen, gebaseerd op de suggestie dat zij zich zelfverzekerder voelen wanneer iemand bij het consult aanwezig is [22]. In juni 2013 is een vragenlijst gestuurd naar een steekproef van panelleden van het Consumentenpanel Gezondheidszorg van het NIVEL (respons 70\%, N=1.300). Door middel van een regressie model hebben we de relatie geschat tussen de beschikbaarheid van sociale steun enerzijds, en de houding die mensen hebben ten aanzien van het hebben van een actieve rol in de medische besluitvorming anderzijds. We vonden dat mensen die meer steun in de vorm van medische informatie tot hun beschikking hebben, het gaat dan om het kennen van een zorgverlener (huisarts, medisch specialist of verpleegkundige), een positievere houding hebben ten aanzien van het hebben van een actieve rol in de medische 
besluitvorming. Een verklaring hiervoor kan zijn dat het voor deze mensen makkelijker is om aan een zorgverlener in hun netwerk informatie te vragen die nodig is om een medische beslissing te kunnen nemen. Anderzijds vonden we geen relatie tussen de beschikbaarheid van steun in de vorm van informatie van 'leken' en de houding ten aanzien van het hebben van een actieve rol in de besluitvorming. Met leken bedoelen we hier mensen die geen zorgverlener zijn. Ook vonden we dat voor laag opgeleiden de beschikbaarheid van emotionele steun positief gerelateerd is aan de houding die zij hebben ten aanzien van het hebben van een actieve rol. Dit verband vonden we niet voor mensen met een middel en hoog opleidingsniveau. Deze laatste twee groepen hebben, onafhankelijk van het niveau van emotionele steun dat zij beschikbaar hebben, een positievere houding ten aanzien van het hebben van een actieve rol in de medische besluitvorming. Samenvattend laten onze resultaten zien dat sociale steun een rol speelt in de betrokkenheid van patiënten. Echter, niet alle vormen van sociale steun spelen een rol bij alle groepen patiënten. Onze hypothese is dan ook deels bevestigd.

Hoofdstuk 4 gaf inzicht in hoe sociale normen een rol spelen in zelf-gerapporteerde betrokkenheid in de medische besluitvorming. Sociale normen definiëren welke handelingen als normaal worden gezien door een groep mensen en welke handelingen als afwijkend [23]. Wij maakten onderscheid tussen twee normen. De eerste is de subjectieve norm: doen wat anderen denken dat jij behoort te doen. De tweede is de descriptieve norm: doen wat anderen doen [24]. Voor beide normen veronderstelden we dat hoe meer het gewoon is in iemands sociale omgeving om een medische beslissing over te laten aan een arts, hoe minder iemand aangeeft dat hij betrokken is in de medische besluitvorming. De reden hiervoor is dat we verwachten dat mensen zich gedragen naar de normen die gelden in hun sociale omgeving, omdat dit leidt tot sociale goedkeuring. In mei 2015 is een vragenlijst gestuurd naar een steekproef van panelleden van het Consumentenpanel Gezondheidszorg van het NIVEL (respons 46\%, N=974). Door middel van een regressie model hebben we de relatie geschat tussen sociale normen enerzijds, en zelf-gerapporteerde betrokkenheid in de medische besluitvorming anderzijds. Onze resultaten bevestigden onze hypothese. Met betrekking tot de subjectieve norm vonden we dat hoe meer iemand denkt dat volgens belangrijke anderen hij of zij de beslissing moet overlaten aan een arts, hoe minder die persoon aangeeft betrokken te zijn in de medische besluitvorming. Hetzelfde vonden we voor de descriptieve norm. Hoe meer mensen denken dat 
anderen de beslissing aan een arts over laten, hoe minder ze aangeven betrokken te zijn in de medische besluitvorming.

Samenvattend laten de resultaten van de hoofdstukken 2, 3 en 4 zien dat gezondheidsvaardigheden, sociale steun en sociale normen alle drie mechanismen zijn die gerelateerd zijn aan de betrokkenheid van patiënten in de medische besluitvorming. Onze resultaten laten zien dat, in het algemeen, er een positieve relatie is tussen hoge kritische gezondheidsvaardigheden, de beschikbaarheid van steun in de vorm van medische informatie en niet-conservatieve sociale normen en de betrokkenheid van patiënten in de medische besluitvorming. Patiënten moeten dan als actor worden opgenomen in theorieën over variatie. Onze resultaten impliceren ook dat de beslissing om deel te nemen aan de medische besluitvorming niet zo individueel is als je op het eerste gezicht zou zeggen; de sociale omgeving van iemand speelt ook een rol.

\section{De betrokkenheid van patiënten en variatie in medisch handelen}

Wanneer patiënten betrokken zijn in de medische besluitvorming kan dit leiden tot andere medische beslissingen. Dit komt omdat de preferenties van een patiënt voor een behandeling kunnen afwijken van de beoordeling van een arts [25]. Omdat de medische besluitvorming een bepalende factor is voor variatie, kunnen patronen van variatie ook veranderen door de betrokkenheid van patiënten. In de literatuur wordt verondersteld dat door de betrokkenheid van patiënten, en in het bijzonder door gezamenlijke besluitvorming, praktijkvariatie zal afnemen [8-12]. Tot nu toe was hier echter geen empirisch bewijs voor. Daarom onderzochten we in dit proefschrift hoe de betrokkenheid van patiënten, en in het bijzonder gezamenlijke besluitvorming, van invloed is op variatie in medisch handelen.

In hoofdstuk 5 toetsten we empirisch de hypothese dat gezamenlijke besluitvorming leidt tot minder variatie in medisch handelen. We veronderstelden dat gezamenlijke besluitvorming is gerelateerd aan minder variatie tussen eenheden (bijvoorbeeld ziekenhuizen). De reden hiervoor is dat we verwachtten dat als gevolg van gezamenlijke besluitvorming een meer conservatieve behandeling werd gekozen zowel in eenheden waar artsen deze behandeling prefereren als in eenheden waar artsen de meer invasieve behandeling prefereren, omdat geïnformeerde patiënten een voorkeur hebben voor een meer 
conservatieve behandeling. Op basis van een beperkte data set onderzochten we hoe gezamenlijke besluitvorming gerelateerd is aan de variatie in de keuze voor het terugplaatsen van één (SET) of twee (DET) embryo's na in vitro fertilisatie. We vonden veel variatie in de keuze voor SET of DET tussen ziekenhuizen in de controle groep, maar minder variatie tussen ziekenhuizen in de groep waarin een strategie om gezamenlijke besluitvorming te bevorderen was toegepast. Onze hypothese is dus bevestigd. Ook vonden we dat binnen de meeste ziekenhuizen de variatie in de keuze voor SET of DET toenam als gevolg van een strategie om gezamenlijke besluitvorming te bevorderen. Binnen andere ziekenhuizen vonden we juist dat de variatie afnam of gelijk bleef. Een implicatie die volgt uit onze resultaten is dat een afname in variatie tussen alle ziekenhuizen niets zegt over de verandering in variatie binnen een individueel ziekenhuis.

Hoofdstuk 6 gaf inzicht in het mogelijke conflict dat kan ontstaan tussen het volgen van richtlijnen enerzijds, en het meenemen van preferenties van patiënten in de besluitvorming aan de andere kant. We onderzochten of preferenties van patiënten een rol spelen in het voorschrijven van antibiotica binnen de huisartsenpraktijk en hoe dit het volgen van richtlijnen beïnvloedt. We veronderstelden dat preferenties van patiënten een grotere rol spelen in het voorschrijven van antibiotica als de richtlijn ruimte biedt om rekening te houden met preferenties. Dat wil zeggen dat volgens de richtlijn antibiotica een optie is die kan worden overwogen en dat er geen duidelijke aanbeveling is om antibiotica wel of niet voor te schrijven. We onderzochten drie verschillende richtlijnen: acuut hoesten, acute rhinosinusitis en urineweginfecties. Met behulp van data van NIVEL Zorgregistraties eerste lijn bepaalden we de indicatie voor antibiotica en het voorschrift voor antibiotica. Deze data hebben we gecombineerd met data verzameld binnen het Consumentenpanel Gezondheidszorg van het NIVEL. Met behulp van een vragenlijst zijn de preferenties van patiënten in kaart gebracht. Volgens data van NIVEL Zorgregistraties eerste lijn hebben 286 patiënten contact gehad met hun huisarts voor acuut hoesten, acute rhinosinusitis of urineweginfecties in 2015. We gebruikten een logistische multilevel regressie analyse om onze hypothese te toetsen. We vonden dat de preferenties van patiënten alleen een rol spelen in de beslissing van de huisarts als het voorschrijven van antibiotica volgens de richtlijn kon worden overwogen (interactie tussen indicatie en preferentie: $p=0.049$ ). Als patiënten in dergelijke situaties om antibiotica vragen, dan worden deze door huisartsen vaker voorgeschreven. In deze situaties is er echter geen conflict tussen het volgen van richtlijnen en het 
meenemen van preferenties van patiënten in de beslissing. De reden hiervoor is dat het voorschrijven van antibiotica in zulke situaties gerechtvaardigd is, omdat de richtlijn ruimte biedt om rekening te houden met de preferenties van patiënten. Onze hypothese kunnen we dan ook bevestigen.

Samengevat laten de resultaten van de hoofdstukken 5 en 6 zien dat als patiënten een actieve rol hebben in de medische besluitvorming dit van invloed is op de beslissing, en dus op de variatie.

\section{Conclusies}

In dit proefschrift is voor het eerst een theoretisch model getoetst dat variatie in medisch handelen verklaart en tegelijkertijd ook de interactie tussen de arts en de patiënt meeneemt. Hierdoor kregen we inzicht in omstandigheden waaronder de interactie tussen arts en patiënt niet wordt gedomineerd door de arts. En indien dit het geval is, hoe de betrokkenheid van de patiënt de beslissing beïnvloedt, en dus de variatie. We vonden dat gezondheidsvaardigheden, sociale steun en sociale normen alle drie mechanismen zijn die gerelateerd zijn aan de betrokkenheid van patiënten in de medische besluitvorming. Onze resultaten laten zien dat, in het algemeen, er een positieve relatie is tussen hoge kritische gezondheidsvaardigheden, de beschikbaarheid van steun in de vorm van medische informatie en niet-conservatieve sociale normen en de betrokkenheid van patiënten in de medische besluitvorming. Patiënten moeten dan als actor worden opgenomen in theorieën over variatie. Onze resultaten impliceren ook dat de beslissing om deel te nemen aan de medische besluitvorming niet zo individueel is als je op het eerste gezicht zou zeggen; de sociale omgeving van iemand speelt ook een rol. Dit proefschrift laat ook zien dat de betrokkenheid van patiënten in de medische besluitvorming van invloed is op de beslissing die wordt genomen, en dus de variatie. We vonden dat gezamenlijke besluitvorming door arts en patiënt leidt tot minder variatie tussen ziekenhuizen. Op deze manier bevestigden we empirisch de hypothese uit de literatuur dat gezamenlijke besluitvorming leidt tot minder variatie in medisch handelen. Tot nu toe was hier geen empirisch bewijs voor. Daarnaast vonden we dat gezamenlijke besluitvorming leidt tot een ander patroon van variatie binnen ziekenhuizen. Een implicatie die volgt uit onze resultaten is dat een afname in variatie tussen alle ziekenhuizen niets zegt over de verandering in variatie binnen een individueel ziekenhuis. Ten slotte vonden we dat twee 
mechanismen, te weten richtlijnen en betrokkenheid van patiënten, niet met elkaar hoeven te botsen. Onze resultaten suggereren dat preferenties van patiënten alleen een rol spelen als de richtlijn ruimte biedt om rekening te houden met deze preferenties. Samenvattend, bleek ons model waardevol om inzicht te krijgen in omstandigheden waaronder de interactie tussen arts en patiënt niet gedomineerd wordt door de arts, en als dit het geval is, hoe dit de medische beslissing beïnvloedt, en dus de variatie. In onze ogen geeft dit proefschrift voldoende inzicht dat onder bepaalde omstandigheden patiënten niet kunnen worden genegeerd in theorieën over variatie. Desalniettemin liet dit proefschrift ook nog vragen onbeantwoord. Om inzicht te krijgen in deze vragen hebben we verschillende suggesties voor vervolgonderzoek gegeven. 


\section{Referenties}

1. Corallo AN, Croxford R, Goodman DC, Bryan EL, Srivastava D, Stukel TA. A systematic review of medical practice variation in OECD countries. Health Policy 2014; 114(1):5-14

2. Paul-Shaheen P, Clark JD, Williams D. Small area analysis: a review and analysis of the North American literature. Journal of health politics, policy and law 1987;12(4):741809

3. Wennberg JE. Tracking medicine: a researcher's quest to understand health care. Oxford: Oxford University Press, 2010

4. De Jong JD, Groenewegen PP, Westert GP. Sociological Model for Understanding Medical Practice Variations. In: Sobolev B (Series ed), Johnson A, Stukel T (eds). Health Services Research Series. Medical Practice Variations. New York: Springer, 2015; 25-39

5. Guadagnoli E, Ward P. Patient participation in decision-making. Social Science \& Medicine 1998; 47(3):329-39

6. RVZ. De participerende patiënt. Den Haag, 2013

7. Institute of Medicine. Crossing the quality chasm: A new health system for the 21st century: National Academies Press, 2001

8. Greer AL, Goodwin JS, Freeman JL, Wu ZH. Bringing the patient back in. Guidelines, practice variations, and the social context of medical practice. International Journal of Technology Assessment in Health Care 2002; 18(4):747-61

9. O'Connor AM, Llewellyn-Thomas HA, Flood AB. Modifying unwarranted variations in health care: shared decision making using patient decision aids. Health Affairs 2004; Var63-72

10. O'Connor AM, Wennberg JE, Legare F, Llewellyn-Thomas HA, Moulton BW, Sepucha $K R$, et al. Toward the 'tipping point': decision aids and informed patient choice. Health Affairs 2007; 26(3):716-25

11. Stiggelbout AM, Van der Weijden T, De Wit MP, Frosch D, Legare F, Montori VM, et al. Shared decision making: really putting patients at the centre of healthcare. The BMJ 2012; 344:e256 
12. Weinstein JN, Bronner KK, Morgan TS, Wennberg JE. Trends and geographic variations in major surgery for degenerative diseases of the hip, knee, and spine. Health Aff 2004; Suppl Variation:Var81-9

13. Say $R$, Murtagh $M$, Thomson R. Patients' preference for involvement in medical decision making: a narrative review. Patient Education \& Counseling 2006; 60(2):10214

14. Beauchamp A, Buchbinder R, Dodson S, Batterham RW, Elsworth GR, McPhee C, et al. Distribution of health literacy strengths and weaknesses across socio-demographic groups: a cross-sectional survey using the Health Literacy Questionnaire (HLQ). BMC Public Health 2015; 15:678

15. Dodson S, Beauchamp A, Batterham RW, Osborne RH. Information sheet 1: What is health literacy? In Ophelia Toolkit: A step-by-step guide for identifying and responding to health literacy needs within local communities. www.ophelia.net.au

16. Osborne RH, Batterham RW, Elsworth GR, Hawkins M, Buchbinder R. The grounded psychometric development and initial validation of the Health Literacy Questionnaire (HLQ). BMC Public Health 2013; 13:658

17. Chinn D. Critical health literacy: a review and critical analysis. Social Science \& Medicine 2011; 73(1):60-7

18. Arrow KJ. Uncertainty and the welfare economics of medical care. The American economic review 1963; 941-73

19. Charles C, Whelan T, Gafni A, Reyno L, Redko C. Doing Nothing is No Choice: Lay Constructions of Treatment Decision-making Among Women with Early-stage Breast Cancer. Sociology of Health \& Illness 1998; 20(1):71-95

20. Marzuk PM. The right kind of paternalism. New England Journal of Medicine 1985; 313(23):1474-6

21. Pellegrino ED. Patient and physician autonomy: conflicting rights and obligations in the physician-patient relationship. Journal of Contemporary Health Law \& Policy 1994; $10: 47$

22. Wolff JL, Roter DL. Family presence in routine medical visits: a meta-analytical review. Social Science \& Medicine 2011; 72(6):823-31 
23. Coleman J. Foundations of social theory. Cambridge, MA: Belknap 1990

24. Cialdini RB, Kallgren CA, Reno RR. A focus theory of normative conduct: A theoretical refinement and reevaluation of the role of norms in human behavior. Advances in experimental social psychology 1991; 24(20):1-243

25. Wennberg JE. Variation in Use of Medicare Services among Regions and Selected Academic Medical Centers: Is More Better? Commonwealth Fund, 2005 


\section{Valorisation}


As defined by the Maastricht Valorisation Centre, "valorisation is the process of creating value from knowledge, by making this knowledge available and suitable for economic and social exploitation and to translate this knowledge into products, services, processes and new business" [1]. Valorisation also relates to making the findings of scientific research available, or more easily available, to enhance the chances that other stakeholders outside the academic world will make use of it. It is also about making knowledge in co-production with non-academic stakeholders [2]. In this valorisation section, we will describe how the findings of this thesis can be of value outside the academic world. More specific, we discuss valorisation in the context of patient involvement in medical decision-making and in the context of patient involvement and medical practice variation. Furthermore, activities that have been done to disseminate our findings to others, both inside and outside the academic world, are presented. We also describe how non-academic stakeholders were involved in the studies performed in this thesis.

In this thesis, we tested a theoretical model and as a result we gained knowledge about the role of patients in theories about variation in medical practice. First, we found that the decision to be involved in the decision-making process is not that individual as it at first seems. This conclusion is based on our findings that suggest that both social support and social norms play a role in the decision to take an active role in medical decision-making. We also found that critical health literacy plays a role in this decision. Second, we found that if patients are involved in the decision-making process this influences the decision taken and thus the variation. This observation is based on our findings that shared decision-making (SDM) results in less variation between hospitals, and another pattern of variation within hospitals. Furthermore, we found that two mechanisms, guidelines and patient involvement, that are both able to reduce practice variation, do not have to conflict with each other. Valorisation was part of this thesis as will be explained below.

\section{Patient involvement in medical decision-making}

Part $A$ of this thesis showed under which circumstances patients take an active role within medical decision-making. In 2006, the Netherlands introduced a new health insurance system based on managed competition. The introduction of this system was, among others, intended to force a shift from supply to demand driven care: the demand and needs of patients should be leading in the provision of care [3]. 
This implies that, at an individual level, patients have to take up an active role in decisions about their health. Not only in the Netherlands, also in other countries, patient involvement is on the agenda of policy makers, professional bodies, patient representatives groups, and health insurers $[4,5]$. Our findings are therefore not only relevant for policy and practice in the Netherlands, but also for other countries that aim to emphasise patient involvement in decision-making. It has been argued that there is a strong patient participation movement at both the macro and meso level in the Netherlands. However, at the micro level, or in daily practice, there is room for improvement [5]. Findings of this thesis provide directions for addressing this improvement and therefore producing social value of our results. SDM is found to be positively related to patient outcomes, such as improved satisfaction and less decisional conflict [6]. Through this thesis, we have provided insight into three mechanisms that play a role in whether patients take an active role in decisions about their health. We found that the decision to be involved is not that individual as it at first seems. Our findings provide some directions to improve patient involvement in daily practice, however, it has to be recognised that there always will be a group of patients that is not able or not willing to take an active role in medical decision-making.

Our findings confirm that people do not make decisions in a 'vacuum' even in the context of SDM. Strategies aimed at emphasising SDM within daily practice have to address this social context too. To inform the Ministry of Health, Welfare and Sport about this, we presented our results to several delegates of the Ministry of Health, Welfare and Sport in October 2017. Next to the results, we presented several directions for policy. For example, supported by our finding that for low educated people taking someone with you to a medical consultation is positively related to involvement, patients can be more actively stimulated to take someone with them to the medical consultation when decisions about their health have to be taken. Afterwards, there was a discussion with the attendees about the role that the context of people might play in decisions they make. In the near future, we aim to present our results to other stakeholders, for example by giving a presentation during a meeting of the program committee of the Dutch Health Care Consumer Panel. Within this committee several stakeholders are represented.

Although our findings provide some directions to improve patient involvement in daily practice, the mechanisms examined in this thesis did not explain all variation in whether patients take an active role in medical decision-making. Therefore, we 
provided some directions for future research in the Discussion of this thesis. Efforts have already been made to examine several of these directions for future research. In 2018, we start with unravelling the relation between trust and patient activation (i.e. having the knowledge, skills, confidence, and behaviours needed for managing one's own health and health care [7]) on the one hand, and patient involvement on the other. In addition, for the Dutch Ministry of Health, Welfare and Sport, patient involvement is an important topic. Besides the data used for this thesis, also other data about this subject have been collected in the Dutch Health Care Consumer Panel. Since 2016, the Ministry have asked us to measure levels of SDM, using the SDMQ-9 [8], among the Dutch population aged 18 years and older. Moreover, we measure since 2016 the extent to which patients find that their general practitioner involves them in decisions about their treatments ( $88 \%$ answered mostly or always, in 2016). This percentage is shown as key figure on the website of 'De Staat van Volksgezondheid en Zorg' (Staat van VenZ) [9]. The goal of this Staat van VenZ is to present actual and unambiguous key figures to monitor and to account for the policy of the Dutch Ministry of Health, Welfare and Sport [10]. Furthermore, we presented our results in two one page factsheets [11, 12], which were sent to, among others, the Ministry of Health, Welfare and Sport. These factsheets were highly appreciated in the field. Finally, the data collected can be used in the future to examine new research questions about this subject, and to examine whether patient involvement has been improved in daily practice.

\section{Patient involvement and medical practice variation}

Compared to our results regarding patient involvement in medical decision-making, valorisation of our results about the role of patient involvement in explaining medical practice variation is more complex. Part B of this thesis shows that if patients are involved in medical decision-making this is of influence on the decision taken, and therefore on variation. Although there is increased attention for patient involvement in decision-making, the question of how this is of influence on practice variation is a rather new one in the field. Before this thesis, no clear theoretically derived hypotheses were available. Furthermore, empirical data confirming that patient involvement, and more specifically SDM, reduces practice variation was lacking. We tried to close this gap in the knowledge by formulating several hypotheses and by empirically testing the hypothesis that SDM reduces practice variation. By including patients as an actor in theories about practice variation, we 
diverged from current research that explains variation by focusing mainly on physicians and the organisations they work in.

Our results show that if patients are involved in medical decision-making this is of influence on the decision taken, and thus on variation. However, a limitation is that both studies in part B of this thesis are based on limited data sets, each focusing on just one decision-making situation. An important question is to what extent our results are applicable to other decision-making situations. Nevertheless, our findings are important to consider for several stakeholders. As argued, practice variation is in itself not a bad thing, as without variation there might not be any advancement in health care [13]. However, the problem is that it is not clear what is behind practice variation as physicians are not able to clarify why there is such variation. For policy makers and health insurance companies, practice variation is a sign of physicians using unnecessary treatments, and thus a sign of unnecessary spending [13]. Our observation that SDM reduces practice variation between hospitals might provide new insights for policy makers and insurance companies about this subject. If they aim to decrease variation, it might be a possibility to focus on the involvement of patients instead of on the behaviour of physicians only. However, policy makers and insurance companies have to be aware that SDM might increase variation within an individual hospital.

For researchers, our findings provide directions for further research about theories on practice variation. Next to testing whether our results are applicable to other decision-making situations, it is recommended to further elaborate upon possible hypotheses about the role of patients in theories about variation. Regarding this, we are now examining to what extent SDM is associated with inappropriate antibiotics prescription rates in general practice. We hypothesise that rates of inappropriate antibiotics prescription are lower in general practices where SDM takes more often place. To test this we make use of a combined set of data of the NIVEL Primary Care Database and NIVEL's Dutch Health Care Consumer Panel.

\section{Dissemination}

To disseminate our results inside and outside the academic world several activities have been employed. These activities are explained hereafter. We also explain how we involved non-academic stakeholders in the studies performed. 
First, the scientific results that are presented in the Chapters 2 to 6 are published in five different international peer-reviewed journals. Most of these journals are open access journals, which means that the articles are available for the public freely and without any restrictions. Some of these articles have already been cited by authors of other scientific articles. Moreover, our study published in 2016 in the BMJ Open (see Chapter 5) is referred to in a blog of 'Innovations in Healthcare', being a nonprofit organisation hosted by Duke University [14].

Second, we presented our findings at three international conferences. These were: 1) the Wennberg International Collaborative (London, September 2015), 2) the European Public Health Conference (Milan, October 2015), and 3) the European Public Health Conference (Stockholm, November 2017). At the European Public Health Conference of 2015, an abstract of the study presented in Chapter 3 was nominated for the Ferenc Bojan Young investigator award.

Third, we have disseminated our findings to relevant stakeholders outside the academic world. The Dutch Health Care Consumer Panel has a program committee. This committee consists of representatives of the following stakeholders in the healthcare sector: the Dutch Ministry of Health, Welfare and Sport, the Association of Health Care Insurers in the Netherlands, the National Health Care Institute, the Dutch Healthcare Authority, the Federation of Patients in the Netherlands, the Dutch Health Care Inspectorate and the Dutch Consumers Association. All the publications that are based on data collected within the Consumer Panel are sent to the members of the program committee to inform them about the results and to give them the possibility to distribute the results to relevant persons within their organisation. In this thesis, the Chapters 2, 3, 4 and 6 are based, or partly based, on data collected within the Consumer Panel, and as such sent to the members of the committee.

The members of this program committee were also involved in the development of the questionnaires used in the studies of the Chapters 2, 3, 4 and 6 . We send all the draft questionnaires to the members of the committee to give them an opportunity to comment on the draft questionnaire. Based on the comments of the committee, we were able to improve our questionnaires, and to make sure that these are more in line with practice. 
The study of Chapter 6 is partly based on research performed in the cooperative framework that NIVEL and The National Health Care Institute had. During this research an employee of the Health Care Institute was seconded at NIVEL for one day a week to work together with NIVEL researchers on the research about the role of patients in non-adherence to antibiotic guidelines by general practitioners. Both NIVEL and the Health Care Institute published a news item on their website to pay attention to the report that has been published about this research. This news item was taken over by several others, like the Nationale Zorggids [15] and Skipr. We also disseminated the results to general practitioners by publishing a short summary of the report in Huisarts en Wetenschap [16], the official journal of the College of General Practitioners.

Finally, to stay informed about other research and to stay in contact with other researchers in the field of medical practice variation, the author of this thesis is member of the Wennberg International Collaborative (WIC). The WIC aims to "accelerate research into the causes and consequences of unwarranted health care variation across regions and providers" [17]. Both researchers and policy makers are members of the WIC [17]. 


\section{References}

1. Maastricht Valorisation Centre. Available at: https://www.maastrichtuniversity.nl/ about-um/other-offices/maastricht-valorisation-centre (8 December, 2017, date last accessed)

2. Benneworth $P$, Jongbloed BW. Who matters to universities? A stakeholder perspective on humanities, arts and social sciences valorisation. Higher Education 2010; 59(5):567588.

3. RVZ. De participerende patiënt. Den Haag, 2013

4. Harter M, Moumjid N, Cornuz J, Elwyn G, van der Weijden T. Shared decision making in 2017: International accomplishments in policy, research and implementation. Zeitschrift für Evidenz, Fortbildung und Qualität im Gesundheitswesen 2017; 123$124: 1-5$

5. Van der Weijden T, Post H, Brand PLP, Van Veenendaal H, Drenthen T, Van Mierlo LA, et al. Shared decision making, a buzz-word in the Netherlands, the pace quickens towards nationwide implementation. Zeitschrift für Evidenz, Fortbildung und Qualität im Gesundheitswesen 2017; 123-124:69-74

6. Shal LA, Lafata JE. Where is the evidence? A systematic review of shared decision making and patient outcomes. Medical Decision Making 2015; 35(1):114-131

7. Hibbard JD, StockardJ, Mahoney ER, Tusler M. Development of the Patient Activation Measure (PAM): Conceptualizing and measuring activation in patients and consumers. Health Services Research 2004; 39:1005 - 1026

8. Kriston L, Scholl I, Hölzel L, Simon D, Loh A, Härter M. The 9-item Shared Decision Making Questionnaire (SDM-Q-9). Development and psychometric properties in a primary care sample. Patient Education and Counseling 2010; 80(1):94-9

9. De Staat van Volksgezondheid en Zorg. Kerncijfers Kwaliteit: huisarts betrekt patiënt bij beslissingen. Available at: https://www.staatvenz.nl/kerncijfers/kwaliteit-huisartsbetrekt-patiënt-bij-beslissingen (8 December, 2017, date last accessed) 
10. De Staat van Volksgezondheid en Zorg. Waarom wordt de Staat van Volksgezondheid en Zorg gemaakt. Available at: https://www.staatvenz.nl/content/waarom-wordt-destaat-van-volksgezondheid-en-zorg-gemaakt (8 December, 2017, date last accessed)

11. Van der Schors W, Brabers A, Hoefman R, De Jong J. We zijn positief over de bejegening door onze huisarts in Nederland. Utrecht: NIVEL, 2016

12. Van der Schors W, Brabers A, Hoefman R, De Jong J. Hoe kijken patiënten in Nederland aan tegen het samen beslissen met hun arts over een behandeling? Utrecht: NIVEL, 2016

13. De Jong JD. Explaining medical practice variation. Social organization and institutional mechanisms. NIVEL, 2008

14. Innovations in healthcare. Bending the Cost Curve Through Shared Decision Making. Available at: https://www.innovationsinhealthcare.org/bending-the-cost-curvethrough-shared-decision-making (8 December, 2017, date last accessed)

15. Nationale Zorggids. Onderzoek biedt houvast voor verstandiger antibioticagebruik. Available at: https://www.nationalezorggids.nl/ziekenhuizen/nieuws/36428onderzoek-biedt-houvast-voor-verstandiger-antibioticagebruik.html (8 December, 2017, date last accessed)

16. Huisarts en Wetenschap. Minder antibiotica door meer te praten. Available at: https://www.henw.org/nieuws/id515-minder-antibiotica-door-meer-te-praten.html (8 December, 2017, date last accessed)

17. Wennberg International Collaborative. The Wennberg International Collaborative. Available at: http://wennbergcollaborative.org/about (8 December, 2017, date last accessed) 


\section{Dankwoord}


De laatste punt is gezet. Mijn proefschrift is af! Wat een onwerkelijk gevoel! Het was een bijzondere periode de afgelopen jaren. Een proefschrift schrijven 'naast' je gewone werkzaamheden op onderzoeksprojecten is best wel een uitdaging. Dit proefschrift was er dan ook niet gekomen zonder de hulp van veel mensen, welke ik hier graag wil bedanken.

Judith, in november 2010 begon ik als toen nog assistent-onderzoeker op het Consumentenpanel Gezondheidszorg. In de afgelopen ruim zeven jaar ben ik onder jouw vleugels uitgegroeid tot de onderzoeker die ik nu ben. Ik heb veel van je geleerd in de afgelopen jaren! Vanaf het begin hebben we bijzonder prettig samengewerkt op allerlei projecten naast dit proefschrift. Ook waren je eigen ervaringen met een sprokkelpromotie voor mij heel waardevol als ik even niet zag zitten hoe nu verder. Tot slot is het fijn om een promotor te hebben waar je altijd terecht kan, en niet alleen voor werkgerelateerde zaken. Het is altijd gezellig om even met je bij te kletsen. Judith, bedankt voor alles in de afgelopen jaren en dat we nog maar lang prettig mogen samenwerken!

Peter, met jouw kritische blik bewaakte je vanaf het begin de hoofdlijnen van dit proefschrift. Bedankt daarvoor! Vanaf 2016 had je meer ruimte in je agenda en was je meer, en in een eerder stadium, betrokken bij de studies in dit proefschrift. Dat heb ik als heel prettig ervaren.

Liset, als co-auteur van alle vijf de artikelen heb je een belangrijke bijdrage geleverd aan dit proefschrift. Maar je bijdrage gaat verder dan dit proefschrift. Al heel lang speel je voor mij een belangrijke rol en vaak heb je me van advies voorzien in met name studie en werkgerelateerde zaken. Ontzettend bedankt daarvoor. En heel fijn dat je op dit belangrijke moment naast mij wil staan als paranimf.

Leden van de beoordelingscommissie, prof. dr. Trudy van der Weijden, prof. dr. Sandra Beurskens, prof. dr. Jako Burgers, prof. dr. Glyn Elwyn en prof. dr. Gert Westert, hartelijk dank voor jullie kritische beoordeling van dit proefschrift.

Jany, Thamar, Karin, Pé en Arno, als co-auteurs hebben jullie ieder op jullie eigen manier bijgedragen aan dit proefschrift. Jany, als hoogleraar gezondheidsvaardigheden heb je een belangrijke bijdrage geleverd aan de studie in Hoofdstuk 2. Bedankt voor je altijd heldere reactie op mijn stukken. Op naar onze volgende gezamenlijke artikelen over health literacy! Thamar, bedankt voor het meedenken 
over de inhoud en het analyseren van de data voor de studie in Hoofdstuk 6. Zonder jouw hulp was dit artikel er niet gekomen! Het is fijn met je samen werken! Arno, dankzij jouw data kon ik de hypothese dat gezamenlijke besluitvorming tot minder variatie leidt toetsen. Bedankt dat je altijd klaar stond om vragen te beantwoorden, zelfs als je op de fiets zat.

Margreet, in de tijd dat wij samen op het Consumentenpanel Gezondheidszorg werkten, stond dit proefschrift nog in de steigers en heb ik vaak gedacht dat het er niet zou komen. Het was fijn om altijd mijn verhaal bij jou kwijt te kunnen. Renske, jij kwam op het Consumentenpanel werken toen mijn proefschrift op snelheid kwam. Mede dankzij jou had ik meer tijd om aan mijn proefschrift te besteden. Bedankt daarvoor! Wouter, jij kwam op het panel werken in de laatste fase van dit proefschrift. Je toonde altijd veel belangstelling en ging enthousiast aan de slag met de kaft van mijn proefschrift. Hij is mooi geworden, dank daarvoor!

Dit proefschrift heb ik met name geschreven in kamer 2.17 van het NIVEL. In de afgelopen jaren heb ik veel kamergenootjes gehad, zowel voor kortere als langere tijd. Het was altijd fijn om mijn verhaal bij jullie kwijt te kunnen. Erica, met jou heb ik het langst op de kamer gezeten, en samen hebben we veel lief en leed gedeeld. Ik hoop dat jij over niet al te lange tijd ook de laatste punt van je proefschrift mag zetten.

De panelleden van het Consumentenpanel Gezondheidszorg bedank ik voor het invullen van de vragenlijsten. Collega's van het ondersteuningscluster survey- en panelonderzoek, bedankt voor het beheer van het panel. Han en Natalie, als DESAN team zorgen jullie er altijd weer voor dat de dataverzameling binnen het panel op rolletjes loopt. Lucas, bedankt voor je advies over de statistische analyses in dit proefschrift. Tony, bedankt voor het checken van het Engels van alle hoofdstukken, er zijn er maar weinig die dit proefschrift zo goed gelezen hebben als jij. Christel, veel dank voor het opmaken van mijn proefschrift. Maar niet alleen daarvoor, voor een precies pietje als ik is het fijn om zo'n precies duizendpootje als jou als secretaresse te hebben. Remco, Michelle en Kim, bedankt voor de gezellige gesprekken in de trein in de afgelopen jaren. Het NIVEL is een stuk dichterbij als je niet alleen hoeft te reizen. En tot slot bedank ik al mijn andere collega's die in de afgelopen jaren interesse getoond hebben in mij en in dit proefschrift; dat maakt je werk een stuk leuker. 
Marlinde, Mariska en Kim. Met drie van de vier aan het promoveren was het meer dan eens een onderwerp van gesprek. Nu zijn we alle drie klaar. Het is tijd voor andere gespreksonderwerpen! Al hebben wij die volgens mij al gevonden Mariska...

Max en Ilona, Mark en Karin, Serviel en Marjolijn, Benjamin en Sandy, ofwel family en friends, het is prettig om buiten je werk te kunnen ontspannen en even niet aan je proefschrift te hoeven denken. Bedankt voor alle afleiding in de afgelopen jaren!

Jan en Joke, eindelijk ben ik dan 'afgestudeerd'! Toen ik jullie leerden kennen zat ik in de zesde van het gymnasium, toen volgde de universiteit en nu ruim 13 jaar later is de cirkel rond met dit proefschrift. Al was het vaak een ver van jullie bed show, bedankt voor jullie interesse in mijn 'studie' tijdens al die jaren.

Papa en Mama, Merel en Frank, er gaat niets boven een veilige thuisbasis. Wat hebben we het gezellig met zijn allen. En wat is het fijn dat ik altijd bij jullie terecht kan; het maakt niet uit waarmee. Bedankt voor jullie onvoorwaardelijke steun en liefde in de afgelopen jaren. Op naar een mooie toekomst! Merel, als zusje, maar bovenal heel goede vriendin, ben je heel belangrijk voor mij. Ik ben blij dat ook jij naast mij staat als paranimf.

Sven, wat geef je ons veel liefde en wat maak je ons gelukkig! Onbewust heb jij er voor gezorgd dat dit proefschrift in een stroomversnelling kwam. Lieve Ger, de stille kracht achter dit proefschrift, en niet alleen achter dit proefschrift. Zonder jou was het er zeker niet gekomen. Ontzettend bedankt voor alles wat je voor mij hebt gedaan in de afgelopen jaren. Ik hou van jou. Voor nu en voor altijd.

Anne Brabers, december 2017 


\section{About the author}


Adriana Elisabeth Maria (Anne) Brabers was born on the $6^{\text {th }}$ of May, 1987 in Oosterhout (NB), the Netherlands. In 2005, she completed her secondary school at St. Oelbert Gymnasium in Oosterhout (NB). After that, she studied the bachelor and research master Science and Innovation Management at Utrecht University, respectively. After obtaining her master degree in August 2010, Anne started her career at NIVEL (the Netherlands Institute for Health Services Research). Within NIVEL's Health Care System and Governance programme, she mainly works as a researcher at the Dutch Health Care Consumer Panel. She is also involved in several other research projects within the programme, like the Dutch eHealth-monitor. In 2014, Anne started with the research described in this PhD-thesis, under the supervision of prof. dr. Judith de Jong and prof. dr. Peter Groenewegen. She combined her PhD-research with other research projects. Anne her research has resulted in many international and national publications, including this PhD-thesis. An abstract of the study described in Chapter 3 was nominated for the Ferenc Bojan Young investigator award at the European Public Health Conference of 2015. Currently, Anne is still working as a researcher within NIVEL's Health Care System and Governance programme.

Anne is married with Ger de Vries, and together they have one son: Sven (2016). 


\section{List of publications}


Hereafter, a selection of publications is presented. For a full list of publications, visit www.nivel.nl/anne-brabers.

\section{Publications in international journals}

Brabers AEM, Van Esch TEM, Groenewegen PP, Hek K, Mullenders P, Van Dijk L, De Jong JD. Is there a conflict between general practitioners applying guidelines for antibiotic prescribing and including their patients' preferences? Patient Preference and Adherence 2018; 12:9-19 https://doi.org/10.2147/PPA.S147616

Brabers AEM, Rademakers JJDJM, Groenewegen PP, Van Dijk L, De Jong JD. What role does health literacy play in patients' involvement in medical decision-making? Plos One 2017; 3;12(3):e0173316 doi: 10.1371/journal.pone.0173316

Brabers AEM, De Jong JD, Groenewegen PP, Van Dijk L. Social support plays a role in the attitude that people have towards taking an active role in medical decision-making. BMC Health Services Research 2016; 16:502 doi/10.1186/s12913-016-1767-x

Brabers AEM, Van Dijk L, Groenewegen PP, De Jong JD. Do social norms play a role in explaining involvement in medical decision-making? European Journal of Public Health 2016; Dec; 26(6):901-905 doi: 10.1093/eurpub/ckw069

Brabers AEM, Van Dijk L, Groenewegen PP, Van Peperstraten AM, De Jong JD. Does a strategy to promote shared decision-making reduce medical practice variation in the choice of either single or double embryo transfer after in vitro fertilisation? A secondary analysis of a randomised controlled trial. BMJ Open 2016; 6:e010894 doi: 10.1136/bmjopen-2015010894

Brabers AEM, De Jong JD. Perceptions about affordability of care in the Netherlands. Eurohealth 2014; 20(4): 31-34

Brabers AEM, Van Dijk L, Bouvy ML, De Jong JD. Where to buy OTC medications? A crosssectional survey investigating consumers' confidence in over-the-counter (OTC) skills and their attitudes towards the availability of OTC painkillers. BMJ Open 2013; 3:e003455 doi: 10.1136/bmjopen-2013-003455

Brabers AEM, Reitsma-Van Rooijen M, De Jong JD. The Dutch health insurance system: mostly competition on price rather than quality of care. Eurohealth 2012; 18(1): 30-33 
Brabers AEM, Moors EHM, van Weely S, De Vrueh RL. Does market exclusivity hinder the development of Follow-on Orphan Medicinal Products in Europe? Orphanet Journal of Rare Diseases 2011; 6(59) doi: 10.1186/1750-1172-6-59

Van der Gaag M, Van der Heide I, Spreeuwenberg PMM, Brabers AEM, Rademakers JJDJM. Health literacy and primary health care use of ethnic minorities in the Netherlands. BMC Health Services Research 2017; 15;17(1):350 doi: 10.1186/s12913-017-2276-2

Van Esch TEM, Brabers AEM, Van Dijk CE, Gusdorf L, Groenewegen PP, De Jong JD. Increased cost sharing and changes in noncompliance with specialty referrals in The Netherlands. Health Policy 2017; 121(2):180-188 doi: 10.1016/j.healthpol.2016.12.001

Peeters JM, Krijgsman JW, Brabers AEM, Jong JD, Friele RD. Use and Uptake of eHealth in General Practice: A Cross-Sectional Survey and Focus Group Study Among Health Care Users and General Practitioners. JMIR Medical Informatics 2016; 6;4(2):e11 doi: 10.2196/ medinform. 4515

De Veer AJ, Peeters JM, Brabers AEM, Schellevis FG, Rademakers JJDJM, Francke AL. Determinants of the intention to use e-Health by community dwelling older people. BMC Health Services Research 2015; 15;15(103) doi: 10.1186/s12913-015-0765-8

Rademakers JJDJM, Nijman J, Brabers AEM, De Jong JD, Hendriks M. The relative effect of health literacy and patient activation on provider choice in the Netherlands. Health Policy 2014; 114(2-3):200-206 doi: 10.1016/j.healthpol.2013.07.020

Nijman J, Hendriks M, Brabers AEM, De Jong JD, Rademakers JJDJM. Patient activation and health literacy as predictors of health information use in a general sample of Dutch health care consumers. Journal of Health Communication 2014; 19(8):955-969 doi: 10.1080/ 10810730.2013.837561

\section{Publications in national journals}

Brabers A, Swinkels I, Krijgsman J, De Jong J. Online een afspraak maken bij de huisarts. Huisarts en Wetenschap 2017; 60(3):111

Hoefman R, Brabers A, De Jong J. Huisartsenzorg in cijfers: wat missen patiënten in het consult? Huisarts en Wetenschap 2016; 59(7):305 
Van Dijk L, Brabers A, De Jong J, Korevaar J. Huisartsenzorg in cijfers: antibiotica. "Kuur volledig afmaken". Huisarts en Wetenschap 2016; 59(6):258

Reitsma-Van Rooijen M, Brabers A, De Jong J. Beperkt inzicht in zorgkosten. Economisch Statistische Berichten 2015; 100(4706):174-175

Brabers A, Krijgsman J, De Jong J. Huisartsenzorg in cijfers: online contactmogelijkheden bij de huisarts. Huisarts en Wetenschap 2014; 57(10):541

Reitsma-Van Rooijen M, Brabers A, De Jong J. Selectie aan de poort: onterechte zelfverwijzers op de SEH terugdringen. TSG: Tijdschrift voor Gezondheidswetenschappen 2013; 91(1):41-43

Brabers A, Reitsma-Van Rooijen M, De Jong J. Huisartsenzorg in cijfers: gebruik van internet voor gezondheidsinformatie. Huisarts en Wetenschap 2012; 55(8):359

Brabers A, Reitsma-Van Rooijen M. Huisartsenzorg in cijfers: patiënten over telefonische bereikbaarheid. Huisarts en Wetenschap 2011; 54(5):265

\section{Reports}

Wouters M, Swinkels I, Sinnige J, De Jong J, Brabers A, Van Lettow B, Friele R, Van Gennip L. Kies bewust voor eHealth: eHealth-monitor 2017. Den Haag/Utrecht: Nictiz, NIVEL, 2017. $116 \mathrm{p}$

De Jong J, Van Esch T, Brabers A. De zorgverzekeringsmarkt: gedrag, kennis en solidariteit. Een verdiepend onderzoek naar verschillen tussen groepen verzekerden. Utrecht: NIVEL, 2017. $71 p$

De Hoon S, Weesie Y, Brabers A, De Jong J, Verheij R. Health checks en de effecten op het gebruik van zorg: kennisvraag. Utrecht: NIVEL, 2017. $62 \mathrm{p}$

Van der Schors W, Brabers A, De Jong J. Solidariteit in het Nederlandse Zorgstelsel: een onderzoek naar de bereidheid om voor anderen te betalen onder de algemene bevolking. Utrecht: NIVEL, 2017. $28 p$

Van Esch T, Mullenders P, Brabers A, Hek K, De Jong J. De rol van patiënten bij het afwijken van richtlijnen door huisartsen: een onderzoek naar het voorschrijven van antibiotica. Utrecht: NIVEL, 2017. $104 p$ 
Van Esch TEM, Brabers AEM, Van Dijk C, Groenewegen PP, De Jong JD. Inzicht in zorgmijden: aard, omvang, redenen en achtergrondkenmerken. Utrecht: NIVEL, 2015. $75 p$

De Jong JD, Brabers AEM, Bouwhuis S, Bomhoff $M$, Friele R. Het functioneren van de zorgverzekeringsmarkt: een kennissynthese. Utrecht: NIVEL, 2015. $69 \mathrm{p}$

Krijgsman J, Peeters J, Burghouts A, Brabers A, De Jong J, Moll T, Friele R, Van Gennip L. Tussen vonk en vlam: eHealth-monitor 2015. Utrecht/Den Haag: NIVEL, Nictiz, 2015. 168 p

Krijgsman J, Peeters J, Burghouts A, Brabers A, De Jong J, Beenkens F, Friele R, Van Gennip L. Op naar meerwaarde! eHealth-monitor 2014. Den Haag/Utrecht: Nictiz, NIVEL, 2014. 157 p

\section{Factsheets}

Brabers A, Swinkels I, Van Lettow B, De Jong J. Zorggebruikers zien zowel positieve als negatieve kanten van het e-consult. Gebruikers zijn positiever over het e-consult dan niet gebruikers. Utrecht: NIVEL, 2017

Brabers A, Van der Schors W, De Jong J. Zorggebruikers zien patiëntenorganisatie als belangrijke bron voor lotgenotencontact. Utrecht: NIVEL, 2017

Van der Schors W, Brabers A, De Jong J. Een vijfde van de verzekerden overwoog om te wisselen van zorgverzekeraar, maar zag hier vanaf. Utrecht: NIVEL, 2017

Van der Schors W, Brabers AEM, De Jong JD. 8\% wisselt van zorgverzekeraar. Deel verzekerden lijkt steeds vaker inhoudelijke overwegingen mee te nemen bij keuze zorgverzekering. Utrecht: NIVEL, 2017

Swinkels ICS, Brabers AEM, Krijgsman J, De Jong JD. Merendeel bezoekers weet na afloop meer over mogelijkheden eHealth: een impressie van de e-healthweek 2017. Utrecht: NIVEL, 2017

De Jong J, Brabers A. Toename van verzekerden die kiezen voor een vrijwillig eigen risico. Vooral mannen, jongeren, hoger opgeleiden, verzekerden met een hoger inkomen en verzekerden met een goede gezondheid kiezen voor een vrijwillig eigen risico. Utrecht: NIVEL, 2016

Brabers A, Verleun A, Hoefman R, De Jong J. Percentage wisselaars blijft gelijk. Premie net als in eerdere jaren de belangrijkste reden om te wisselen. Utrecht: NIVEL, 2016 
Verleun A, Hoefman RJ, Brabers AEM, De Jong JD. De zorgverzekeringsmarkt vraagt om vaardigheden van verzekerden waar niet iedereen in dezelfde mate over beschikt. Utrecht: NIVEL, 2016

Hoefman RJ, Brabers AEM, De Jong JD. Vertrouwen in zorgverzekeraars hangt samen met opvatting over rol zorgverzekeraars. Utrecht: NIVEL, 2015

Brabers AEM, Reitsma-Van Rooijen $M$, De Jong JD. Inzicht in zorgrekeningen door verzekerden: stand van zaken 2013. Utrecht: NIVEL, 2014

Brabers AEM, Reitsma-Van Rooijen M, Van Dijk L, De Jong JD. Bijna een derde van de patiënten die geneesmiddelen heeft opgehaald bij de apotheek ervaart dat deze niet op voorraad zijn. Utrecht: NIVEL, 2014

Brabers AEM, Reitsma-Van Rooijen M, Wigersma L, De Jong JD. Samenwerking in de zorg kan beter denken zowel zorggebruikers als artsen. Utrecht: NIVEL, 2012 

